



\section{Die Frage \\ der Verstaatlichung der Kaliindustrie}

Von

Dr. H. Giebel

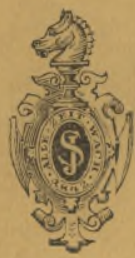

Berlin

Verlag von Julius Springer 1918 
Biblioteka Politechniki Krakowskiej

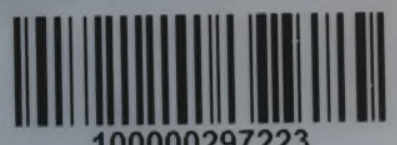

100000297223 

3
3
3
3
3
3
3 


\section{Die Frage}

\section{der Verstaatlichung}

\section{der Kaliindustrie}

Von

Dr. H. Giebel
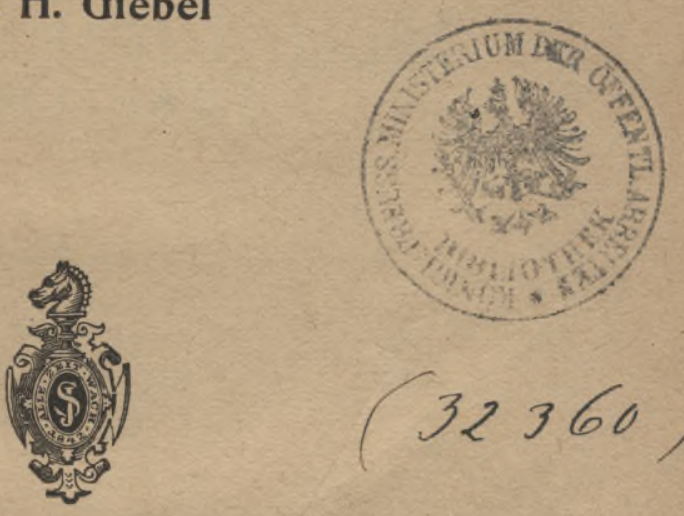

(32360)

Berlin

Verlag von Julius Springer 1918 
Alle Rechte vorbehalten.

BHBLIOTEKA POLIIEGHHIGZMA

KRAKÓ W

$$
119+45
$$

Akc. Nr. $\quad 951 / 49$ 


\section{Inhalt.}

Einleitung

I. Die Voraussetzungen und Bedingungen der Rentabilität eines Staatsmonopols.

Das Monopol an Kali ............. I2

Das Monopol an Kalisalzen ........... 26

Die Möglichkeit der Betriebszusammenlegung . . . 46

Die Wassergefahr . . . . . . . . . . . 54

II. Die Nachteile des Staatsbetriebs.

Bedenken allgemeiner Natur ..........6r

Die Gefahr des technischen Stillstandes . . . . . 75

Die Schwierigkeiten des Erwerbs der Kaliindustrie . . 84

Die Erschwerung des Absatzes . . . . . . . . 91

Die handelspolitische Gefahr ......... 106

III. Die finanzielle Nutzbarmachung der Kaliindustrie . . . . 109 



\section{Einleitung.}

Die Kaliindustrie gründet sich auf die Förderung, Verarbeitung und Verwertung der Kalisalze. Hierunter versteht man leichtlösliche Verbindungen des Kalis in der verschiedensten Zusammensetzung. Wie bekannt, wurden diese Salze früher als Abraumsalze bezeichnet und auf die Halde geschüttet, bis der Chemiker Professor Marchand entdeckte, da $B$ sie erhebliche Mengen Kali enthielten. Nun hatte Liebig schon früher die. Bedeutung des Kalis für das Pflanzenwachstum nachgewiesen. Die Verwendung desselben zu Düngungszwecken war aber noch nicht in größerem Umfange erfolgt, weil es an einer ergiebigen Kaliquelle mangelte. Diese war mit der Entdeckung Marchands gefunden. Damit war die Grundlage für die Entwicklung der Kaliindustrie gegeben.

Unsere Kalilagerstätten weisen in der Hauptsache folgende Salzsorten auf:

$$
\begin{aligned}
& \text { Steinsalz }=\mathrm{NaCl} \\
& \text { Sylvin }=\mathrm{KCl} \\
& \text { Karnallit }=\mathrm{KCl}+\mathrm{Mg} \mathrm{Cl}+6 \mathrm{H}_{2} \mathrm{O} \\
& \text { Kainit }=\mathrm{KCl}+\mathrm{Mg} \mathrm{SO} \mathrm{SO}_{4}+3 \mathrm{H}_{2} \mathrm{O} \\
& \text { Kieserit }=\mathrm{Mg} \mathrm{SO} \mathrm{SO}_{4}+\mathrm{H}_{2} \mathrm{O} .
\end{aligned}
$$

Die Kalisalze werden zum Teil als Rohsalze unmittelbar dem Verbrauch zugeführt. In diesem Falle werden sie vorher auf rein mechanischem Wege in Mühlen zerkleinert. Ein erheblicher Teil erfährt eine fabrikatorische Umarbeitung. Demgemäß unterscheidet man Rohsalze hierzu gehören Kainit bzw. Sylvinit ${ }^{1}$ ), Hartsalz ${ }^{2}$ ), Karnallit und Bergkieserit - und fabrikatorisch gewon. ne ne Salze (Chlorkalium, schwefelsaures Kali, schwefel-

1) Sylvinit $=$ Gemenge von Steinsalz und Sylvin.

2) Hartsalz = Kieserit, Steinsalz und Sylvin. 
saure Kalimagnesia und mehrere Sorten Kalidüngesalze). Von dem geförderten Kainit und Sylvinit werden ungefähr $1 / 6$ weiterverarbeitet, ebenso der weitaus größte Teil des Karnatlits.

Hieraus werden gewonnen:

Kalidüngesalz mit $20 \% \mathrm{~K}_{2} \mathrm{O}$

$\begin{array}{llll}" & \Rightarrow & 30 \% \mathrm{~K}_{2} \mathrm{O} \\ & \Rightarrow & 40 \% \mathrm{~K}_{2} \mathrm{O} \\ \text { kalium } & \Rightarrow & 50-62 \% \quad \mathrm{~K}_{2} \mathrm{O}\end{array}$

Chlorkalium ", $50-62 \% \quad \mathrm{~K}_{2} \mathrm{O}$

schwefelsaures Kalium 48,4 od. $52 \% \quad \mathrm{~K}_{2} \mathrm{O}$ und

Kalimagnesia kalz. mit 22 od. $26 \% \mathrm{~K}_{2} \mathrm{O}$.

Außerdem werden bei der Umsetzung als Nebenprodukt noch gewonnen: Blockkieserit, kalz. Kieserit, Bittersalz, Brom und eine Anzahl anderer Erzeugnisse.

Ueber die Entwicklung der Förderung der Kalisalze und den Umfang der fabrikatorischen Weiterverarbeitung geben die Tabellen I und II im Anhang Aufschluß.

Es ergibt sich daraus der beinahe ununterbrochen fortgesetzte Aufstieg der Kaliindustrie. Diese Entwicklung ist ihr typisch. Sie ist zugleich Ursache und Folge für die gegenwärtigen Produktions- und Absatzverhältnisse.

Ueber den Absatz der Kaliprodukte unterrichtet Tab. III.

Wie daraus ersichtlich, ist Abnehmer der Kalisalze in erster Linie die in - und ausländische Landwirtschaft. Auf beide zusammen entfiel 1913 ein Gesamtabsatz von rund 10,04 Mill. $\mathrm{dz} \mathrm{K}_{2} \mathrm{O}$. Von dieser Ziffer kommen auf den inländischen Verbrauch 5,36 Mill. dz $\mathrm{K}_{2} \mathrm{O}$, auf das Ausland 4,68 Mill. dz $\mathrm{K}_{2} \mathrm{O}$; der Rest der Produktion in Höhe von 1 Mill. dz $\mathrm{K}_{2} \mathrm{O}$ wird an die chemische Industrie abgesetzt. Von dieser Menge entfallen auf das Ausland $382760 \mathrm{dz} \mathrm{K}_{2} \mathrm{O}$, auf das Inland $681802 \mathrm{dz} \mathrm{K}_{2} \mathrm{O}$. Die Industrie verarbeitet ihrerseits die Salze zu Alaun, Pottasche, Aetzkali, Blutlaugensalz, Bromkalium, chromsaurem und chlorsaurem Kali u. a.

Will man sich ein Bild über die zukünftige Absatzgestaltung machen, so dürfte sich diese auf Grund der bisherigen Erfahrungen etwa wie folgt entwickeln: 
Der Absatz stellt sich

Durch-

schnittspreis

im Jahre $19003036099 \mathrm{dz}=57246896$ M. $17,50 \mathrm{M}$.

$19085916220 \mathrm{dz}=102059276$ M. $17,25 \mathrm{M}$.

$191311103694 \mathrm{dz}=190600000$ M. 17,13 M.

Die Steigerung beträgt, jeweilig auf den Wert des Vorjahres gerechnet, von 1900 bis 1908 nicht voll $10 \%$, von 1900 bis 1913 über $10 \%$, von 1908 bis 1913 11,4\%.

Geht man vom Jahre 1913 als dem letzten Friedensjahr aus und nimmt eine weitere Steigerung von 10 (8) Frozent jährlich an, so würde der Absatz betragen: im Jahre 1920: $21637958 \mathrm{dz}=368658219 \mathrm{M}$.

$$
(19029781),=(325980158) \text {, }
$$

$17,13 \mathrm{M}$.

1922: $26181929 \mathrm{dz}=448496443 \mathrm{M}$.

" (22 196 336) , = (380222 325) ,

Die Folgen des Krieges dürften bewirken, daß die in Friedenszeiten erfolgte Steigerung von $10 \%$ wohl auch erreicht wird. Der Durchschnittspreis betrug 1900 M. 17,50, 1908 M. 17,25 und 1913 M. 17,13. Nehmen wir an, daß der Durchschnittspreis einmal infolge der durch den Krieg bewirkten Steigerung überhaupt, sodann infolge der Mehrlieferung an Fabrikaten, die durch die Frachtnot bedingt wird, nur auf $25 \mathrm{M}$. steigt, so würden die Absatzzahlen betragen im Jahre

$$
\begin{aligned}
& \text { 1920: } 491771775 \text { M. } \quad(438704200) \\
& \text { 1922: } 654548225 \text { M. }(554907700) \text {. }
\end{aligned}
$$

Die in Klammern gesetzten Zahlen würden einer Steigerung von $8 \%$ jährlich, bezogen auf 1913 , entsprechen.

Wenn diese Berechnung auch keinen Anspruch auf unbedingte Richtigkeit machen kann, so wohnt ihr doch ein hoher Grad von Wahrscheinlichkeit inne.

Hinsichtlich des Absatzes an die Landwirtschaft dürfte es interessieren, zu erfahren, in welchem Umfange die einzelnen Länder pro Quadratkilometer landwirtschaftlich genutzten Bodens Kali verbrauchen: Der Verbrauch stellt sich im einzelnen wie folgt: 
Insgesamt in dz Kali

Deutschland

Vereinigte Staaten

Holland

Frankreich

Oesterreich

Ungarn

Großbritannien und
5361026

2316896

434784

331149

250727
Auf $1 \mathrm{qkm}$ Anbaufläche in $\mathrm{kg}$ Kali

1529,3

120,4

2000,4

89,9

114,2

18,8

Irland

ramt

234106

117,4

Insgesamt 10039132

$-,-$

Holland mit seiner hochentwickelten Landwirtschaft steht an erster Stelle, dann folgt Deutschland und erst in weitem Abstande die anderen Länder. Daß der Verbrauch in vielen Ländern noch so gering ist, liegt zum Teil an dem unentwickelten Zustande der Landwirtschaft, teils an den ungünstigen Transportverhältnissen, die die Salze zu sehr verteuern. Schuld an dem geringen Absatz hat auch der Mangel geeigneter Propaganda. In dieser Beziehung ist unsererseits nicht genug geleistet worden, insbesondere hat man nicht genügende Mittel zur. Verfügung gestellt. Man stelle sich einmal vor, daß Amerika während der letzten 50 Jahre über ein solches Monopol an Salzen ausschließlich verfügt hätte. Das Absatzresultat wäre sicher ein ganz anderes gewesen. Jedenfalls hat der Kaliabsatz noch weite Möglichkeiten, bis der Bedarf voll gedeckt ist. Dabei ist $\mathrm{zu}$ berücksichtigen, daß bei zunehmender Erschöpfung des Bodens die Notwendigkeit der Kalidüngung fortdauernd wachsen wird.

Es ist nicht ohne Bedeutung, daß der Verbrauch an Kalisalzen sich ständig zugunsten der Landwirtschaft verschoben hat. Während im Jahre 1882 auf die Industrie noch $59 \%$ und auf die Landwirtschaft nur $41 \%$ des Gesamtabsatzes entfielen, ist das Verhältnis im Jahre 1913 ein ganz anderes. Es entfallen auf die Industrie nur noch 9,6\%, auf die Landwirtschaft dagegen 90,4\%. Im Auslande ist der landwirtschaftliche Verbrauch im ungefähr 
gleichen Maße gestiegen. Es darf daher die Absatzvermehrung eigentlich nur von ider Landwirtschaft erwartet werden.

Die Gesamterzeugung der Kaliindustrie verteilt sich nach der Beteiligungstabelle vom 18. 10. 1916 auf 207 Werke. Hiervon haben 73 eine vorläufige Beteiligungsziffer. Eine Anzahl Schachtanlagen, etwa 100, die nicht vollendet sind, sind noch hinzuzuzählen. Die Gesamtbelegschaft der Werke betrug bei Ausbruch des Krieges, d. h. am 1. 7. 1914, 34316 Köpfe. Hiervon waren 74 Frauen. Die Belegschaft ging dann Ende des Jahres 1914, wo die Industrie nur teilweise im Betrieb war, bis auf 13785 Köpfe zurück, stieg nach und nach wieder auf 30659 Anfang Januar 1917. Die Beschäftigung von Frauen hat während des Krieges wesentlich zugenommen. Es waren an dem letztgenannten Datum 1648 weibliche Personen beschäftigt. Diese Ziffer ist in der Gesamtzahl enthalten. Außerdem sind in der Gesamtbelegschaft miteinbegriffen 11036 Kriegsgefangene. Infolge der starken Verminderung der Arbeiterzahl während des Krieges und des Rückgangs der Leistungsfähigkeit der Arbeiter, der in der Hauptsache auf die vermehrte Einstellung von Frauen und Kriegsgefangenen zurückzuführen ist, haben die Vorrichtungsarbeiten in den Gruben und die Versatzarbeiten in weit geringerem Umfange betrieben werden können, als nötig gewesen wäre. Sie mußten auf Anordnung der Kriegsämter schließlich ganz eingestellt werden. Um den erhöhten Förderungsansprüchen zu genügen, wird eine starke Erhöhung der Belegschaft bei Beendigung des Krieges notwendig werden.

Die Gesamtsumme der gezahlten Löhne ergibt sich aus nachstehender Aufstellung:

Gesamtlöhne im Kalibergbau.

\begin{tabular}{|c|c|c|c|}
\hline 1907/09 & $79651717,38 \mathrm{M}$. & 1913 & 44683920,50 \\
\hline $\left.1910^{1}\right)$ & 18110579,14 & 1914 & 229,33 \\
\hline & 33839626,66 & 1915 & 23841779,25 \\
\hline & 8840707,70 & 1916 & 29337810,84 \\
\hline
\end{tabular}

$1917.33956949,07$ M.

1) 1. Juni bis 31. Dez. 1910. 
Die Steigerung der Lohnsumme beruht zum Teil auf der Vermehrung der Arbeiterzahl, aber auch nicht zuletzt auf den sehr erhöhten Arbeitslöhnen. Gegenüber 1907/09 hat die Lohnklasse I allein eine Steigerung von $16,6 \%$ erfahren. Außerdem ist bemerkenswert, daß die Kaliindustrie der einzige Wirtschaftszweig ist, in welchem dem Arbeiter gesetzlich gewisse Mindestlöhne garantiert sind. ( $\$ 13$ d. G.)

Nachdem die Kaliindustrie seit 56 Jahren von privaten Unternehmern entwickelt worden ist, machen sich neuerdings Bestrebungen geltend, sie $\mathrm{zu}$ verstaatlichen. Teilweise haben diese ihren Grund in parteipolitischen Zielen, wie beispielsweise bei den Sozialisten. Nach Abwendung von der alten marxistischen Auffassung, die kapitalistische Wirtschaft ruhig ihren Gang gehen zu lassen, weil sich ihr Schicksal selbst vollende, wird von sozialistischer Seite in neuerer Zeit eine starke Betätigung des Staates auf wirtschaftlichem Gebiet befürwortet und auch anderen weitgehenden Eingriffen in das Wirtschaftsleben das Wort geredet. Von der Verstaatlichung weiter Gebiete der produktiven Arbeit erwarten die Sozialisten, $\Varangle a ß$ die Vergesellschaftung des Kapitals und der Produktionsmittel schneller vor sich gehe, und daß die Lage des Arbeiters bei Lohnkämpfen usw. durch die Verstaatlichung eher gebessert als verschlechtert werde. Hierbei ist der Gedanke bestimmend, daß die sozialistische Partei auf die Wirtschaftsweise des Staates in hohem Maße Einfluß zu gewinnen hofft und auf dem Wege über den Arbeitgeber auch die Lage der arbeitenden Klasse bessern könne.

Finanzpolitisch orientierte Kreise sind der Ansicht, daß durch Verstaatlichung der Kaliindustrie eine gut fließende Finanzquelle erschlossen werden könnte, die zur Deckung des Finanzbedarfs des Reiches heranzuziehen sei. Außerdem glauben sie, daß die Wirtschaftsweise in der Kaliindustrie kapitalverschwendend sei, ein Luxus, den sich Deutschland nach dem Kriege nicht mehr leisten könne. Auf diese Behauptungen wird später einzugehen sein. Es darf indessen vorweg gesagt werden, da $B$ diese letzt- 
genannte Begründung für ein Kalimonopol hinfällig ist. Wenn überhaupt die Verstaatlichung gerechtfertigt werden kann, so könnte dies nur unter dem fin a nziellen Gesichtspunkt geschehen, nämlich, daß das Reich auf diesem Wege eine unverhältnismäßig hohe Einnahme erzielen könnte. Außer diesem Grunde ist nichts anzuführen, was eine so weitgehende Maßnahme notwendig erscheinen lassen könnte. Weder die Arbeiterinteressen noch die Interessen der Konsumenten haben bis jetzt unter der Wirtschaftsweise der privaten Kaliindustrie Schaden gelitten, um so weniger als beide durch das Kaligesetz geschützt sind. Noch weniger sind durch die privaten Unternehmungen in diesem Wirtschaftszweig andere Schäden entstanden, die im Interesse der allgemeinen Nützlichkeit Abhilfe erfordern könnten.

Auffällig ist, daß auch vereinzelte Kaliindustrielle sich für eine Verstaatlichung der Industrie ausgesprochen haben. Dahinter verbergen sich starke Eigeninteressen. In der Gewißheit, daß mit einem weiteren Bestand eines ausschließlichen Monopols Deutschlands an Kalisalzen nicht mehr gerechnet werden kann, möchten diese Kreise ihren Besitz an Kaliwerten zu hohen Preisen absetzen. Es kommt hinzu, daß vielfach die Besitzverhältnisse dieser Industriellen ungünstig sind, weil ihre Werke sich nicht in der Weise entwickelt haben, noch entwickeln werden, wie sie es erhofften. Vielfach handelt es sich um ersoffene Bauten oder im Ausbau stecken gebliebene Schächte oder um unerschlossene Felder. Die Verstaatlichung erscheint ihnen daher als das beste Mittel, das festgelegte Kapital wieder flüssig zu machen und ihren Besitz zu verwerten. Eigeninteressen dürften indessen kaum für die Begründung einer so tief in das. Wirtschaftsleben eingreifenden $\mathrm{Maß}$ nahme ausschlaggebend sein. 


\section{Die Voraussetzungen und Bedingungen der Rentabilität eines Staatsmonopols.}

\section{Das Monopol an Kali.}

Die Einführung eines Monopols macht den Staat zum Unternehmer und belastet ihn mit den gesamten Gefahren und dem Risiko, das die monopolisierte Industrie oder Unternehmungen laufen. Es sichert ihm andererseits als Entgelt für das Unternehmerrisiko den möglichen Gewinn. Seine Stellung unterscheidet sich indessen sehr wesentlich von derjenigen, die ein privater Unternehmer einnimmt. Es liegt ihm nämlich nicht nur ob, seine Gewinninteressen $\mathrm{zu}$ verfolgen, sondern es kommen auch noch die Interessen der Gesamtwirtschaft in Frage. Oft sind letztere für bedeutsamer gehalten worden, als die finanzielle Nutzbarmachung eines Industriezweiges. Ihre Wahrnehmung hat häufig als Grund für die Verstaatlichung gedient. Von dieser Feststellung ausgehend, kann die Verstaatlichung der Kaliindustrie nur unter einer doppelten Voraussetzung gerechtfertigt werden, nämlich daß:

1. eine dauernde Rentabilität gesichert ist, und da B diese im richtigen Verhält. nis zum laufenden Risiko steht,

2. die Gesamtwirtschaft durch die Verstatlichungkeinenwesentlichen Scha den erleidet.

Die Voraussetzung zu 1 erachten die Befürworter eines Staatsmonopols fast durchweg für gegeben. Sie stützen 
sich dabei auf die angebliche Tatsache des deutschen Monopols an Kali, oder wenigstens des Monopols an den leichtlöslichen Verbindungen des Kalis, den Kalisalzen. Im Besitz dieses vermeintlich unbrechbaren Monopols glauben sie jeden beliebigen Preis für die Kaliprodukte dem Auslande gegenüber berechnen zu können und sogar einen weitgehenden politischen Druck und Einfluß damit ausüben zu können. Diese in ihren Augen sichere Möglichkeit ist geradezu in alle Welt hinausgeschrieen worden. Wie verhält es sich demgegenüber nun in Wirklichkeit mit unserem Monopol an Kali?

In dieser Beziehung ist zunächst festzustellen, daß wirein Monopol an Kali überhauptnicht besitzen. Das Element Kali findet sich in ungeheurer Menge auf dem ganzen Erdkreis. Es tritt auf in zahlreichen Gesteinen, Meerestang, Seen, den Rückständen bei der Zuckergewinnung usw. So enthalten z. B.:

\begin{tabular}{lr} 
Kalifeldspat & $10-18 \% \mathrm{~K}_{2} \mathrm{O}$ \\
Leucit & $15-21 \% \mathrm{~K}_{2} \mathrm{O}$ \\
Kaliglimmer & $8-10 \% \mathrm{~K}_{2} \mathrm{O}$ \\
(Muscovit) & \\
$\begin{array}{l}\text { Glaukonit } \\
\text { (Grünsand) }\end{array}$ & $2-14 \% \mathrm{~K}_{2} \mathrm{O}$. \\
\hline
\end{tabular}

Allerdings ist Kali in diesen Verbindungen nicht ohne weiteres verwendbar, weil sie unlöslich oder nur schwer löslich sind. Es muß, um verwendet werden zu können, aufgeschlossen, das heißt in wasserlösliche Form gebracht werden. Dieser Bedingung wird genügt, wenn es in eine Salzverbindung übergeführt wird. Seine Gewinnung ist also abhängig von den Fortschritten der Technik. Unser Kalimonopol beruht daher auf der negativen Voraussetzung, da $B$ die Technik keine Fortschritte macht, womit seine Unsicherheit und Gefährdung ohne weiteres gegeben ist. In dieser Hinsicht ist folgende Tatsache von Bedeutung. Wenn die Grundstoffe eines Produktes in genügendem $\mathrm{MaBe}$ vorhanden sind und ein wirkliches Bedürfnis an letzterem sich einstellt, so hat erfahrungsgemäß die Wissenschaft und Tech- 
nik es fast immer verstanden, ein Verfahren zu seiner Herstellung zu finden. Beim Kali wird dieses um so mehr der Fall sein, als der Technik die Zusammensetzung der Kalisalze und ihre fabrikatorische Herstellung längstens bekannt sind, und es sich nur darum handelt, eine rentable Methode der Gewinnung zu finden. Letzteres ist aber eigentlich nur eine Frage der Zeit, der Kapitalsaufwendung und der Arbeit. Wir sind heute in derselben Lage wie Chile mit seinem Salpeter, Indien mit seinem Indigo und mit dem Rohrzucker. Wie bekannt, ist das Monopol in diesen Stoffen durch die technischen und wissenschaftlichen Fortschritte grundlegend gebrochen worden. Nach Entdeckung des synthetischen Indigos sind wir aus einem Einfuhrland für Indigo zu einem starken Ausfuhrland geworden. Wir deckten vor dem Kriege den weitaus größten Teil des Weltbedarfs. Es steht ferner heute schon außer allem Zweifel, daß Deutschland nach dem Kriege nicht nur seinen Salpeter- bzw. Stickstoffbedarf selbst decken wird, sondern auch erhebliche Mengen zur Ausfuhr zur Verfügung stehen werden. Auch andere Länder, z. B. Frankreich und England, werden höchstwahrscheinlich in der Lage sein, größere Mengen Stickstoff auszuführen.

Bekanntlich ist es gelungen, mehrere Verfahren zur Herstellung des synthetischen Salpeters zu finden. Es war dies nur möglich, weil sich das Hauptelement des Salpeters, der Stickstoff, in der Luft findet, und zwar in unbegrenzter Menge. An sich ist Stickstoff ein chemisch sehr schwer an andere Stoffe bindbares Element. Das Problem bestand daher darin, sowohl geeignete Elemente zu finden, mit denen der Stickstoff chemische Verbindungen bilden konnte, als auch geeignete Einwirkungen zu entdecken, die die Entstehung dieser Verbindungen bewirkten. Es gelang nun Professor Dr. F. Haber mittels Synthese aus den Elementen Stickstoff und Wasserstoff Ammoniak herzustellen, ein Verfahren, das von der Badischen Anilin- und Sodafabrik technisch entwickelt wurde und eine große Zukunft besitzt. Ammoniak kann bekanntlich leicht in schwefelsaures Ammoniak oder auch in Salpeter übergeführt werden. Das zweite Verfahren, Stickstoff 
zu binden, beruht darauf, daß man Stickstoff auf Calciumcarbid einwirken läßt, wobei Calciumcyanamid, d. i. der sogenannte Kalkstickstoff, entsteht. Es handelt sich also auch hier ur. synthetische Herstellung. Erfinder dieses Verfahrens sind Frank und Caro. Bekanntlich hat das Reich in großem Umfange die Erzeugung von Kalkstickstoff aufgenommen und die sogenannten "Reichsstickstoffwerke" bauen lassen. Daneben gibt es noch eine dritte Art, Stickstoff zu binden. Dieses Verfahren beruht darauf, daß durch die Einwirkung großer elektrischer Lichtbögen sich der Stickstoff und Sauerstoff der Luft verbinden zu Stickstoffdioxyd. Setzt man dieser neuen Verbindung Wasser zu, so erhält man unmittelbar Salpetersäure, woraus leicht Salpeter gewonnen wird.

Man stelle sich vor, welche Kapitalien der chilenische Staat verlieren würde, wenn er, wie es jetzt allem Anschein nach bei der Kaliindustrie beabsichtigt ist, die Salpeterfelder und -gewinnungsstätten unter Berufung auf das frühere Monopol in Salpeter erworben hätte. Und doch ruht das deutsche Monopol an Kali auf keiner besseren Grundlage wie das frühere Salpetermonopol Chiles. Wie grundverschieden die Verhältnisse liegen bei Stoffen, die als Element selten sind und nur in gewissen Ländern in ausreichender Menge vorkommen, zeigt eine Betrachtung des für die Düngung ebenso wichtigen Phosphors.

An phosphorhaltigen Stoffen besitzen wir außer geringen Mengen von Koprolithen, Phosphoriten und Knochen nur das phosphorhaltige Eisenerz, die "Minette“. Die Gewinnung des Phosphors aus diesem Erz ist sowohl nach Menge und Zeit an bestimmte Grenzen gebunden. Der gewonnene Phosphor deckt bei weitem nicht den deutschen Bedarf. Da das Element Phosphor, im Gegensatz zum Kali, sich aber in anderer Form oder Verbindungen im Heimatsgebiet nicht findet, so wären auch die größten wissenschaftlichen und technischen Fortschritte nicht imstande, es uns zu verschaffen, wenn es dem Auslande eines Tages einfallen sollte, uns von dem Bezug der Rohstoffe, den Phosphaten, auszuschließen. Es leuchtet ein, daß ein Monopol, das im ausschließlichen Besitz eines Grundstoffes, den andere benötigen, besteht, ganz anders 
ausgenutzt werden kann, als ein solches, wo die Möglichkeit vorhanden ist, $\mathrm{da} B$ es durchbrochen wird.

Wie steht es nun mit den Bestrebungen, Kali auf anderem Wege als durch Abbau der Kalisalze zu gewinnen? In dieser Beziehung ist festzustellen, daß sofort bei Kriegsbeginn, teilweise auch schon viel früher, aber nicht in intensiver Weise, die größten Anstrengungen hierin gemacht worden sind. Insbesondere hat Amerika, wo die Abhängigkeit von den deutschen Salzen am meisten empfunden wurde, es an nichts fehlen lassen, um das Ziel zu erreichen. Sowohl die allgemeinen geologischen Landesbehörden, U. S. Geological Survey, wie verschiedene andere Behörden wenden bedeutende finanzielle Mittel auf und machen große Anstrengungen, eine rentable Gewinnungsart von Kali zu finden. Auch das Frivatkapital hat sich auf diesem Gebiete in weitem Maße betätigt. Es wurden eine ganze Reihe von Gesellschaften gegründet, die die Kaliherstellung betreiben. Zum Teil sind diese allerdings wieder eingegangen, weil ihre wirtschaftliche Grundlage ungenügend war. Diese Enttäuschungen sind indessen kaum ein Hemmnis für die Fortführung der Arbeiten gewesen.

Für die fabrikatorische Gewinnung von Kali in Amerika kommen in erster Linie in Betracht die $\mathrm{kalihal-}$ tigen Silikate, die sich in Eruptivgesteinen, insbesondere in dem Granit, Syenit, Porphyr, Phonolit usw. als Gemengteile finden. Diese Gesteine enthalten durchweg Kali in der Menge von etwa $5-8 \% \mathrm{~K}_{2} \mathrm{O}$. Bei den Gehaltsangaben an Kali ist zu beachten, daß auch unsere Kalisalze nur einen gewissen Prozentsatz an Reinkali enthalten. Es bestehen eine ganze Anzahl Patente bezüglich des Aufschlusses von kalihaltigen Silikaten.

Die größte Aussicht der wirtschaftlichen Herstellung hat bisher ein Verfahren von Cushman \& Goggeshall11).

1) Das neuere Verfahren von Cushman \& Goggeshall besteht darin, daß Feldspat mit $20 \%$ gebranntem Kalk vermischt, auf einem Transportband mit 15,4\% Calciumchlorid (in 40\%iger Lösung) befeuchtet und im Drehofen gebrannt wird. Das Brennprodukt wird 
nach welchen bereits $\mathrm{F}$ eld s p at in größerem Maßstabe aufgeschlossen worden ist. Das mittels dieses Verfahrens gewonnene Kali soll im Vergleich mit den Friedenspreisen von 1912/13, die für deutsches Kali gefordert wurden, nach Angabe der Erfinder nicht wesentlich teurer sein. Von anderer Seite wird dieses jedoch bestritten. So kommt Neumann ${ }^{1}$ ) zu dem Schluß, daß der Aufschluß von Feldspat zum Zwecke der Kaligewinnung bei normalen Kalipreisen zunächst noch nicht wirtschaftlich $\operatorname{sei}^{2}$ ).

Es darf hierbei jedoch nicht außer acht gelassen werden, daß die Friedenspreise von 1912/13 für Amerika und überhaupt wohl für das Ausland nicht mehr in Frage kommen, so daß sich der Begriff der Wirtschaftlichkeit zurzeit schon gegenüber den Friedensverhältnissen mehr und mehr zugunsten des genannten Verfahrens verschoben hat $\left.{ }^{3}\right)$.

ausgelaugt und die Lauge eingedampft. Es sollen $83 \%$ des Kalis auslaugbar sein. (Metallurg. Chem. Eng. 13, 99, 1915.)

1) Die Aufschließung von Feldspat zum Zwecke der technischen Kaligewinnung. Prof. Dr. B. Neumann und Dip!.-Ing. Fritz Draisbach. Zeitschrift für angewandte Chemie, Jahrgang 29, S. 65 u. 67 vom 15. u. 22 . August 1916, S. $313 \mathrm{ff}$, und $326 \mathrm{ff}$.

2) Aehnlich E. Böhler, Weltwirtschaftliches Archiv, Heft 4, Seite $500 \mathrm{ff}$.

3) Vor der Institution of Mining \& Metallurgy in London hat im Dezember 1917 Mister E. A. Ashcroft Mitteilungen über die Möglichkeit der Gewinnung von Kali aus Feldspat in England gemacht. Im Nordwesten in Schottland nahe der Küste sei ein Vorkommen, das mindestens 12 Millionen, vielleicht auch 20 Millionen Tonnen Feldspat enthalte, der im Tagebau gewonnen werden könne und welcher einen Kaligehalt von $8 \% \quad \mathrm{~K}_{2} \mathrm{O}$ oder $12 \% \mathrm{KCl}$ besitze. Aus diesem Vorkommen könne der Bedarf Englands an Kali für 50 . Jahre gedeckt werden. Das 80 prozentige Kalisalz würde im Frieden vielleicht nicht teuerer als 140 Mark oder höchstens 300 bis 400 Mark die Tonne zu stehen kommen. Nach der Ansicht des Vortragenden kann, nach dem von ihm beschriebenen Verfahren das gewonnene Kali den Wettbewerb mit den deutschen Kalisalzen aufnehmen. Der neuen Industrie komme zugute, daß das Ausgangsmaterial in großer Menge vorhanden sei, einen hohen Prozentsatz von Kali enthalte und im Tagebau gewonnen werden könne. Außerdem könne der Feldspat per Wasser transportiert werden. Das Verfahren sei sehr einfach und benötige keine Säuren oder andere teuere Materialien. Obwohl die Erzeugang von Nebenprodukten keine große Rolle spiele, so sei trotzdem Aussicht vorhanden, daß die Rückstände weitere nützliche Verwendung finden könnten, wodurch sich der Gewinn erhöhe bzw. die Herstellungskosten des Kalis

Giebe1, Kalindustrie. 
Als ein zweites kalihaltiges Silikat kommt noch der Glaukonit in Frage. In den Atlantischen Staaten, insbesondere in New-Jersey, ferner in Delawware, Maryland und Kentucky sind Grünsande, Glaukonit führende Sande und Mergel der Kreideformation weit verbreitet. Außer dem Kaligehalt besitzen dieselben einen für die Düngung wichtigen geringen Phosphatgehalt. Der Kaligehalt soll durchschnittlich 4,4 bis $4,8 \% \quad \mathrm{~K}_{2} \mathrm{O}$ betragen. Während des Krieges haben verschiedene Gesellschaften die Gewinnung von Kali aus Glaukonit aufgenommen. Ueber ihre Erfolge ist Genaueres noch nicht bekannt. Die Grünsandlagen wurden ferner bereits vielfach zur Kalidüngung unmittelbar verwendet, beispielsweise in Süd-New-Jersey. Die Sandmengen wurden dort in offenen Gruben im Kleinbetrieb gewonnen und in der näheren Umgebung auf die Felder gestreut. Durch die Einfuhr der deutschen Kalisalze ist dieser Abbau zum Erliegen gekommen, zumal die Landwirtschaft in jenen Gegenden zurückging, und eine Verfrachtung auf größere Entfernungen aus wirtschaftlichen Gründen wenig in Frage kam. Während des Krieges dürfte das Interesse der Amerikaner auch wiederum auf dieses Vorkommen gelenkt worden sein.

Im allgemeinen wird man über die Gewinnung von Kali aus kalihaltigen Silikaten sagen können, daß sie zuviel Energie verbraucht. Gewöhnlich geht die Gewinnung unter starkem Wärmeaufwand vor sich, was eine erhebliche Verteuerung des Produkts zur Folge hat. $\mathrm{Ob}$ der Energieverbrauch durch geeignetere Verfahren herabgesetzt werden kann, läßt sich noch nicht sagen, steht aber im Bereiche der Möglichkeit.

Während die Aufschließung der Kalisilikate im allgemeinen, wie ausgeführt, schwierig ist, gelingt sie verhältnismäßig einfach beim Alunit (Alaunstein), welcher beispielsweise in Italien, Australien und Amerika in größeren Ablagerungen, aber auch sonst an der Erdoberfläche häufig vorkommt. Seit langen ist die Gewinnung von Kali-Alaun aus demselben bekannt.

In Amerika kommt der Alunit weitverbreitet in enger Verknüpfung mit Erzgängen in jungen Eruptivgesteinen vor. Be-

geringer würden. („,Chemiker-Zeitung“ Nr. 6566 v. 1. 6. 1918.) Wenn es tatsächlich richtig ist, daß die Abbaukosten des Fe'dipats, die in Amerika 2 Dollars die Tonne betragen sollen, sehr gering sind, so verdienen die vorstehenden Mitteilungen die ernsteste Beachtung. 
kannt ist das Vorkommen von Marysvale in Utah mit Gehalten an $\mathrm{K}_{2} \mathrm{O}$ von $10,46,9,71$ und $11,4 \%$. Bisher wurden die Gänge bis auf, 80 Meter Tiefe festgestellt,

Ein anderes Vorkommen von Alunit am Westabhange der Tushar-Berge bei Baever gab in den Durćhschnittsproben nur 2,9 bis $6,87 \% \quad \mathrm{~K}_{2} \mathrm{O}$. Auch sonst sind Alunitvorkommen vielfach festgestellt, meist im Zusammenhang mit durch den Erzbergbau gewonnenen Aufschlüssen, so u. a. ein solches in Arizona bei Patagonia.

Von - Friedensburg ${ }^{1}$ ) wird der Betrieb der Gewinnung des Vorkommens von Marysvale näher geschildert. Dort wird der Alunit in fein gemahlenem Zustand mit feiner Kohle gemischt in Drehrostöfen abgeröstet und die ausgeglühte Masse in Lösekesseln ausgelaugt. Die gewonnene Lauge wird in einer Filterpresse von der unlöslichen Tonerde gereinigt und in Vakuumvorrichtungen eingedampft. Das ausgeschiedene Kalisulfat, welches mehr als $93 \% \quad \mathrm{~K}_{2} \mathrm{SO}_{4}$ enthält, wird getrocknet, gemahlen und in Säcken versandt. Der Filterrückstand soll aus nahezu reiner Tonerde bestehen und für die Aluminiumfabrikation und zur Herstellung hochfeuerfester Stoffe sehr geeignet sein. Nach den bisherigen Nachrichten konnte die geschilderte Anlage täglich bis zu 35 t Kaliumsulfat erzeugen.

Weitere derartige Gewinnungsstätten sind in den Vereinigten Staaten errichtet worden ${ }^{2}$ ).

In Italien (Tolfa) und Australien (Bullati Dela in Neu-SüdWales) wurde der Alunit bisher nur für Alaunherstellung verwendet. Es bleibt die Frage offen, ob nicht auch diese Länder nach dem Vorgehen Amerikas die Herstellung eigener Kalisalze ins Auge fassen werden, und die Alunitvorkommen anderer Länder mehr und mehr zu diesem Zweck herangezogen werden. Hierin liegt eine, relative Gefahr, weil dieses Verfahren die meiste Aussicht auf Wirtschaftlichkeit hat. Allerdings wird es dabei darauf ankommen, ob genügende Mengen dieses Gesteins sich in den einzelnen Ländern finden.

Beachtenswert ist noch, $\mathrm{da}$ B die amerikanischen Bergbehörden in neuerer Zeit immer wieder darauf hinweisen, daß häufig die Aufbereitungstrüben von Erzbergwerken, welche kalihaltige Gang- oder Nebengesteine verarbeiten, Kali führen.

1) Glückauf, Jahrg. 53, Heft 22, Seite 447/448.

2) Vergl. hierüber E. Böhler: Weltwirtschaftliches Archiv, 12. Bd., Heft 4, Seite $498 \mathrm{ff}$. 
welches unbedingt nutzbar gemacht werden müsse. Neueren Nachrichten zufolge wird in Amerika bereits Kali auf diesem Wege gewonnen.

Es verdient noch erwähnt zu werden, daß in Italien das Leucitgestein eine gewisse Bedeutung für die Gewinnung von Kali in der Hauptsache durch unmittelbare Verwendung zur Düngung gewonnen hat. Ein größeres Vorkommen von Leucit stellt das Gestein der Roccamonfina dar. Die mit diesem vorgenommenen Versuche sollen nach den vorliegenden Nachrichten bemerkenswerte Erfolge ergeben haben. Es handelt sich um die Ausnutzung vulkanischer Lava, welche dort und auch am Vesuv in größeren Ablagerungen vorkommt und außerordentlich reich an zerreiblichem, unschwer zerlegbarem Leucit ist, welch letzterer seinen Kaligehalt leicht an die Pflanzen abgibt. Es ist lediglich ein Zermahlen und Sieben erforderlich, um die leucithaltige Lava zur Benutzung als Dünger vorzubereiten. Die Verbreitung des Vorkommens von Roccamonfina soll $17 \mathrm{qkm}$ noch übersteigen. Die Mächtigkeit der leucitischen Gesteine dieses Vorkommens ist schwankend und wird durchschnittlich zu ca. $20 \mathrm{~m}$ angegeben.

Bein Leucitgestein kann ferner nach geeigneter Trennung und Extraktion mit Salzsäure auch Chlorkalium gewonnen werden. Vor Ausbruch des Krieges war in Italien der Bau einer geeigneten Anlage in Aussicht genommen. Wieweit diese zur Ausführung gekommen ist, entzieht sich der Kenntnis.

Kali entsteht u. a. a ch als Nebenprodukt bei der Zementfabrikation. Wenn bei der Herstellung des Zements kalihaltige Rohstoffe zur Verwendung kommen, so kann das sich verflüchtigende Kali durch geeignete Verfahren aufgefangen und nutzbar gemacht werden. 50 bis $75 \%$ des Kaligehaltes verflüchtigen sich nach Peacock beim Brennen der Rohmischung für Portlandzement, und 40 bis $60 \%$ hiervon sind als Silikat wasserunlöslich.

Es bestehen bereits geeignete Verfahren zur Gewinnung des Kalis So wird die Gewinnung von löslichen Kalisalzen aus Zementflugstaub bereits auf den Anlagen der Riverside-Portland-Cement Co. bei Riverside unweit von Los Angeles in Südkalifornien ausgeführt. Der Flugstaub wird nach dem Cottrell-Verfahren aufgefangen und in einem besonderen Ofen 
mit frischem Rohgut erneut gebrannt, und so der Kaligehalt angereichert. Friedensburg möchte die Möglichkeit, daß sich die Gewinnung dieses Nebenerzeugnisses wirtschaftlich lohnt, bei den heutigen Kriegspreisen nicht völlig von der Hand weisen. Für die Wirtschaftlichkeit dürfte sprechen, daß bereits eine größere Anzahl ähnlicher Anlagen zur Gewinnung von Kalisalzen aus Flugstaub in Amerika erbaut und in Betrieb genommen wurde, und diese Bewegung sich augenscheinlich dauernd fortsetzt.

Von amerikanischer Seite ist früher berechnet worden, daß man aus der Zementindustrie jährlich etwa 10000 Tonnen Kali gewinnen könne. Mitte 1917 hat Richard K. Meade vor dem Institute of Chem. Eng. einen Vortrag gehalten, worin er behauptete, daß durch zweckmäßige Anlagen in der Zementund Eisenindustrie jährlich 200000 Tonnen Kali zu gewinnen seien. Die noch weiterhin benötigte Menge würde sich durch Verarbeitung von Laugen, Melasse, Feldspat und Alunit herstellen lassen, Hierzu sei nur nötig, daß die amerikanische Gesetzgebung verhindere, daß seitens Deutschlands $\mathrm{zu}$ billigen Preisen geliefert wird $^{1}$ ).

Im Zusammenhang hiermit sei darauf hingewiesen, daß auch der Flugstaub von Hochöfen und Metallhütten als Kaliquelle in Betracht kommt. Es ist interessant, daß im Jahre 1917 Kali dieser Herkunft von deutschen Hüttenwerken in Holland angeboten wurde. Auch in Amerika wird Kali auf diese Weise gewonnen. Man setzt dort große Hoffnungen auf dieses Verfahren.

Bedeutung hat ferner die Gewinnung von Kali aus Kelp (Meerestang). Diese Herstellungsart unter gleichzeitiger Gewinnung von Jod ist alt und wurde früher an den Küsten Englands, Frankreichs, Spaniens usw. betrieben. Noch heute findet diese Gewinnung in Norwegen und Schottland, in Rußland und in Japan statt. Während des Krieges ist man in Amerika dazu übergegangen, die Tange des Stillen Ozeans der Kaligewinnung dienstbar zu machen. Gewaltige Mengen von Riesentangen wachsen an der ganzen pazifischen Küste der Vereinigten Staaten, von Alaska bis nach Südkalifornien. Sie bedecken eine

1) "Chem.-Zeitung“" Nr. 6566 v. 1. 6. 18. 
Fläche von etwa 400 Quadratmeilen. Nach einem Bericht des Bureau of Soils des Department of Agriculture sollen die Kelpfelder an der pazifischen Küste mehr als 2200000 Tonnen $\mathrm{KCl}$ enthalten. Insbesondere kommen für die Kaligewinnung in Betracht die Arten Nereocystis und Macrocystis. Es werden Durchschnittsgehalte bis zu $31 \%$ $\mathrm{KCl}$ und $0,29 \mathrm{~J}$ im ofentrockenen Zustande der Tange angegeben.

Die Vorkommen sind außerordentlich ergiebig. Die abgeernteten Felder wachsen sehr schnell nach. Naturgemäß bietet die Einerntung mancherlei Schwierigkeiten; sie geschieht im allgemeinen maschinell, indem die Tange bis zu $2 \mathrm{~m}$ unter der Wasseroberfläche geschnitten, heraufgeholt und zu Bündeln vereinigt werden. An anderen Stellen überläßt man den Transport der geschnittenen Massen der Brandung. Die Tange werden zunächst an der Luft getrocknet. Zum Teil wird der rohe Tang unmittelbar zu Düngezwecken verwandt. Im Hinblick auf die Transportverbilligung findet allgemein eine weitere Verarbeitung statt, indem eine Einäscherung vorgenommen wird, meist in Oefen oder Retorten. Die Asche enthält über 60\% $\mathrm{KCl}$. Für die weitere Verarbeitung sind verschiedene Verfahren in Anwendung.. Für eine Tonne Chlorkalium sollen bis zu $30 \mathrm{t}$ frischen Tangs erforderlich sein, eine sehr große Menge; in wirtschaftlicher Hinsicht fällt dies erschwerend ins Gewicht. Eine Reihe von Anlagen sind mit der Gewinnung und Ausnutzung der amerikanischen Tangvorkommen beschäftigt ${ }^{1}$ ). Im Jahre 1916 war die mutmaßliche Erzeugung von Chlorkalium im Verhältnis zu dem gesamten amerikanischen Bedarf noch verhältnismäßig gering. Inzwischen dürfte eine Steigerung derselken stattgefunden haben, deren Höhe leider unbekannt ist.

1) Vergl, E. Böhler a. a. O. S. 501 ff. - Regierungsseitig ist eine Fabrik in Summerland (Kal.) gegründet worden, die täglich 200 Tonnen Kelp verarbeitet und hieraus 5 Tonnen salzsaures Kalium gewinnen sollte. Zu nennen sind fërner die American Potash Cio., die in Long Beach, Kal., eine Fabrik errichtet hat. Die letztgenannte verarbeitet täglich 1500 Tonnen Kelp, woraus sie 18 Tionnen Kaliumsalze und 24 Tonnen Essigsäure gewinnt, wodurch der Gestehungspreis der Kalisalze heruntergedrückt wird. Aufgeführt seien ferner die Diamond Match Co., Swift u. Co., Chicago, Pacific-Products Co. Daneben gibt es noch zahlreiche andere. Im ersten Halbjahr 1917 betrug die Produktion von Kalisalzen aus Kelp 2143 Tonnen. 
Friedensburg legt der Gewinnung des Kali aus Meerestang von allen Gewinnungsarten die größte Bedeutung bei ${ }^{1}$ ). Allerdings glaubt er nicht, daß diese Fabrikation mit dem deutschen Kali in Wettbewerb treten könne; auch deshalb nicht, weil die im Osten liegenden amerikanischen Verbrauchsgebiete das Kali von Deutschland frachtlich billiger erhalten können, als das Fabrikationsprodukt, das erst durch den ganzen Erdteil gefahren werden müsse. Man kann dieser Ansicht wohl nicht unbedingt beipflichten, weil schließlich für einen großen Teil der Verbrauchszentren die Frachtlage günstiger ist, und weil insbesondere nach dem Kriege auch für die deutschen Salze ganz andere Frachtsätze in Geltung kommen werden.

Außer der Asche des Meerestangs wird auch noch Kali aus den festen Rückständen beim Verbrennen von $\mathrm{Holz}$ und Sträuchern gewonnen.

Die zur Herstellung der Holzasche als Ausgangsmaterial der Seifenfabrikation erforderliche Veraschung von Vegetabilien war früher die einzige Gewinnungsart von Kalisalzen, bevor die mächtigen deutschen Kalisalzlager entdeckt wurden. Währenc des Krieges hat der im Ausland eingetretene Mangel an Kali dazu geführt, auch dieser Möglichkeit der Kaligewinnung ernstere Beachtung zu schenken.

Im Jahre 1878 wurde nach Krische ${ }^{2}$ ) noch die Menge aus der Holzasche erzeugten Kalisalze auf 20000 Doppelzentner geschätzt. Namentlich Rußland, die Vereinigten Staaten und Kanada, welche sämtlich waldreiche Gebirgsteile besaßen, waren an dieser Produktion beteiligt. Da die so gewonnene Pottasche später gegenüber der Pottasche aus deutschen Kalisalzen nicht konkurrenzfähig war, und außerdem die Waldbestände abnahmen, ging der Pottascheexport beispielsweise in RuBland von 1864 bis 1873 von 100000 Doppelzentnern auf 55000 Doppelzentner, sowie in Nordamerika in der gleichen Zeit von 19000 auf 4000 Doppelzentner zurück.

In Rußland bestand vor dem Kriege noch eine nicht unbedeutende Fabrikation von Pottasche, welche aus Sonnenblumenstengeln gewonnen wurde, als Nebenprodukt der umfangreichen Sonnenblumenölfabrikation im Nord-Kaukasus. Die

1) Aehnlich Böhler a. a. O. S. 494.

2) Dr. P. Krische. Die, Gewinnung von Kalisalzen durch Vegetabilien. Kali 1912, Nr. 17, S. 416 ff. 
Stengel wurden verbrannt. Nach Krische sollen noch 1907 im Nord-Kaukasus 24 Fabriken die Verarbeitung von Sonnenblumenstengeln auf Pottasche betrieben und ca. 147500 Doppelzentner Pottasche im Werte von 2 Millionen Rubel erzielt haben. Von der Produktion gingen ca. $3 / 4$, also 115000 Doppelzentner Pottasche, ins Ausland. Für die Verwendung zu Düngezwecken dürfte der geringste Teil benutzt worden sein; meist wurde diese Pottasche für industrielle Zwecke benutzt.

In den Weststaaten Amerikas, namentlich im Wüstengebiet, sind zwei Buschpflanzen, die Mesquitbüsche (Prosopis juliflora) und das Sagegestrüpp (verschiedene Artemisia-Arten) außerordentlich stark verbreitet. Diese werden zu Asche verbrannt, welche bis zu $30 \% \quad \mathrm{~K}_{2} \mathrm{O}$ enthält. Eine gewisse örtliche Bedeutung ist auch dieser Kaliquelle nicht abzusprechen. In den tabakbauenden Ländern wird ferner die Asche der zur Tabakfabrikation nicht verwendbaren festen Pflanzenteile als Düngemittel mit hohem Kaligehalt geschätzt.

$\mathrm{Z}_{\mathrm{i} \mathrm{i}}$ erwähnen bleibt noch die Gewinnung von Kali aus der Melasse, aus Weinpresserückständen und Woll$\mathrm{schweiB}$. In Deutschland wird nur ein verhältnismäßig kleiner Bruchteil der Jährlich gewonnenen Melasse als Viehfutter verwertet. Der größte Teil wird entzuckert und die Restmasse zur Spiritusfabrikation verwandt, und das in dem Rückstand verbleibende Kali eingedampft und verbrannt. Die so entstehende Schlempekohle enthält $50-70 \%$ kohlensaures Kali bzw 34,1 bis $47,7 \% \quad \mathrm{~K}_{2} \mathrm{O}$. In Frankreich werden nach Schätzungen jährlich 20000 Doppelzentner Kali aus Rübenmelassc bei der Spiritusfabrikation gewonnen, in Oesterreich etwa 5000-bis 10000 Doppelzentner. Auch Italien hat eine verhältnismäßig hohe Erzeugung.

Trotzdem die beschriebenen Kalivorkommen sehr mannigfaltig und weit verbreitet sind und verschiedene Verfahren zu seiner Gewinnung bzw. Verwertung schon bestehen, soll nicht behauptet werden, daß eines derselben bereits eine rentable Grundlage besitze und somit geeignet sei, eine Gefährdung des deutschen Absatzes hervorzurufen. Hierzu wird es noch weiterer Verbesserungen und Vervollkommnungen bedürfen. Es kann vermutet werden, daß bis jetzt noch kein geeignetes Verfahren gefunden ist, das auf dauernde Einführung rechnen 
könnte. Aber aus der Schilderung ergibt sich, daß man eifrig bestrebt ist, Kalisalze aus einer Reihe vorhandener Quellen zu gewinnen und daß der Weg für gangbar gehalten wird. Bei der Beurteilung dieser Versuche ist zu beachten, daß zwar bei den vor dem Kriege gültigen

- Preisen die einzelnen Verfahren nicht rentabel gewesen sind, aber bei einer Verstaatlichung der Industrie, die aller Voraussicht nach sehr hohe Preise - schon des fiskalischen Zweckes halber - im Gefolge haben würde, kann das eine oder andere Verfahren sehr wohl rentabel werden. Es kommt hinzu, daß auch die Frachtsätze ganz andere sein werden, wie vor dem Kriege, womit ohne weiteres eine Verteuerung der Salze gegeben ist. Es darf nicht verkannt werden, daß systematisch mit unbegrenzten Mitteln und viel Energie an dem Kaligewinnungsproblem gearbeitet wird. Auch ist nicht anzunehmen, daß die Amerikaner als praktische und nüchterne Geschäftsleute an eine von vornherein aussichtslose Sache soviel Mühe und Geld verschwenden. Vielleicht trennt die Technik von dem erstrebten Ziele nur noch ein Schritt, vielleicht ist es noch ein weiter Weg, aber eines scheint festzustehen, es handelt sich um ein erreichbares Ziel, und dieses allein dürfte entscheidend sein. Von Bedeutung ist auch, daß die neuere Entwicklung dahin geht, möglichst viel Nebenprodukte bei der Herstellung von Kali zu gewinnen. Sämtliche in Frage kommende Verfahren ergeben solche. Aus Kelp wird Gas, Teer, Ammoniak, Jod, Essigsäure usw. gewonnen, wodurch der Gestehungspreis der Kalisalze stark herabgedrückt wird. Auch die Gewinnung aus Silikaten liefert zahlreiche Nebenprodukte. So ist es möglich, da $B$ das Problem eines Tages plötzlich dadurch gelöst wird, daB $\mathrm{Kali}$ in einem chemischen ProzeB als Nebenprodukt auf rentable Weise gewonnen wird. In dieser Beziehung ist interessant, daß auch in Deutschland Gewinnungsarten gepflegt werden, bei denen Kali als Nebenprodukt abfällt. In Frage kommt in erster Linie der sogenannte Rhenaniaprozeß. 
Die chemische Fabrik Rhenania in Stolberg i. Rhld. stellt aus geringhaltigen belgischen Rohphosphaten sogenannte Rhenaniaphosphate her. Der Aufschluß wird in Drehöfen (Zementöfen) unter Zugabe von Kalk und Phonolith durch hohe Wärmeentwicklung bewirkt. Bekanntlich ist Phonolith ein Kalisilikatgestein. Das fertige Produkt enthält neben dem citratlöslichen Phosphat etwa 2-3\% aufgeschlossenes Reinkali. Érhebliche Mengen dieses Düngemittels sind während des Krieges an die deutsche Landwirtschaft geliefert worden. Die Herstellung von Hochöfenkali wurde schon erwähnt. Es soll bereits vor dem Kriege eine nennenswerte Ausfuhr hieran bestanden haben:

Vielleicht -wird man auch nicht fehlgehen, wenn man die von Friedensburg gegebene Darstellung, die sich wenig günstig für die Möglichkeit, Kali aus Gesteinen aufzuschließen, ausspricht, angesichts der bedeutenden Fortschritte der. Technik gerade während des Krieges als etwas reichlich optimistisch ansieht. Jedenfalls wird der Staat, der ein Kalimonopol ins Auge faßt, die einmal gegebene Möglichkeit als eine bedeutende Risikoquelle in Rechnung stellen müssen.

Wie die vorausgehenden Darlegungen zeigen, haben wir kein absolutes Kalimonopol besessen, höchstens ein relatives. Ein grundlegender Fortschritt der Technik und Wissenschaft kann Kali der ganzen Welt verschaffen und auch das relative Monopol brechen.

\section{Das Monopol an Kalisalzen.}

Im Zusammenhang mit der früher getroffenen Feststellung ist nunmehr zu untersuchen, ob unser bisheriges Monopol an leichtlöslichen Kalisalzen noch besteht und welche Aussicht auf Weiterbestand vorhanden ist. Hier $\mathrm{zu}$ ist festzustellen, da $B$ das Kalisalzmonopol nicht mehr vorhanden ist. Noch bei den Beratungen des Kaligesetzes im Jahre 1910 zweifelte kaum jemand an dem ausschließlich deutschen Monopol. Führte 
doch der Sachverständige Professior Dr. Beyschlag bei den Verhandlungen im Reichstage aus, daß Kaliablagerungen, wie sie bei uns vorkommen, nur unter den ganz besonders günstigen Verhältnisse, wie sie in Deutschland zur Zeit der Bildung der Lager geherrscht haben, vorkommen könnten. Es seien so außerordentliche Zufälle nötig, daß ein Vorkommen im Ausland höchst unwahrscheinlich sei. Während lange Jahrzehnte die Kalifunde nur in der Zechsteinformation stattfanden, wurde plötzlich im E1s a B Kali in großer Menge und guter Ablagerung im Tertiär gefunden. Diese Funde machten bedenklich und legten eine Bresche in die bisher geschlossene Anschauung. Heute gibt es, wie Gothein ${ }^{1}$ ) richtig bemerkt, keinen Sachverständigen mehr, der an das ausschließliche Naturmonopol Deutschlands glaubt. Insbesondere hat die Auffindung der $\mathrm{Kalilager}$ in $\mathrm{Catalonien}$ in Spanien zur richtigen Erkenntnis der Sachlage beigetragen. Es steht ganz außer Zweifel und muß als Tatsache hingenommen werden, daß dort erhebliche abbauwürdige Kalivorkommen entdeckt worden sind. Diese Vorkommen finden sich, ebenso wie im Elsa $B$, im Tertiär, eine Tatsache, die die frühere Theorie scharf widerlegt. Es ist weiter von Bedeutung, daß die Oligocänablagerungen, die in Spanien kaliführend sind, eine weite Verbreitung haben. Sie machen einen bedeutenden Teil der Provinzen Barcelona und Lerida aus. Daraus ist zu-schließen, daß die spanischen Kalilager eine erhebliche Ausdehnung haben.

Die Entdeckung der spanischen Kalivorkommen ist durch Zufall erfolgt. Schon seit langem war der große Salzstock von Cardona im Tertiärbecken des Ebro bekannt. Wenn auch dieses Vorkommen neben rotem Steinsalz ein schönes weißes Salz von großer Reinheit enthält, welches in Tafeln geschnitten, hauptsächlich nach Afrika verkauft und dort bis weit in die Sahara hinein als Geld benutzt wird, so war doch infolge der ungenügenden Eisenbahnverbindung bisher nur eine geringe Ausnutzung des Vor-

1) Reichsbergbaumonopol, Stuttgart 1916, S. 65. 
kommens erfolgt und dasselbe nicht genauer erforscht. Im Jahre 1912 wurde dann südöstlich von Cardona bei dem Orte Suria ein anderer Salzhorst entdeckt und durch bergmännische Arbeiten aufgeschlossen. Hierbei stieß man auf verschiedene Karnallit- und Sylvinitschichten, welche einen hohen Gehalt an Kali und nur einen geringen Gehalt an Magnesia aufwiesen. Weitere Tiefbohrungen trafen ebenfalls Kalilager an. Auf Grund dieser Funde haben im Jahre 1913/14 eingehende Untersuchungsarbeiten des tertiären Ebrobeckens stattgefunden, welche auch nach Kriegsausbruch weiter fortgesetzt worden sind.

Zunächst wurde das Auftreten größerer Kalisalzmengen bei dem Orte Suria mit Sicherheit festgestellt. Es scheint aber keinem Zweifel zu unterliegen, daß sich das Vorkommen nicht auf diesen Fundort beschränkt, denn bereits an beiden Flanken des Salzhorstes von Cardona sind Sylvinfunde mit vereinzelt 96 bis $97 \% \mathrm{KCl}$ gemacht worden. Der erhebliche Kaligehalt von bei Cardona austretenden Quellen ließ ebenfalls auf das Vorhandensein von ausgedehnten Kalilagern schließen. Während von verschiedenen Gelehrten angenommen wurde, $d a \beta$ es sich bei diesem Vorkommen um ein solches linsenförmiger Gestalt und geringer Erstreckung handele, wird demgegenüber von anderen namhaften Geologen die Ansicht vertreten, daß man es mit ausgedehnten Lagern zu tun habe. Die weitere Entwicklung hat letzteren Recht gegeben.

Nach dem „Mining Journal“ vom 15. 12. 1917 steht die Abbauwürdigkeit der in Suria und Cardona aufgefundenen Kalisalzlager außer Zweifel. In Anbetracht dieser Tatsache hat sich die spanische Regierung gewisse Gebiete vorbehalten, die der Ausbeutung durch private Unternehmer entzogen worden sind. Außer dem deutschen Kalisyndikat hat eine französisch-belgische und eine amerikanische Gruppe, ferner die Fodina Compagnie, die Sociedad General de Industria y Comercio Gerechtsame erworben. Ein Bericht der spanischen Geologen Rubio und Marin führt aus, daß die französisch-belgische Gruppe bei Suria 12 Bohrlöcher niedergebracht habe. Mit Aus- 
nahme von einer einzigen erreichten sämtliche Bohrungen in verschiedenen Tiefen das Kalisalzlager. Daraus wird geschlossen, daß das Lager in beträchtlicher Ausdehnung der Oberflächengestaltung folgt. Nach Mitteilung eines spanischen Fachblattes ${ }^{1}$ ) haben die Bohrlöcher der französisch-belgischen Gruppe eine Zone von ungefähr $10 \mathrm{qkm}$ aufgeschlossen und das Vorhandensein von Kalisalzlagern in einer bergbaulich günstigen Tiefe nachgewiesen.

Ganz kürzlich aus Spanien eingetroffene Nachrichten sprechen von reichen Kalifunden bei Suria, Callas, Gérona, Cardona, Manresa, Sallens, bestätigen also die früheren Angaben. Nach ihnen wird in Spanien schon unmittelbar nach dem Kriege mit einer bedeutenden Ausfuhr von Kalisalzen gerechnet.

Nach den bisher veröffentlichten Nachrichten sollen die Aufschlüsse in Spanien bis zu 8 Meter mächtige Sylvinit- und 16 Meter mächtige Karnallitlager ergeben haben, welche einen auffallend hohen Kaligehalt, der denjenigen der mitteldeutschen Ablagerungen weit übersteigt, besitzen sollen. Das Kalisyndikat hat, in richtiger Würdigung der neuen Funde bedeutende spanische Konzessionen erworben, die jährlich erhebliche Abgaben bedingen.

Soviel bekannt ist, hat die spanische Regierung ein besonderes Kaligesetz erlassen, um die wertvollen Funde dem Staate selbst zu sichern und die Erschließung durch private Unternehmer nachdrücklichst zu fördern. Nach dem Gesetz ${ }^{2}$ ) beabsichtigt der Staat einen weitgehenden Einfluß auf die Produktion und den Vertrieb der Salze zu nehmen. Von wesentlicher Bedeutung für die Frage der Entstehung einer spanischen Kaliindustrie ist der im Gesetz enthaltene Produktionszwang. Damit ist die Möglichkeit ausgeschlossen, durch Belegen der Felder den Bau neuer Werke zu verhindern. Es ist deshalb mit Bestimmtheit damit zu rechnen, daß sehr bald in Spanien ein bedeutender Kali-

1) „Revista Minera“ v. 8. 11. 1917.

2) Vergl. Anlage. 
bergbau beginnen wird. Welche Folgen dieses für die deutsche Industrie hat, ist leicht vorauszusehen.

Ein weiterer, vielleicht ebenso bedeutsamer, Fund ist an der Grenze der italienischen Kolonie Erithrea in Dancalien gemacht worden. Nach Berichten des amerikanischen Konsuls in Aden ist an der Grenze der genannten Kolonie bereits im Jahre 1911 ein Kalivorkommen entdeckt worden, zu dessen Abbau eine Konzession der abessinischen Regierung erteilt worden ist. Es handelt sich hier um Chlorkaliumfunde. Die Konzession ist von einer italienischen Gesellschaft übernommen worden, welche die vorhandene Menge Kalisalze auf wenigstens 850000 Tonnen schätzt, die angeblich durch Ablagerungen von aus heißen Brunnen stammenden Salzen fortgesetzt vergrößert werden. Vermutlich handelt es sich dabei nur um eine Umlagerung. Die Lagerstätte soll sich ungefähr 74 Kilometer von dem Flecken Fatimari am Roten Meer befinden.

Gemäß einer in Nr. 35 der holländischen Zeitschrift "In en Uitvoer" vom 29. August 1917 erschienenen Mitteilung wurden von dieser Gesellschaft bereits umfangreiche Vorbereitungsarbeiten für die Ausbeutung der Lagerstätten in Angriff genommen, namentlich auch die Anlage einer Straße nach Fatimari und der Bau eines Hafens dortselbst, von wo die Kalisalze zu Schiff nach Aden und Massaua weitergeleitet werden sollen. Die bisherige Monatsproduktion beträgt danach vorläufig 1000 Tonnen, soll jedoch bald auf monatlich 7000 Tonnen und mehr vergrößert werden. Eine Schmalspurbahn mit 7000 Tonnen monatlicher Leistungsfähigkeit wird jetzt gebaut, da der Kameltransport nicht ausreicht. Allerdings wird in der Mitteilung weiter gesagt, daß infolge von Schwierig, keiten in der Direktionsfrage und der Versendung der Salze auf dem Seewege momentan die Arbeiten einschließlich derjenigen der Kaligewinnung stillgelegt worden seien. Nach einer anderen Zeitschrift stellt die Salzebene zum größten Teil eine Depression unter der Meeresoberfläche dar und ist nichts anderes, als das Becken eines früheren Meeres, das vulkanische Ausbrüche vom Roten 
Meer abgetrennt haben. Das Lager hat eine Ausdehnung von $1250 \mathrm{qkm}$. An der Oberfläche findet man nur reines Chlorkalium von $90-95 \%$. Die unteren Schichten bestehen aus Chlorkalium von $40-80 \%$. Die angestellten Untersuchungen und Berechnungen haben nach diesem Blatt eine ungefähre Menge von 2 Mill. Tonnen Chlorkalium von $95 \%$ ergeben. Hiervon liegen 140000 Tonnen an der Oberfläche. Die Gesellschaft hat von Februar bis September 1916 nach Italien 2500 Tonnen Chlorkalium eingeführt und rechnete, von Dezember 1916 monatlich 1000 Tonnen einzuführen. Auch erklärte sie, diese Lieferungen gegen jeden Wettbewerb durchführen zu können ${ }^{1}$ ). Ausführungen im „New Statesman" bestätigen, daß die „Verbandsländer seit Beginn des Krieges Kalisalze aus Erithrea bezogen haben. Obwohl die Läger erst vor kurzer Zeit entdeckt worden seien, betrage die Produktion schon 200000 Tonnen jährlich." Die Richtigkeit dieser Erzeugungsziffer mag dahingestellt bleiben.

Wenn auch vorläufig infolge des Fehlens direkter Nachrichten nicht $\mathrm{zu}$ übersehen ist, welche Bedeutung den neuen Meldungen über das abessinische Kalivorkommen zukommt, so kann man daran nicht achtlos vorübergehen. Wird doch die Meldung dadurch besonders bedeutungsvoll, daß darin das Vorhandensein von heißen Brunnen festgestellt wird, welche dauernd weitere Salzmengen zum Absatz gelangen lassen. Dies würde unzweifelhaft darauf hinweisen, daß sich tatsächlich in diesem Gebiete in der Teufe größere Kalisalzlagerstätten befinden müssen, über deren Ausdehnung und Beschaffenheit natürlich vorläufig noch nichts Sicheres bekannt ist, die aber eine ähnliche Ueberraschung bringen könnten, wie sie seinerzeit das elsässische Vorkommen gebracht hat. Nach den vorliegenden Berichten scheint Italien bereits Interesse für diese Vorkommen an den Tag zu legen und die Einrichtung geregelter Schiffsverbindungen zum Abtransport größerer Mengen von Kalisalzen in Erwägung zu ziehen. Wenn auf

1) „Le Phosphate" vom 15. 5. 1918. 
der einen Seite die Schwierigkeiten, welche durch die geographische Lage, abnormen Arbeitsverhältnisse und Beschaffenheit der Fundorte, welche in süßwasserloser Gegend liegen, bisher ohne geeignete Verkehrsmittel außerordentlich große sind, so muß auf der anderen Seite doch damit gerechnet werden, daß die durch den Krieg veränderten Verhältnisse den Wert der gemeldeten Funde bereits um ein Vielfaches erhöht haben und daß sich die Kapitalisten der Ententeländer gewiß auf das energischste bemühen werden, das hier festgestellte Vorkommen in größtmöglichstem Umfange nutzbringend zu verwerten.

Aehnlich wie in Spanien und Abessinien sind auch in anderen Ländern mit hoher Wahrscheinlichkeit Kalifunde zu erwarten. Es gibt weite Gegenden, die geologisch durchaus nicht erforscht sind oder wo die geologischen Bedingungen für die Auffindung neuer Salzlager nicht ungünstiger sind als in Deutschland oder Spanien. Es gilt beides insbesondere in bezug auf RuBland.

Mehrfach wurde bereits in der Presse die Nachricht verbreitet, $\mathrm{da} B$ in den bekannten Steinsalzvorkommen in dem . Gouvernement Perm auch Kalisalzablagerungen vorhanden seien. Seit Jahrhunderten wird dort Siedesalz gewonnen. Nach Davidsohn liefern in Perm 74 Bohrlöcher und Schächte die Rohsole, die ihren Salzgehalt den im Innern der Erde lagernden Steinsalzen verdankt ${ }^{1}$ ). Bedeutungsvoll ist, daß ein Gehalt von $\mathrm{K}_{2} \mathrm{O}$ in der Höhe von $5 \%$ in dort vorkommenden Salzen sicher nachgewiesen sein soll. Früher wurde die-Möglichkeit, das Vorkommen wirtschaftlich auszubeuten, bestritten. Unter den heutigen Verhältnissen dürfte diese Frage eine wesentlich andere Beưrteilung erfahren müssen. Die Aehnlichkeit zwischen dem geologischen Typus der dortigen Ablagerungen mit der deutschen Perm-Formation gibt zu denken. In der Tat liegt es sehr nahe, daß eine Fortsetzung der deutschen Vorkommen auch in Rußland in erreichbarer Tiefe aufgefunden werden kann. Es darf bei dieser Gelegenheit noch erwähnt werden, daß man nach Meldungen aus Rußland beabsichtigt, dort Kali aus dem Meerwasser und den Salzen

1) Buschmann: Das Salz, Wien, 1909. 1. Bd., S. 8. 
der Salzlagunen in der Krim zu gewinnen. Nach angestellten Untersuchungen soll die Möglichkeit vorhanden sein, diese Gewinnung praktisch und rentabel durchzuführen. Anfang 1917 sollte nach Zeitungsnachrichten mit dem Bau von geeigneten Fabrikeı begonnen werden, denen behördliche Zuschüsse zugesichert waren. Infolge der Revolution dürfte dieser Plan vorläufig nicht zur Ausführung kommen.

Neuerdings eingetroffene Nachrichten besagen, da $B$ bei Solikamsk (Gouvernement Perm) große Kalilager entdeckt worden sind, die an einem kleinen schiffbaren FluB, der zur Wolga führt, liegen.

Es ist noch nicht abzusehen, welche Bedeutung diese Nachricht für die deutsche Industrie hat.

Die bekannten Kalifunde in den miozänen Salzstöcken der Nordkarpathen sind an einer Stelle, nämlich bei $\mathrm{Kalusz}$ in Galizien, bereits Gegenstand eines besonderen Kalibergbaues geworden. Es wurde dort schon im Jahre 1871 eine Kalibergbau- und Salinen-A.-G., Kalusz, gegründet, welche jedoch nicht in der Lage war, das Unternehmen erfolgreich durchzuführen. In den Jahren 1911/1913 wurden dann wiederholt Projekte zur Ausbeutung der galizischen Kalilager bekannt. Nunmehr hat nach Meldungen des „Prager Tageblattes" der galizische Landesausschuß gemeinsam mit der Industriebank und der Kaligesellschaft $\mathrm{m}$. b. $\mathrm{H}$. in Lemberg eine Aktiengesellschaft für Exploitation von Kalisalzen mit einem Aktienkapital von 6 Millionen Kronen gegründet. Diese Aktiengesellschaft wollte nach den im Jahre 1914 bestehenden Plänen ein großes modernes Werk in Kalusz erbauen, welches im Herbste 1914 in Betrieb genommen werden sollte. Ihr wurde 1914 das Abbaurecht von Kalivorkommen in den von ihr belegten Freischürfgebieten Galiziens auf 60 Jahre verliehen. Die Kriegsereignisse dürften diese Absichten bisher vereitelt haben. Nach Zeitungsnachrichten sind die Grubenanlagen von den Russen nicht zerstört worden.

Nach den vorhandenen Mitteilungen der Literatur ${ }^{1}$ ) ergibt

1) Vergl. insbesondere hierüber: J. Niedzwiedski, Geol. Skizzen des Salzgebirges von Kalusz in Ostgalizien. Oesterreich. Zeitschrift f. Berg- und Hüttenwesen 1912, S. 413 ff. u. 432 ff.

Giebel, Kaliindustrie. 


\section{$-34-$}

sich folgendes Bild der Lagerungsverhältnisse der dem Miozän angehörigen Kalilagerstätte.

Unter einer Decke von Tonen folgen geringmächtige Gipse und Gipstone und darunter die sogenannten oberen und unteren Salztone. Im Liegenden der unteren Salztone folgen obligozäne Schichten. Die unteren Salztone besitzen eine Mächtigkeit von ca. 90 Metern; sie bestehen aus Tonen mit Salzbänken. In dieser Schichtfolge befinden sich die alten Sinkwerksbaue zur Gewinnung von Kochsalz. Die oberen Salztone, deren Mächtigkeit 40 bis 45 Meter beträgt, setzen sich ebenfalls aus Tonen- und Steinsalzbänken zusammen, enthalten aber außerdem drei Linsen Kalisalze. Die hangende und liegende Linse führen Sylvinit, die dazwìschen liegende Kainit; hier und da befinden sich in diesen oberen Salztonen Karnalliteinschlüsse. Für den Abbau kommen heute nur noch die beiden Sylvinitlinsen in Frage, während der Kainit bereits abgebaut ist. Die beiden Sylvinitvorkommen besitzen beide eine größere Ausdehnung als das Kainitlager und haben in den bisher bekannten Partien eine durchschnittliche Mächtigkeit von ca. 1 Meter. Welche Pläne die Aktiengesellschaft für Exploitation von Kalisalzen verfolgt, ist nicht bekannt. Da von besonderen neuen Aufschlüssen bisher nichts verlautet, wird man annehmen können, daß vorläufig die beschriebenen Sylvinitlager abgebaut werden sollen, und es bleibt abzuwarten, was die sich bei diesem Abbauen ergebenden neuen Aufschlüsse und die sonstigen dort etwa vorzunehmenden Untersuchungsarbeiten bringen werden. Hat man bereits in Deutschland selbst vielfache große Ueberraschungen mit Kalifunden erlebt, so dürfte in Galizien die Möglichkeit bestehen, daß man auch dort ausgedehntere Kalilager findet.

Es müssen weiter noch erwähnt werden die Vorkommen von Kalisalzen in $\mathrm{Chile}$, in den Provinzen $\mathrm{T}$ a r a p a ca und Antofagasta, die bereits häufig in der Literatur aufgeführt worden sind. In der Provinz Tarapacà im nördlichsten Teile Chiles liegt östlich der Küsten-Cordillere die Pampa von Tamarugal, eine ca. 1000 Meter über dem Meere liegende regenlose Hochfläche von ca. $200 \mathrm{~km}$ Länge und bis zu $50 \mathrm{~km}$ Breite. Im westlichen Teile dieser Pampa finden sich ausgedehnte Salzsteppen oder Salare. Der wichtigste ist der Salar von Pintados. Sein äußerer Anblick gleicht einem weiten grauen Meer, dessen Wellen plötzlich erstarrt sind. Ein 
Schollengewirr, aus welchem sich seltsame Salzgebilde herausheben, und in dem helle Flächen mit ruhiger Oberfläche auftreten, kennzeichnet das Bild, welches sich dem Beobachter darbietet.

Es liegt hier eine Oberflächenbildung vor, deren Mächtigkeit von 10 Zentimetern bis zu 1 Meter wechselt, bei einer Durchschnittsmächtigkeit von ca. 30 Zentimetern. Die Ablagerung liegt auf einem lockeren Boden von toniger Beschaffenheit, welcher mit Gips durchsetzt ist und einen ziemlich hohen Stand des Grundwassers zeigt, welches natürlich auch salzhaltig ist.

Während von einzelnen Forschern die Ansicht vertreten wird, $\mathrm{da} B$ hier eine Ablagerung von Salzen stattgefunden hat, welche durch Wassermassen der Wolkenbrüche, welche in den Cordilleren niedergehen, mitgeführt werden, hat die von der Compagnie Minera Pintados entsandte Kommission als wahrscheinlich angenommen, daß in der Tiefe der Pampa sich ähnlich mächtige Salzablagerungen vorfinden wie in Staßfurt, und $\mathrm{da} \beta$ aus diesen Salzflözen nach oben dringende Solen die Oberflächenbildung veranlaßt haben, so daß sich aus den Bohrlöchern, die im Salar angelegt sind, in kürzester Zeit weitere neue Salzschichten ausscheiden. Wenn auch letztere Beobachtung als richtig anerkannt wird, so wird doch die Annahme der Neubildung des Salars aus unterirdischen Saltlagern bestritten, weil auch Süßwasservorkommen festgestellt sind, und daher eine Anreicherung derselben mit Salzen beim Durchdringen der Salzablagerung und eine Wiederablagerung infolge der Verdunstung an der Oberfläche möglich erscheint.

Während die Salze anderer Salare in den hohen Cordilleren 15 bis $18 \%$ Chlorkalium enthalten sollen, ist durch chemische Untersuchung, welche von Dr. Simon ${ }^{1}$ ) ausgeführt wurde, nur ein dưrchschnittlicher Kaligehalt sämtlicher ausgeführter 58 Salz- und Wasserproben von 1,73\% festgestellt worden, wobei allerdings einzelne Proben bis zu 9,6\% Kaligehalt aufwiesen. Die gefundenen Salze zeigten eine sehr wechselnde Zusammensetzung. Im allgemeinen stellen die Salze ein Gemenge von Chlornatrium, schwefelsaurem Natron, schwefelsaurem Kalk, schwefelsaurer Magnesia, schwefelsaurer Tonerde, kohlensaurem Natron, borsauren Salzen und Spuren von Salpetersäure

1) Kali 1907, Heft 9. Das Vorkommen von Kalisalzen in Chile von Dr. Karl Riemann. 
dar, jedoch fehlen einzelne Gemengteile stellenweise völlig. Nach neueren Mitteilungen haben Analysen der Salzlager von Guaica am Salar von Pintados Gehalte von $14,5 \% \mathrm{KCl}$ ergeben, und der Chlorkaliumgehalt der Salzkruste soll sogar zwischen $3 \%$ bis $36 \%$ Chlorkalium wechseln, während die darunter befindliche Flüssigkeit ebenfalls stark chlorkaliumhaltig sein soll.

Bis zum Kriege war man der Ansicht, da $B$ die chilenischen Kalifunde für eine Gewinnung in Konkurrenz mit den deutschen Kalisalzen nicht in Frage kämen. Ob dieses auch in Zukunft nach Verschiebung der Verhältnisse durch den Krieg noch der Fall sein wird, kann nicht mit Bestimmtheit gesagt werden.

Neuerdings beschäftigt sich eine Gesellschaft, die „Du Pont Nitrate Corporation", mit der Gewinnung der Kalisalze.

Außer Chile besitzt noch $\mathrm{P}$ e $\mathrm{r}^{1}$ ) nennenswerte Vorkommen von Kalisalpeter an der $\mathrm{K}$ üste von Quilca. Dort ist die Oberfläche von etwa 4 Millionen Quadratmeter mit einer bis zu $15 \mathrm{~cm}$ starken salpeterführenden Schicht bedeckt, welche aus einer bräunlichen lockeren mit vegetabilischen Pflanzenresten durchsetzten Erde besteht. Diese besitzt einen Gehalt an in Wasser löslichen Bestandteilen von 12,5\%. Davon sind $3 \% \quad \mathrm{KNO}_{3}$, neben $1,5 \% \quad \mathrm{NaNO}_{3}, 6,5 \% \quad \mathrm{NaC} 1$ und $1,5 \%$ anderer Chloride. Bei der technischen Verarbeitung wird ein Ausbringen von $2 \%$ Nitratenserzielt. Die Beobachtung, daß sich solche salpeterführenden Schichten verhältnismäßig schnell regenerieren, und daher mit einer wesentlich größeren Abbaumenge zu rechnen ist, als das oberflächlich vorhandene Lager vermuten läßt, wird auch von diesem Vorkommen berichtet. Vielleicht sind unterirdische Lagerstäten von Nitraten vorhanden, welche die Regeneration verursachen. Ueber den Umfang dieser unterirdischen Vorräte liegen noch keinerlei Forschungen vor. Bereits im Jahre 1912 bestand eine kleinere Fabrik, welche damals, nach den Angaben der Besitzer, jährlich etwa 2500 Tonnen Kali-Salpeter produzierte, jedoch war damals bereits eine Verzehnfachung der Produktion in Aussicht genommen.

$\mathrm{Ob}$ inzwischen diese Vorkommen in größerem Maßstabe als Kaliquelle infolge der durch den Krieg abgeschnittenen Zufuhr von deutschen Kalisalzen herangezogen worden sind, ist bisher nicht bekannt geworden.
1) "Ka
in Peru".
1) „Kali“ 1912, Heft 12 „Ein Vorkommen von Kalisalpeter 
Kalisalpeter findet sich ferner in Indien. Es handelt sich um den sogenannten Bengal-Salpeter $\left(\mathrm{KNO}_{3}\right)$, welcher bei der in Bengal in Ostindien herrschenden lang andauernden Hitze durch Wasserausdünstung sich aus dem Boden ausscheidet, und der schon Gegenstand einer lohnenden Gewinnung geworden ist. In Indien kommt in dem silurischen Stein. salz der Myoggruben des Salthange in Punjap Sylvin $(\mathrm{KCl})$ vor. Dieses Vorkommen soll nach einer Veröffentlichung in den "Bergwirtschaftlichen Mitteilungen" in wirtschaftlicher Beziehung etwa demjenigen von Kalusz in Galizien entsprechen.

In Nordamerika konnten bisher eigentliche Kalisalzlager nicht nachgewiesen werden. Doch wurden in dem abfluBlosen Becken der Wüstengegend im Westen kalihaltigje Salze, Solquellen und Salzseen angetroffen. Nach Mayer ${ }^{1}$ ) sind die in den Staaten Neuyork, Ohio, Michigan, West-Virginia, Pennsylvanien, Kansas und Luisiana vorkommenden Salzquellen ohne ernsthafte technische Bedeutung, weil es sich bei ihnen größtenteils um schwache, ganz vorwiegend kochsalzhaltige Solen mit einem Kaligehalt von 0,09 bis $0,5 \%$ des Gesamtrückstandes handelt. Von Wichtigkeit sind dagegen die Vorkommen in Newada und Kalifornien im Bezirk des sogenannten Great Basin, welche vorläufig allein für eine Gewinnung von Kali in Frage kommen sollen. Das Great Basin bildet den trockenen Teil der ariden amerikanischen Weststaaten, nämlich Kalifornien, Newada, Utah, Idaho und Oregon, und stellt ein Sammelbecken einer Anzahl Flüsse dar, die sich zum Teil in Seen ergießen, welche sich infolge ihrer Verdunstung mit Salzen angereichert haben. Im Bereich des Great Basin sind nach Mayer vier Arten des Vorkommens von gelösten und festen Salzen zu unterscheiden:

1. Seen, welche noch einen Zufluß, haben, deren Wasser nicht mehr süß, aber auch noch nicht sehr weitgehend konzentriert ist $z$. B. der große Salzsee in Utah,

2. Seen, welche noch einen Zufluß haben, deren Wasser ater schon sehr weitgehend konzentriert ist, wie dies bei dem Owens- und Mono-See der Fall ist,

3. Seen, welche keinen direkten Zufluß mehr haben, ausgetrocknet sind und eine feste Salzablagerung von größerer

1) Kali 10. Jahrg., Heft 18 bis 20. Versuche zur Gewinnung von Kalisalzen aus Salzsolen in den Vereinigten Staaten von Amerika. 
Mächtigkeit, die noch stark mit Mutterlauge durchzogen ist, enthalten, wie beispielsweise der Searles-See.

4. der Fluß verdunstet oder versumpft allmählich unter Bildung größerer Mengen Schlamm und einzelner kleiner Seen, die ihrerseits dann wieder austrocknen und kleine Salzablagerungen durch Ausblühungen ergeben: der Death ValleyTypus mit Wüsten-, Sumpf-, Playa- und Marschbildungen.

Uebergänge von einer zu der anderen Form sind zu beobachten. Für die Gewinnung von Kali kommen hauptsächlich der Searles-See, Death-Valley, Columbus-Marsch und der Owens-See in Betracht.

Der im Bonneville-Becken liegende große Salzsee mit einer Wasserfläche von $5700 \mathrm{qkm}$ und einer Tiefe bis zu $15 \mathrm{~m}$ enthält eine stark gesättigte Lauge von $21,37 \%$ Abdampfrückstand; in demselben sollen sich $1,95 \% \quad \mathrm{~K}_{2} \mathrm{O}$ befinden. Aus dem großen Salzsee werden Soda und Kochsalz in offenen Salzgärten gewonnen. Neuerdings soll seitens verschiedener Gesellschaften der Plan bestehen, die Endlaugen dieser Gewinnung auf Kalisalze zu verarbeiten. Bereits im Frühjahr 1916 wurden von der Diamond Matsch Co. bei Grants am Südende des Sees Versuchsanlagen hierfür errichtet. Ein ähnliches Vorkommen ist in dem Salduro-Salzsumpf bekanntgeworden.

Der in Kalifornien gelegene Mono-See von $220 \mathrm{qkm}$ Oberfläche und $18,5 . \mathrm{m}$ Durchschnittstiefe hat einen Salzgehalt von $5,12 \%$ mit einem Kaliumgehalt von $1,85 \%$. Der KCl Gehalt des Abdampfrückstandes beträgt 3,54\%, und der des Seewassers $0,18 \%$. Die Gesamtmenge des im Mono-See gelösten $\mathrm{KCl}$ wird auf nicht weniger als $9,5 \mathrm{M}$ illi on en Tonn en geschätzt.

Der gleichfalls völlig abgeschlossene benachbarte OwensSee ist ebenfalls mit einer starken Salzlösung gefüllt. Seine Oberfläche schwankt zwischen 250 qkm bis zu 600 qkm Fläche, je nach dem Wasserstande. Zur Ausscheidung fester Salze ist es bisher nicht gekommen. Das Wasser des Owens-Sees ist noch stärker konzentriert und kalireicher, als dasjenige des Mono-Sees. Bei einem Salzgehalt von 7,27\% im Seewasser enthält der wasserfreie Abdampfrückstand 2,18 \% Kalium, was 4,17\% Chlorkalium im Abdampfrückstand und 0,13\% im Seewasser entspricht. Man schätzt die im Seewasser enthaltenen Mengen $\mathrm{KCl}$ auf $2 \mathrm{Millionen} \mathrm{T}$ onnen. Hier 
findet seit langer Zeit auch eine Sodagewinnung statt. Während früher die Endlaugen in den See zurückflossen, wird neuerdings aus ihnen auch Kali gewonnen. Nachdem im Mai 1915 die Versuche begonnen waren, wurden bereits im September des gleichen Jahres die ersten Kalisalze hergestellt und verkauft. Eine Vergrößerung der Versuchsanlage zwecks Erzeugung von mehreren tausend Tonnen Kalisalz war für das Jahr 1916 in Aussicht genommen.

Der in Kalifornien gelegene Searles-See, nordöstlich von Rendsburg, bedeckt mit seinen Rückständen eine Oberfläche von etwa 11 Quadratmeilen. Die Mächtigkeit der Schichten ist bedeutend; bedeckt werden die Ablagerungen von Lehm und Salzton und stellen selbst eine wechselnde Schichtenfolge salzhaltiger und tonhaltiger Lager dar. Nach Friedensburg-1) stellt das den Mittelteil des Sees bildende eigentliche Salzlager einen 20 bis $30 \mathrm{~m}$ mächtigen Salzkörper dar, der bis zu $10 \mathrm{~cm}$ Tiefe im allgemeinen trocken, darunter von einer konzentrierten Sole durchtränkt ist, welche besonders die leichtlöslichen Salze, vor allem auch die Kalisalze, enthält. Der Kaligehalt der festen Salze wurde in einer Durchschnittsprobe für alle durchbohrten Lager mit $3,64 \% \mathrm{KCl}-\mathrm{Geh}$ alt angegeben; dagegen enthält die Sole einen wesentlich höheren gleichbleibenden Gehalt an Chlorkalium, welcher auf rd. 12\% Chlorkalium im Abdampfrückstand beziffert wird, eine bemerkenswert hohe Zahl. Friedensburg berechnet die Gesamtmenge des in der Sole enthaltenen Chlorkaliums unter Zugrundelegung eines durchschnittlichen $\mathrm{KCl}-\mathrm{Gehaltes}$ der Sole von nur $4 \%$ auf eine Gesamtmenge von 5,5 Million en Tonnen $\mathrm{KCl}$.

Diese Verhältnisse haben zur Gründung der A mericanTrona-Corporation zur Verarbeitung der Sole auf Chlorkalium und andere Salze geführt. Die Sole soll aus den Bohrlöchern gepumpt und zunächst auf Soda verarbeitet werden. Durch künstliches Eindampfen und Auskristallisieren in großen Kasten fallen Natriumsulfat, Kochsalz, Borax und Chlorkalium aus. Die beabsichtigten Anlagen sollen für eine tägliche Verarbeitung von fast $12000 \mathrm{t}$ Sole, aus denen rund $440 \mathrm{t}$ Chlorkalium, $200 \mathrm{t}$ Borax, $460 \mathrm{t}$ wasserfreie Soda, $1350 \mathrm{t}$ Kochsalz und $450 \mathrm{t}$ Natriumsulfat gewonnen werden sollen, ausreichen:

1) Glückauf, Jahrg. 53, Nr. 21, S. 429 ff. 
Die Gesellschaft hat inzwischen zwei Fabriken errichtet, eine in Trona, in der die Lake eingedampft wird, und eine in St. Pedro, Kal:, in der die Salze hergestellt werden. Die Erzeugung der Gesellschaft ist im Jahre 1916 bedeutend gewesen, doch sind ihre Erzeugnisse nicht ganz einwandfrei, weil sie Beimengungen von Salpeter und Borax enthalten. Insbesondere sollen die Düngergesellschaften das Erzeugnis aus diesem Grunde ablehnen. Anfang 1918 hat die tägliche Ausbeute der Trona an gemischten Salzen mit 65\% Chlorkaliumgehalt $50 \mathrm{t}$ betragen. Nach Mitteilungen, die auf der Generalversammlung gemacht worden sind, soll die Erzeugung auf täglich $90 \mathrm{t}$ gesteigert werden. Gegen Ende des Jahres 1918 soll die Produktion $270 \mathrm{t}$ täglich betragen ${ }^{1}$ ). Inzwischen haben sich zwei weitere Gesellschaften zur Gewinnung von Kalisalzen aus dem Searles-See zusammengeschlossen. Es sind dies die Pacific Borax Co. und die Solvay Process Co. Die Erzeugung hat im Mai 19171000 t 80\% iges Chlorkalium ketragen. Die Gesamterzeugung des Searles-Sees ist in dieser Zeit auf täglich $50 \mathrm{t}$ angegeben. Hervorzuheben ist bei den erwähnter Fabriken, daß die Erzeugung von Kalisalzen als Nebenprodukt erfolgt, was die Aussicht auf Rentabilität des Verfahrens wesentlich erhöht. Es werden neben Kali Borax, Jod, Karbonate und Nitrate gewonnen ${ }^{2}$ ).

Ein weiteres Kalivorkommen wird im abflußlosen Death Valley (Todestal) gemeldet, einem fast $200 \mathrm{~km}$ langen und nur bis zu $15 \mathrm{~km}$ breiten Tale, in welches der Amargosa River fließt. Auf dem Talboden desselben befinden sich gewaltige Salzablagerungen mit einer Gesamtoberfläche von über 400 Quadratkilometer. Abwechselnd kommen weiches und hartes Salz und Schlamm vor, alles durchtränkt von gesättigter Sole, welche auf den Abdampfrückstand bezogen, etwa $5 \% \mathrm{KCl}$ enthairt.

Von Mayer wird ferner als Kalivorkommen die ColumbusMarsch im Staate Newada erwähnt, eine breite Ebene, welche unter trockener Oberfläche mit einem teilweise sehr stark kalihaltigen Schlamm ausgefüllt ist. Es wurden Gehalte an $\mathrm{K}_{2} \mathrm{O}$ in den löslichen Salzen bis zu $25,18 \%$ festgestellt. Auf Grund dessen wurden alle kaliverdächtigen Ländereien der Columbus-Marsch für Regierungszwecke reserviert. Nach-

1) Fin. Times v. 9. 5. 18.

2) E. Böhler, a. a. O. S. 495. 
richten über begonnene Ausbeutung des Schlammlagers, dessen $\mathrm{K}_{2} \mathrm{O}$-Gehalt im Durchschnitt die obengenannte Zahl jedoch bei weitem nicht erreichen dürfte, liegen bisher nicht vor.

In der Gewinnung der Kalisalze teils aus den Seen, teils aus den nach früher behandelten Verfahren aus kalihaltigen Steinen haben die Amerikaner während des Krieges zweifellos beachtenswerte Erfolge erzielt. Nach Friedensburg ${ }^{1}$ ) sind im Kriegsjahr 1915 zum ersten Male auf dem amerikanischen Markte Kalisalze heimischer Erzeugung erschienen, und zwar wasserlösliche Kalisalze im Gesamtwerte von 1438000 M., nach seiner Schätzung insgesamt etwa 4000 Tonnen Kalisalze. Friedensburg schätzt ferner die gesamte tägliche amerikanische Erzeugung zu Anfang des Jahres 1917 auf 150 bis 200 t, nimmt also eine Jahreserzeugung von 45000 bis 60000 t Kalisalze an. Nach Böhler beträgt die Erzeugung des Jahres 1917 ungefäh- 25000 sh. t. $\mathrm{K}_{2} \mathrm{O}$, das sind etwa $10 \%$ des normalen Verbrauchs vor dem Kriege.

Das Ergebnis der Ausführungen kann dahin zusammengefaßt werden, daß neben der Möglichkeit, Kalisalze a uf rentablewirtschaftliche Weise a s Gesteinen usw. $z$ u gewinnen, diese a uch aus kalihaltigen Gewässern und Ablagerungen erzeugt werden können. Es ergab sich, daß zahlreiche Gewinnungsstätten schon im Betrieb sind, wenn auch ein endgültiges Urteil über ihre wirtschaftlichen Aussichten noch nicht abgegeben werden kann. Indessen muß auch hier darauf hingewiesen werden, daß mögliche technische Fortschritte für das eine oder andere Verfahren eine wirtschaftliche Grundlage schaffen können. In hohem Maße hängt dies davon ab, wie sich die Nebenproduktengewinnung bei den einzelnen Verfahren gestaltet. Sobald sich diese als wirtschaftlich erweist, wird auch Kali auf rentable Weise hergestellt werden können.

Die Bedeutung aller dieser Möglichkeiten tritt aber weit zurück gegenüber der Tatsache, daB wir nichteinmal mehrein Monopolanden leicht-

1) Glückauf, 53. Jahrg., Nr. 19, Seite 397. Kalivorkommen und Kaligewinnungsversuche in den Vereinigten Staaten von Nordamerika, 
löslichen Kalisalzen besitzen. Die Auffindung abbauwürdiger.Vorkommen in Spanien, Abessinien und wahrscheinlich, a uch in $R u B$. land, wird die Entstehung größerer ausländischer Industrien zur Folge haben.

Damit sind aber alle dem Monopol schädlichen Momente noch nicht erschöpft. Die Tatsache, daß die spanischen Funde, ebenso wie im Elsaß in der Tertiärformation liegen, zwingt uns, mit der Möglichkeit weiterer Funde in Ländern, die gleicheoderähnliche geologische Bedingungen wie Deutschland und Spanien a uf we isen, zu rechnen. Wenn diese Erkenntnis auch bitter ist, so ist es doch besser, die Dinge so zu sehen, wie sie sind, statt falschen Vorstellungen nachzuhängen, die nicht die Wirklichkeit als Boden haben.

Es fragt sich nun, welche Wirkung eine in anderen Ländern neu entstehende Kaliindustrie haben wird. Hierüber kann es eigentlich kaum Zweifel geben: sie kann nur äußerst schädlich sein. Dieses erkennt auch ein unbedingter Befürworter eines Staatsmonopols ${ }^{1}$ ), allerdings ohne die richtigen Folgerungen aus dieser Erkenntnis zu ziehen. Er äußert sich hierzu wie folgt:

„Wird im Ausland bauwürdiges Kali gefunden und billig gefördert, so muß Deutschland mit seinen Kalipreisen entsprechend herabgehen, wenn es nicht den Markt verlieren will. An sich wird es bei richtiger Betriebskonzentration immer so billig fördern und hochprozentige Düngesalze herstellen können wie das Ausland. Nur hat es infolge der unglücklichen Ueberproduktion von Kaliwerken ein mehrfach zu hohes Anlagekapital zu verzinsen, das die Produktionskosten stark belastet."

Nach Meinung des genannten Verfassers kann allerdings dieser Gefahr durch starke Einschränkung der Betriebsstätten und Ausnutzung der noch bis zur Errichtung fremder Kaliindustrien verfließenden Zeit, in der noch be-

1) Gothein a. a. O. Seite 65/66. 
deutende Gewinne gemacht werden könnten, begegnet werden. Auf die Möglichkeit einer Betriebskonzentration wird an anderer Stelle eingegangen werden. So viel kann hier schon gesagt werden, daß die seitens Gotheins von ihr erhofften Folgen kaum eintreten dürften. Das Abschreiben des Gestehungspreises der Kaliwerke dürfte die ungünstige Wirkung einer ausländischen Industrie nicht aufheben. Ein ausländischer Wettbewerb wird ganz zweifellos eine gewaltige Herabminderung des Anlagekapitals, das der Fiskus für den Erwerb der Kaliwerke gezahlt haben würde, zur Folge haben, weil er den Absatz der Kaliprodukte im Auslande stark beeinträchtigen, vielleicht zum großen Teile unmöglich machen wird. Damit aber wird der Kaliunternehmer, in unserem Falle der Staat, in doppelter Weise geschädigt. Er wird sein Anlagekapital zum Teil als verloren betrachten müssen und wird auch die erhofften Einnahmen nicht finden. Die rücksichtslose Ausbeutung des einheimischen Marktes durch Zölle und Einfuhrverbote, wie Gothein empfiehlt, hat ebenfalls ihre natürliche Grenze. Wird doch schon von anderer Seite die Ansicht vertreten, daß die jetzt im Kriege geltenden Preise für Kalisalze im Frieden nicht beibehalten werden könnten, weil damit die landwirtschaftliche Erzeugung zu sehr belastet werde, was wiederum in der Richtung einer allgemeinen Preissteigerung wirke ${ }^{1}$ ). Im übrigen fragt man sich mit Recht, wo bleibt dann der große Gedanke des Monopols? Wo bleiben die enormen Produktions-, Fabrikations- und Handelsgewinne, die das Monopol an sich bringen soll, wenn ein Ueberschuß überhaupt nur durch Einfuhrverbote oder Zölle, wie es Gothein vorschlägt, erzielt werden kann? Das Monopol würde dann weiter nichts anderes darstellen, als eine große indirekte Steuer. Um eine solche einzuführen, bedarf es nicht des ungeheueren Aufwandes und der Fesselung der Triebkräfte des Wirtschaftslebens, die ein Monopol bedingt. Gothein gesteht selbst, daß der Hauptnutzen beim Kaligeschäft in dem Auslandsgeschäft liege. Die stärkere Ausnutzung des

1) Blankenstein: Reichsfinanzquellen, Berlin 1917 , S. 60/61. 
inneren Marktes kann daher unter kẹinen Umständen einen annehmbaren Ausgleich für den Verlust des Auslandsabsatzes bilden. Auch wird sich die Landwirtschaft gegen diesen Gedanken wehren müssen; denn seine praktische Ausführung bedeutet für sie nichts weniger als eine Sonderbelastung mit den Kosten des Monopols. Auch die Behauptung, daß D'eutschland stets so billig fördern könne wie das Ausland, steht auf schwachen Füßen. Es fehlt $\mathrm{zu}$ ihrer R'echtfertigung jeder Beweis. Im Gegenteil ließe sich eher vermuten, daß Spanien die Salze wird billiger liefern können, weil unsere Industrie, namentlich infolge des Krieges, mit vielerlei Abgaben und Erschwerungen rechnen muß, die dort wegfallen. Es ist hierbei interessant festzustellen, daß es Kreise gibt, die von einer neuen ausländischen Industrie keine schädlichen Folgen für unseren Kaliabsatz befürchten. Sie erhoffen davon sogar noch eine Anregung zum höheren Verbrauch der Salze und damit eine Steigerung des Absatzes im allgemeinen! Begründet wird diese Meinung in der Hauptsache damit, daß die ausländischen Werke ihre Salze sicherlich auch nicht billig verschleudern würden und daß man sich wohl bald auf dem Wege eines stillen oder offenen Uebereinkommens verständigen werde. Als Schulbeispiel wird dabei stets auf Oesterreich, in bezug auf den Bergbaubetrieb bei Kalusz verwiesen ${ }^{1}$. Diese Ansicht widerspricht allen wirtschaftlichen Erfahrungen. Man braucht nur auf die Wirkungen zu verweisen, welche die sogenannten Bradley-Kontrakte gehabt haben. Sie bestanden nur darin, daß das Syndikat seine besten und zahlungsfähigsten Kunden für längere Zeit verlor und diese ihre Salze zu billigen Preisen geliefert erhielten. Genau dieselben Verhältnisse werden bei einem ausländischen Wettbewerb eintreten. Die neue Industrie wird sich die bisherigen Erfahrungen voll zunutze machen. Sie wird große, leistungsfähige Anlagen bauen und diese voll ausnutzen. Wie bekannt, haben sich bereits Kaliindustrielle, wie der

1) Vergl. Paxmann: Tagesfragen in der Kaliindustrie. Berlin 1917. 
Belgier Solvay, der Elsässer Voigt u. a., die auch deutsche Kaliwerke besitzen, in starkem Maße bei den spanischen Funden beteiligt. Diese sind Mitglieder des deutschen Syzdikats und wohnen beide im Auslande. Welche Wirkungen diese Verhältnisse hervorbringen werden, ist leicht vorauszusehen. Die fremde Industrie ferner wird frei sein von den Einschränkungen und Abgaben, die der deutschen Industrie auferlegt sind. Die Lage der spanischen Felder nahe an der See macht einen Schiffstransport ebenso gut möglich, wie bei der deutschen Industrie. Daher wird diese neue Industrie aller Voraussicht nach bei billigeren Preisen noch eine bessere Rentabilität aufweisen als die unsrige. Welche Gründe zu der Annahme führen können, die ausländische Industrie würde unsere Preise nicht oder nur unwesentlich unterbieten, ist unerfindlich. Hat doch gerade der Kampf um den Absatz seinerzeit das deutsche-Syndikat gesprengt. Nur der stärkste staatliche Druck, der schließlich Gesetzesform annahm, hat es wieder bilden können. Die Hoffnung. auf eine offene oder stillschweigende Verständigung mit einer fremden Industrie erscheint angesichts der Wirklichkeit außenordentlich trügerisch. Eine solche Verständigung wird seitens der deutschen Industrie natürlich angestrebt werden müssen, aber schafft man hierfür nicht die allergrößten Schwierigkeiten, wenn man das Deutsche Reich zum Besitzer der Kaliwerke macht oder ihm das Handelsmonopol überträgt? Die private Industrie wird zweifellos eine Verständigung, wenn sie überhaupt möglich ist, viel eher erreichen können als der Staat. Ebenso verfehlt ist der Hinweis auf die österreichischen Verhältnisse. Die Argumentation mag einige Berechtigung haben, unter der Voraussetzung, daß die neue Konkurrenz nur aus einem oder höchstens einigen Werken besteht wie das bisher in Oesterreich der Fall ist. In Spanien dagegen wird man mit anderen Größenverhältnissen rechnen müssen. Wie die Ansicht aufkommen kann, daß eine fremde Industrie, die wettbewerbsfähig ist, den eigenen Absatz steigern könne, ist schlechthin unverständlich.

Ergibt sich aus den Darlegungen, daß das Monopol 
an Kalisalzen in Deutschland infolge der Entdeckung neuer Lagerstätten in anderen Ländern nicht mehr besteht, so folgt daraus, daß die wichtigste Voraus setzung für die Rentabilität eines Staats monopols nicht vorhanden ist. Es kann unter diesen Umständen kein berechtigter Grund gefunden werden, der die Investition der ungeheuren Summen, die fürden Erwerb der Kaliindustrie notwendig wären, rechtfertigenkönnte, zumaldie Gefahr weiterer Funde in bisher noch kalifreien Ländern die wirtschaftliche Lage der Industrie weiter erschüttern und in Frage stellen könnte. Hier ist es das Interesse der Allgemeinheit, das die unbedingte Fernhaltung des Staates von solchen gefahrvollen Plänen spekulativer Art erfordert. Die Interessen des Staates werden keinen Schaden leiden, wenn die Spekulation, auch die unbeabsichtigte, wie bisher, der Börse und den an ihr vertretenen Kreisen überlassen bleibt.

\section{Die Möglichkeit der Betriebszusammenlegung.}

Die Rentabilitätsfrage eines Staatsmonopols steht weiter in Zusammenhang mit der Möglichkeit einer Betriebszusammenlegung. Wie die Freunde eines Staatsmonopols behaupten, ergebe sich für den Staat schon daraus ein erheblicher Gewinn, daß er als alleiniger Besitzer die Möglichkeit habe, die Betriebe zusammenzulegen, d. h. die Gesamterzeugung von Kalisalzen wenigen Werken zu übertragen. Die Selbstkosten würden, wie sie glauben, wesentlich niedriger werden, insofern, als mit der Stilllegung eines Teils der Betriebe die volle Ausnutzung der Betriebs- und Förderanlagen der anderen gewährleistet werde. Auch könne man nur diejenigen Werke fördern lassen, welche die besten Salze und Lagerungsverhältnisse haben und die niedrigsten Selbstkosten aufweisen, wodurch die durchschnittlichen Produktionskosten weiter herabge- 
setzt würden. Gothein ${ }^{1}$ ) ist sogar der Meinung, daß $3 / 4$ der Werke überflüssig seien. Paxmann ${ }^{2}$ ) glaubt, daß in normalen Zeiten von den vorhandenen Schächten noch rund $1 / 3$ für die Produktion entbehrt werden könnten. Wenn sämtliche Kalibetriebe indessen in eine Hand kommen würden, hält er eine weitergehende Stillegung für möglich, wodurch nach seiner Ansicht eine größere Anzahl Millionen Mark zu ersparen sei, besonders, wenn man nur diejenigen Werke produzieren lasse, die die niedrigsten $\mathrm{Ge}$ stehungskosten haben. Er macht dabei allerdings den Vorbehalt, daß für die Staatsbetriebe Sondervorrechte nicht bestehen bleiben.

Der genannte Schriftsteller hat selbst darauf aufmerksam gemacht, daß das Urteil darüber, welche Anzahl Werke in der Lage sei, den gesamten Bedarf zu decken, nicht einheitlich gewesen ist, sondern stets stark geschwankt hat. So kann man auch heute die Ansicht vertreten sehen, daß 30 Werke den Gesamtbedarf an Kalisalzen decken können, während von anderer Seite behauptet wird, daß ein Ueberfluß an Kaliwerken überhaupt nicht bestehe. Die Unsicherheit in diesem Urteil gründet sich darauf, da $B$ diese Frage nach der technischen Seite hin noch keiner eingehenden Prüfung unterzogen ist. Eine Prüfung, die, nebenbei bemerkt, auch schwer durchzuführen wäre. Es darf dabei außerdem nicht verkannt werden, $\mathrm{da} B$ die Behauptungen über die unwirtschaftliche Produktionsweise bei der Kaliindustrie teilweise auch agitatorischen Charakter tragen. Einen wissenschaftlichen Wert haben die Zahlenangaben über die stillzulegenden Werke nicht. Dies um so mehr als sich die Verhältnisse mit der Zeit immer mehr nach der entgegengesetzten Seite verschoben haben. Durch die stetig fortschreitende Konzentration der Betriebe, die besonders in letzter Zeit starke Fortschritte gemacht hat, werden die durch Verlegung der Produktion erzielbaren betriebstechnischen und frachtgünstigen Vorteile von den großen Werksgruppen schon

1) a. a. O. S. 57.

2) a. a. O. S. 68,69 . 
voll ausgenutzt. In dem Maße, wie der Zusammenschluß der Werke zunimmt, wird dieses in Zukunft noch mehr der Fall sein. Man begeht daher den Fehler, daß man sich einen Vorteil künstlich konstruiert, der schon längst in der Praxis verwertet wird.

Eine starke Beeinflussung des Urteils über die Möglichkeit einer Betriebszusammenlegung rührt von der Tatsache her, daß die Erzeugungsfähigkeit der Werke während gewisser Jahreszeiten nicht in vollem Umfange ausgenutzt wird. Dennoch würde es verkehrt sein, hieraus den Schluß zu ziehen, daß eine große Anzahl Werke entbehrlich sei.

Der Kaliabsatz ist bekanntlich ein Saisongeschäft. Die Bestrebungen der Industrie, den Absatz gleichmäßig auf das ganze Jahr zu verteilen, sind bisher nur von geringem Erfolge gewesen. Im großen und ganzen werden die Verhältnisse sich auch nicht grundlegend ändern. Die Hauptversandperioden liegen im Frühling und im Herbst, in welchen beiden Jahreszeiten sich erfahrungsgemäß die Landwirtschaft mit den nötigen Kalisalzen eindeckt, und wodurch ein außerordentlicher Hochbetrieb auf den Kaliwerken bedingt wird. Für diese Verhältnisse sind die ganzen Einrichtungen der Kalibergwerke zugeschnitten, sowohl die Bergwerksanlage selbst wie der Fabrikbetrieb. Durch die Anlegung großer Speicherräume ist ferner bereits im Rahmen des Möglichen dafür gesorgt, daß für diese Absatzperioden genügend Material aufgestapelt ist, damit unter gleichzeitiger Höchstleistung sämtlicher Betriebsanlagen ausreichende Mengen von Kalisalzen zum Versand gebracht werden können. In den Versandperioden werden schon jetzt die bestehenden Anlagen voll ausgenutzt; es würde bei den jetzigen Einrichtungennichtmöglichsein, a chnoch gleichzeitig die Produktion einer großen Anzahl von stillzulegenden Betrieben mit$\mathrm{z}$ ü̈bernehmen. Vielmehr würde sich die Notwendigkeit ergeben, sehr umfangreiche neue Betriebseinrichtungen auf denjenigen Werken zu schaffen, welche 
für die Uebernahme der Erzeugung in Frage kommen sollen. Im einzelnen würde diese Vergrößerung der Betriebseinrichtungen oft auf unüberwindliche Schwierigkeiten stoßen, weil die Schacht- und Fabrikanlagen von vornherein nicht für solch hohe Leistungen berechnet waren, und auch die Ausdehnungsmöglichkeit sowohl der Schachtförderung wie der Fabrikation, durchaus begrenzt ist. Außerdem bedeutet die Schaffung und Vergrößerung von Anlagen eine neue Kapitalinvestition, womit wieder die möglichen Ersparnisse ganz oder teilweise verlorengehen würden.

Ferner sei hier noch eine Hauptschwierigkeit betont, welche darin liegt, $\mathrm{da} B$ die Karnallitfabrikation die $\mathrm{Ab}$ leitung der bei derselben entstehenden Endlauge in die Flußläufe erfordert. Schon jetzt bestehen bezüglich der Erlangung von Abwässerkonzessionen die größten Schwierigkeiten, welche die Erzeugungsmöglichkeit der einzelnen Fabrikanlagen auf das schwerste einengen. Es kommt hinzu, da $B$ die Steigerung des Absatzes nach dem Kriege insbesondere in Fabrikaten erfolgen muß, weil der Frachtraum mangelt. Deren Herstellung erfordert aber vergrößerte Fabrikanlagen und damit größere Abwässerkonzessionen, die für konzentrierte Betriebe nicht zu erhalten sind. N u r da durch, da $B$ eine gro $B$ e $Z$ ahlvon Fabrikationsanlagen besteht, welche an sehr zahlreichen örtlichvoneinanderentferntliegenden Punkten ihre Abwässer in die FluBsysteme der Weser und Elbe einleiten, wares bisher möglich, ohne erhebliche Schädigung der FluB- läufe die Ableitung der in der Kaliindustrie entstehenden Endlaugen durchzuführen. In Zukunft wird dies noch mehr der Fall sein. Es handelt sich hier um gewaltige Mengen, welche nicht, wie man annehmen könnte, an wenigen Punkten auf einmal in die Flüsse abgeleitet werden können.

Es ist weiter zu beachten, daß in den Hauptversandperioden die Wagengestellung schon im Frieden sehlecht war. $\mathrm{Da} B$ hierin eine Aenderung eintritt, ist für die ersten 
Jahre nach dem Kriege bei dem Mangel an Material kaum zu hoffen. Dieser Mißstand rührt daher, daß besonders im Herbst der Güterverkehr bei der hohen Erzeugungskraft Deutschlands außerordentlich stark ist und nicht voll bewältigt werden kann. Die Wagengestellung würde bei einer Zusammenlegung der Erzeugung auf eine geringe Anzahl Werke noch wesentlich schlechter werden. Es ist sogar mit Recht zu bezweifeln, daß, wenn der Absatz und damit der Versand, wie vorauszusehen ist, stark steigen wird, die Wagengestellung, selbst bei der jetzigen Verteilung der Erzeugung auf viele Werke, in hohem Maße ungenügend sein wird. Welche Zustände aber durch die Betriebszusammenlegung herbeigeführt werden würden, lassen sich kaum ausdenken.

Hinzu kommt ferner, daß zu großer und schneller Abbau bergtechnisch als gefährlich angesehen wird. Er vergrößert insbesondere im starken Maße die Wassergefahr.

Bei einer Betriebszusammenlegung, die die Erzeugungsmöglichkeit der Werke in vollem Umfange in Anspruch nähme, ist leicht vorauszusehen, daß die Erzeugung der Nebenprodukte vernachlässigt werden müßte. Es würde den Werken weder genügend Zeit bleiben, noch würden sie die technische Möglichkeit haben, diesen Produktionszweig, der immerhin bedeutendes Interesse verdient, zu betreiben und $\mathrm{zu}$ fördern. Auch würde das Interesse hierfür erlahmen.

Für die erste Zeit nach dem Kriege würde ferner die außerordentliche Wohnungsnot ein Hindernis für die $\mathrm{Zu}$ sammenlegung der Förderung auf wenige Betriebe bilden. Jetzt verteilen sich die Belegschaften auf ein breites, meist ländliches Gebiet. Die Wohnungsfrage wird deshalb voraussichtlich einigermaßen zufriedenstellend gelöst werden können; anders bei vollständiger Konzentration der $\mathrm{Be}$ triebe.

Die Betriebszusammenlegung wirft noch eine Reihe anderer Fragen auf, insbesondere die Steuerfrage. Wird der Fiskus den Gemeinden und Kreisen die bisherigen Steuern weiterzahlen oder sie hierfür entschädigen? Auch 
die Entschädigung für die mannigfaltigen Ausfälle anderer

- Art wäre zu regeln.

Vorstehende Ausführungen lassen zunächst einen wichtigen Punkt außer Betracht. Sie gründen sich lediglich auf die Absatzverhältnisse des Jahres 1913. Nun aber haben sich diese durch den Krieg gewaltig verschoben. Schon rein erfahrungsgemäß ergibt sich, wie in der Einleitung gezeigt worden ist, eine gewaltige Steigerung des Absatzes. Unter Annahme, daß der Wettbewerb der ausländischen Industrie bis dahin noch nicht erheblich ins Gewicht fällt, würde nach der dort gegebenen Aufstellung bei einer jährlichen Steigerung von $10 \%$, die nach der bisherigen Entwicklung anzunehmen ist, der Absatz im Jahre 1920 bereits $21637000 \mathrm{dz} \quad \mathrm{K}_{2} \mathrm{O}$ betragen. Prüft man die Möglichkeit des Absatzes im einzelnen, so ergibt sich, daß vorläufig seit 1913 ein gewaltiger Rückgang in der Versendung an das Ausland getreten ist. In bezug auf die zukünftige Entwicklung bedeutet dies nur eine Hinausschiebung der Deckung des tatsächlich vorhandenen Bedarfs. Die Anforderungen des Auslandes werden nach dem Kriege um die nicht gedeckten Mengen höher. Hinzu kommt, daß der Bedarf im Auslande an sich noch steigen wird, wie es erfahrungsgemäß bis jetzt der Fall war. Die Erfahrungen des Krieges sowie die durch ihn geschaffenen Zustände (Frachtraumnot usw.) werden eine Erhöhung der Erzeugung in außerdeutschen Ländern bewirken. Auch wird sich der Absatz dadurch vergrößern, da $\beta$ Länder, die bisher die Kalidüngung noch nicht angewandt haben, mit zunehmender Entwicklung Kaliverbraucher werden.

Eine andere Erscheinung zeigt dagegen der Inlandsmarkt. Hier ist das Vorausgesehene schon eingetreten. Der Absatz an die deutsche Landwirtschaft ist während des Krieges dauernd gestiegen. Wie erwähnt, betrug er 1913 ungefähr 6 Millionen $d z \mathrm{~K}_{2} \mathrm{O}$. Er dürfte im Jahre 1917 bereits um mehr als die Hälfte gestiegen sein. Er wäre wahrscheinlich noch mehr gestiegen, swenn die Transportverhältnisse besser gewesen wären. In- 
folge der wachsenden Einsicht der deutschen Landwirtschaft, welch außerordentlich gewinnbringende Ausnutzung aller Ländereien durch ausreichende Kalidüngung möglich ist, ist nach Friedensschlu $\beta$ damit zu rechnen, $\mathrm{da} B$ der Bedarf im Inlande nicht nur nicht zurückgehen, sondern steigen wird. So steht zu erwarten, daß Deutschland durch Urbarmachung der noch ungenutzten Flächen (Moore, Weide usw.) seine landwirtschaftliche Erzeugung weiter erhöhen wird. Wurde doch 1913 die für Ausnutzung der in Deutschland noch zur Verfügung stehenden Anbaufläche erforderliche Menge Kalisalze auf $40 \%$ des Gesamtabsatzes an die inländische Landwirtschaft geschätzt. Die Kriegserfahrungen werden sicherlich in der Richtung einer Erhöhung der inländischen landwirtschaftlichen Erzeugung wirken. Es wird daher sowohl mit einer größeren Anbaufläche als auch mit einem höheren Verbrauch an Kali pro Quadratkilometer des schon bebauten Bodens zu rechnen sein. Man wird ferner nicht aus dem Auge lassen dürfen, da $B$ das Mißverhältnis zwischen Erzeugungs- und Absatzmöglichkeit durch die Verhinderung des Ausbaues neuer Werke während des Krieges stark ausgeglichen worden ist. Es ist bekannt, $\mathrm{da} B$ die Regierung mit der Verordnung vom 8. 6. 1916 verboten hat, neue Schächte abzuteufen und den Schachtbau von solchen fortzusetzen, die nach dem 1. 8. 1914 in Angriff genommen worden sind. Die Kriegsverhältnisse haben ihrerseits die Bautätigkeit im allgemeinen nur auf das dringendst notwendige $\mathrm{Ma} B$ beschränkt. Es wird Aufgabe der Regierung bleiben, diese günstige Wirkung auch für die Zukunft in geeignetem Maße sicherzustellen.

Schließlich darf noch auf folgendes aufmerksam gemacht werden. Das Staatsmonopol und der damit verbundene gewaltige Kapitalaufwand sind nicht erforderlich, um der nationalen Wirtschaft die Vorteile der Betriebszusammenlegung zu sichern. Lediglich die Aufhebung der Bestimmung des $\S 19$ des Kaligesetzes, wonach ohne Genehmigung der Landeszentralbehörde nur $50 \%$. der Quotenbeteiligung übertragen werden darf, würde- 
hierzu genügen. Warum dieses Hindernis weiterbestehen soll - auch nach den gewaltigen finanziellen und sonstigen Wirkungen des Krieges - , ist nicht recht ersichtlich. Müßte doch das Reich bei Uebernahme des Monopols sich ebenfalls über diese Bestimmung hinwegsetzen und die entgegenstehenden Interessen unbeachtet lassen.

Aus dem Gesagten ergibt sich, daß die Behauptung, 30-60 Kaliwerke würden imstande sein, den gesamten Kalibedarf zu decken, nicht haltbar ist. Sie trifft insbesondere nicht für die Verhältnisse nach dem Kriege zu. Es wird vielmehr behauptet werden können, daß die bestehenden Kaliwerke vielleicht gerade genügen, den zu erwartenden großen Lieferungsansprüchen gerecht zu werden. Dabei wird es vornehmste Aufgabe der Industrie sein, durch rechtzeitige völlige Ausnutzung der Absatzmöglichkeiten sich ein großes und sicheres Absatzgebiet in der Welt zu sichern, bevor der Kampf mit einer nicht-deutschen Industrie beginnt. Sie wird auch die kapitalistische Grundlage für diesen Kampf bilden müssen. Es kann unter diesen Umständen keine Rede davon sein, daß aus der Betriebszusammenlegung so enorme Gewinne fließen könnten, wie man glauben machen möchte. Selbst wenn günstigenfalls einige Werke entbehrlich wären und stillgelegt werden könnten, so müßte das finanzielle Ergebnis schon deshalb gering bleiben, weil es sich dabei nur um eine verhältnismäßig kleine Zahl handeln könnte. Eine wesentliche Begünstigung der Rentabilität kann daher von der Betriebszusammenlegung, soweit sie durchführbar ist, nicht erwartet werden.

Die Behauptung, daß viel mehr Kaliwerke gebaut worden sind, als zur Deckung des Bedarfs notwendig sind, ist indessen nicht $\mathrm{zu}$ jeder Zeit unrichtig gewesen. Sie war zutreffend für die Verhältnisse vor dem Kriege. Erst die durch diesen geschaffenen Zustände, d. h. die Zusammenschiebung des Bedarfs des Auslandes von mehreren Jahren auf verhältnismäßig kurze Zeiträume und der sicher zu erwartende höhere Verbrauch erfordern auch 
mehr Produktionsstätten. Aber sie war auch vor dem Kriege nur eine relative Wahrheit. Für ihre Richtigkeit war Voraussetzung, daß eine Anzahl Kaliwerke streng planmäßig mit höherer Leistungsfähigkeit sowohl bei der Förderung als bei der fabrikmäßigen Herstellung der Kalisalze gebaut worden wären. Dies ist jedoch, wie bekannt, keineswegs geschehen. Wenn von vielen Seiten immer darauf hingewiesen wird, da $\beta$ die Kaliwerke Aschersleben und Sollstedt bei Abwicklung der sogenannten Schmidtmann-Verträge mit den amerikanischen Düngertrusts imstande gewesen wären, außerordentlich hohe Leistungsziffern zu erreichen, so ist dazu zu sagen, daß diese Lieferungen wohl nicht sehr viel länger als geschehen, hätten fortgesetzt werden können. Hierzu hätten weder die Förder- noch Fabrikanlagen ausgereicht.

\section{Die Wassergefahr.}

Bei den Erörterungen über die Rentabilität eines Staatsmonopols hat bisher ein wichtiger Punkt nicht genügende Beachtung erfahren: Die Wassergefahr. Die finanziellen Ergebnisse des Kalibergbaus sind wesentlich beeinflußt von der wirksamen Bekämpfung der schädlichen Einwirkungen des Wassers. In der Regel bringt ein Wassereinbruch größerer Art das Werk zum Ersaufen und zum Stilliegen. Die anteilsmäßige Quote kommt damit in Fortfall. Es dauert sehr oft lange Jahre, bis ein neuer Schacht wieder in Betrieb gesetzt werden kann. Große Kapitalwerte gehen dabei verloren. Auch die Kapitalgewinne fallen für längere Zeit oder überhaupt aus; es sei denn, da $B$ das betreffende Werk aus anderen Schächten zu fördern in der Lage ist. Ferner kommt hin$\mathrm{zu}, \mathrm{da}$ das Ersaufen eines Bergwerks gewöhnlich starke Veränderungen auf der Erdoberfläche hervorruft, die bedeutende Aufwendungen für Bergschäden notwendig machen. So hat der anhaltisch-preußische Fiskus für die infolge der Wassereinbrüche bei den staatlichen Kali- 
werken entstandenen Schäden bis heute etwa 10 Millionen Mark Entschädigung gezahlt.

In welchem ungefähren Umfange die Kaliindustrie unter der Wassergefahr leidet, mag zunächst eine kurze Zusammenstellung der bisher ersoffenen Kalischächte zeigen.

Schwere Kämpfe mit der Wassergefahr hatten die Anlagen der Kaliwerke Aschersleben durchzumachen. Der Schacht I, welcher in den Jahren 1878 bis 1882 abgeteuft wurde, und aus dem dann vier Jahre lang gefördert worden ist, ging mit dem zugehörigen Baufeld infolge Ersaufens im Januar 1886 verloren. Schacht II mußte nach einer Abteufperiode von zwei Jahren nach Erreichung einer Teufe von $270 \mathrm{~m}$ wegen zu großer Wasserzuflüsse aufgegeben werden. Schacht III, welcher in den Jahren 1886 bis 1887 abgeteuft wurde und bis 1895 in Förderung stand, ging mit seinem zugehörigen Baufeld im September 1895 infolge Wassereinbrucis verloren.

Ein gleiches Schicksal ereilte Schacht I der Gewerkschaft Asse, welcher in den Jahren 1900 bis 1906 ersoffen ist.

Der Schacht Hermann des Kalibergwerks Benthe ersoff nach zweijähriger Abteufperiode im Salz bei einer Teufe von $238 \mathrm{~m}$.

Das gleiche Schicksal ereilte den Schacht II der Gewerkschaft Beienrode, welcher infolge von Wassereinbruch bei 301 Metern Teufe dicht über dem Steinsalz ersoff.

Bekannt sind die außerordentlichen Wasserschwierigkeiten, mit welchen das Königliche Salzbergwerk zu Staßfurt zu kämpfen hatte. Die Kalibergwerke von der Heydt, Achenbach und Manteuffel gingen durch einen Wassereinbruch im Jahre 1900 endgültig verloren. Der Schacht von der Heydt hatte von 1856 bis 1860 der Steinsalzförderung gedient. Seine Förderung mußte am 30. Juni 1893 wegen Wassereinbruchs im Abbau eingestellt werden. Er diente dann bis zum endgültigen Verlust als Wetterschacht. Der erwähnte Wassereinbruch am 30. Juni 1893 erstreckte sich auch auf den Schacht Mannteufel, dessen Förderung gleichfalls damit zum Erliegen kam. Aus dem Achenbachschacht wurde bis 1900 gefördert, am 11. Juni 1900 mußte der Schacht wegen Ersaufens aufgegeben werden. Gleichzeitig ging ein Hilfsschacht beim Manteuffel verloren.

Aehnliche Erfahrungen wurden in Leopoldshall gemacht. Der in den Jahren $1858 / 1859$ abgeteufte Schacht I, welcher bis 
1900 in Förderung stand, ging gleichzeitig mit dem Schacht II verloren. Am 10. April 1900 ist das Abbaufeld beider Schächte ersoffen.

Ebenso mußten die Schächte Agatha und Hammacher des Salzbergwerks Neu-Staßfurt wegen Wassergefahr des Baufeldes aufgegeben werden. Der Schacht Agatha wurde in den Jahren 1873 bis 1875 niedergebracht und stand von 1876 bis 1911 in Förderung. Der in den Jahren 1881 bis 1883 abgeteufte Schacht Hammacher förderte bis 1911, wo gleichfalls Wassergefahr für das Baufeld eintrat.

Interesse verdient auch der Wassereinbruch im Schachte der Gewerkschaft Wilhelmshall-Oelsburg, welcher in der Tiefe von $520 \mathrm{~m}$ erfolgte.

Der Aktien-Gesellschaft Westeregeln gingen zwei Schächte verloren. Der 1871 bis 1872 abgeteufte Schacht I stand bis 1891 in Förderung. Am 28. Oktober 1891 ersoff das Baufeld zugleich mit Schacht II.

Das Schicksal des Kalibergwerks Jessenitz in Mecklenburg, welches dieses im Juni 1912 ereilte, hat die allgemeine Aufmerksamkeit auf die Wassergefahr, welche dem Kalibergbau droht, gelenkt. In wenigen Stunden wurden hier Werte von etwa 4 Millionen Mark vollständig zerstört, nachdem schon vorhergegangene kleinere Laugeneinbrüche auf das kommende Unglück hingedeutet hatten.

Inzwischen ist auch der Schacht der Gewerkschaft Friedrich $\mathrm{Franz}$ in Lübtheen, welcher etwa $2 \mathrm{~km}$ von dem früheren Bergwerk Jessenitz entfernt liegt, im Dezember 1916 von einem Wassereinbruch heimgesucht worden, welcher zur Einstellung des Betriebes zwang. In neuerer Zeit gingen Nachrichten durch die Zeitungen über bedrohliche Wassereinbrüche bei den Kaliwerken Neubleicherode. Indessen ist es bisher gelungen, den Betrieb fortzuführen.

Eigentümlich ist den Wassereinbrüchen ihre katastrophale Natur. Sämtliche davon betroffenen Werke haben die größten Anstrengungen gemacht und kein Mittel gescheut, der Wassergefahr Herr zu werden. In einem jahrelangen Kampfe ist schließlich das Wasser Sieger geblieben Die Gewerkschaft Neu-Staßfurt hat versucht, das Wasser durch Errichtung einer undurchlässigen Mauer, die über eine Million Mark gekostet hat, abzuschließen. 
Der Versuch ist mißlungen. Auch die erheblichen Aufwendungen, die Jessenitz und der anhaltische Fiskus zur Bekämpfung der Wassergefahr gemacht haben, sind ergebnislos geblieben. Das $\mathrm{MiBliche}$ der Sachlage besteht insbesonderedarin, da B der Wassereinbruch bei einem Werk a uch die in der Nachbarschaft liegenden stark gefährdet. Der Wassereinbruch bei Jessenitz hatte das Ersaufen des Schachtes der Gewerkschaft Friedrich Franz zur Folge. Die Wassereinbrüche bei den Schächten I und II der herzoglich anhaltischen Salzwerke führten den Verlust eines ganzen Werkkomplexes, die alle in unmittelbarer Nachbarschaft lagen, herbei. Hierzu-gehörten die preußischen Schächte von der Heydt, Manteuffel, Achenbach. Die Schächte der Gewerkschaft Neu-Staßfurt, Agatha und Hammacher und die beiden schon erwähnten anhaltischen Schächte. In dieserErschein ungliegt einegroße Gefahr für die ganze Kaliindustrie. Bei der Einschätzung der Wassergefahr wird man nicht außer acht lassen dürfen, daß die ersoffenen Schächte prozentual einen erheblichen Teil der alten Werke ausmachen. Bei der starken Vermehrung der Werksanlagen auf über 200 wird man in Zukunft mit weit höheren absoluten Verlusten rechnen müssen, denn die Gefahr an sich vergrößert sich entsprechend der Anzahl der Betriebe.

Ein Ausgleich könnte dadurch herbeigeführt werden, daß man in der Bekämpfung der Wassergefahr größere Fortschritte gemacht haben könnte. $\mathrm{Ob}$ dieses zutrifft, hängt wesentlich davon $\mathrm{ab}$, in welchem Maße man imstande ist, die Ursache der Wassereinbrüche zu beseitigen. Einige Wassereinbrüche haben, wie es scheint, ihren Grund darin, daß der Abbau in zu geringer Tiefe aufgenommen worden ist $\left.{ }^{1}\right)$. Nach der oben angeführten Quelle trifft dies bei den Wassereinbrüchen bei dem Kaliwerk Aschersleben zu. Andere Wassereinbrüche sind zurückzuführen auf Gebirgsbrüche, die Süßwasserzuflüsse herbeiführten. Ob

1) Vergl. Kali, Heft 6, Seite 89 , v. 15. 3. 18. 
die Gebirgsbrüche durch ungenügende Unterstützung des Hangenden verursacht sind, steht nicht zweifelsfrei fest. Man wird nicht fehl gehen in der Annahme, die Wassereinbrüche in der Hauptsache auf das Anschlagen von wasserführenden Gebirgsklüften, die in irgendeiner Verbindung mit Süßwassermengen stehen, zurückzuführen. Diese Grundursache ist nicht zu beseitigen, woraus sich auch ergibt, daB die Wassergefahr stets in dem Kalibergbau bestehen bleiben wird. Wenn man auch in der Bekämpfung der Zuflüsse im Laufe der Zeit Fortschritte gemacht hat, so wird man trotzdem hiervon nicht zuviel erwarten dürfen. In der Regel bleibt den Werken, die von Wassereinbrüchen betroffen sind, nichts anderes übrig, als Hebungsanlagen in Betrieb zu setzen. Meistens wird dadurch erreicht, daß der Betrieb noch eine Zeitlang fortgeführt werden kann, dann aber infolge der meistens größer werdenden Kosten der Wasserhebungen, die keinerlei Rentabilität mehr zulassen, eingestellt werden muß. Infolge der tatsächlichen Verhältnisse sind auch die Ansichten Sachverständiger in bezug auf die Wassergefahr ziemlich pessimistisch.

Die Wasserschwierigkeiten sind im Kalibergbau we it häufiger, als in der Oeffentlichkeit bekannt wird. Ein großer Teil der Schächte hat schon beim Abteufen mit bedeutenden Schwierigkeiten zu kämpfen. Viele Anlagen mußten aus diesem Grunde aufgegeben werden. Zwar treten Wasserschwierigkeiten beim Abteufen auch bei andèren Bergbaugebieten auf. Indessen liegen die Verhältnisse im Kalibergbau in dieser Hinsicht ebenfalls ungünstiger. Zahlreich sind außerdem die Fälle, in denen beim Abbau der Salze die sogenannten Laugensäcke, das sind Laugenansammlungen in Hohlräumen, welche mit Süßwasser keinerlei Verbindung haben, angefahren werden. Nach Wegschaffung dieser Laugenmengen ist in der Regel die Gefahr beseitigt. Es kommt indessen auch sehr häufig vor, $d a ß$ die in den Schächten auftretenden Laugen eine' zunehmende Verdünnung aufweisen, wobei 
zu vermuten ist, daß dieselben durch Auflösung von Salzen, durch aus oberen Schichten zutretendes Wasser gebildet werden. Dieses ist der gefährlichste Fall. Es gelingt auch hier den Werken sehr häufig einen Wasserabschluß herbeizuführen, der indessen, wie die Erfahrung lehrt, oft nur dem Anschein nach gelungen ist. Nach kürzerer oder längerer Zeit tritt die Gefahr von neuem auf. So mag es mehreremal durch geeignete Verdämmungsarbeiten gelungen sein, den Verheerungen des Wassers Einhalt zu tun. Dagegen ist es trügerisch, mit einer dauernden Sicherung des Bergwerks zu rechnen. Auf diese Weise gibt es zahlreiche Werke, die dauernd von Wassereinbrüchen bedroht sind, ohne daß die Oeffentlichkeit darüber unterrichtet ist und ohne daß dieser ungünstige Umstand in der Bewertung der Bergwerksanteile zum Ausdruck kommt.

Die durch die Wassereinbrüche vernichteten Kapitalien lassen sich nur ungefähr feststellen. Die Verluste betragen beispielsweise bei

Friedrich Franz 7,2 Millionen ${ }^{1}$,

Aschersleben 5,2 Millionen,

Jessenitz 4 Millionen.

Man wird nicht fehl gehen, wenn man den durch Ersaufen von fertigen Kalischächten entstandenen Kapitalverlust auf etwa 40 Millionen veranschlagt. Hierbei sind die Verluste der Bodenschätze mangels einer annähernd richtigen Bewertung nicht miteinbegriffen. $\mathrm{Da}$ diese ebenfalls bedeutend sind, braucht kaum erwähnt zu werden. So mußten bei dem Wassereinbruch bei den Leopoldshaller und Staßfurter Werken wertvolle Karnallitsalze auf den unteren Sohlen aufgegeben werden. Bei der Gewerkschaft Asse gingen 2 Millionen dz förderfähiger Kalisalze beim Abbau verloren. Die Gewerkschaft Neu-Staßfurt mußte den größten Teil der aufgeschlossenen hochwertigen Hartsalze verlorengeben. Es ist inzwischen nicht gelungen, in den neugebauten Schächten diese Salzarten wieder auf-

1) Geschäftsbericht 1916. 
zufinden. Rechnet man, wie schon erwähnt, hinzu, daß der Eigentümer eines ersoffenen Bergwerks schaden. ersatzpflichtig für entstandene Bergschäden ist, soergibtsich, da B die Wassergefahr das durch den Staat bei Einrichtung eines Statsmonopols einzugehende Risiko bedeutend vergrößert. Um dieses Risiko auszugleichen, würden erhebliche Rückstellungen notwendig sein, die das Monopolerträgnis in entsprechendem Maße beeinträchtigen. 
II.

\section{Die Nachteile des Staatsbetriebs.}

\section{Bedenken allgemeiner Natur.}

Wie die bisherige Darlegung zeigt, ist die erste und wichtigste Voraussetzung für die Einführung eines Staatsmonopols, die dauernde und gesicherte Rentabilität, nicht gegeben. Es bliebe nunmehr noch zu untersuchen, welche Wirkungen die Verstaatlichung, ganz unabhängig von dieser Frage auf. die Gesamtwirtschaft, hervorbringen müßte. Bei dieser Untersuchung dürfte auszugehen sein von der Natur des staatlichen Wirtschaftsbetriebes und seinen Wirkungen in allgemeiner Hinsicht auf die nationale Wirtschaft. Im Anschluß hieran wird zu zeigen sein, welchen Einfluß die Verstaatlichung auf die Entwicklung der Kaliindustrie im besonderen haben würde.

Ueber die Fähigkeit des Staates, wirtschaftliche Unternehmungen zu betreiben, sind die Meinungen nie gleich gewesen. Es hat Zeiten gegeben, wo man alles Gute nur vom Staate erwartete, wo das ganze Wirtschaftsleben mehr oder weniger staatlich geregelt war oder teilweise staatlichen Charakter trug. Diese Zeit ist wieder abgelöst worden von einer anderen, wo man jede mittelbare und unmittelbare staatliche Einmischung ins Wirtschaftsleben unbedingt verwarf. Die Blüte der Wirtschaft wurde vom freien Spiel der Kräfte, von der ungehemmten Entwicklung aller wirtschaftlichen Energie erwartet. Das "laisser faire laisser aller" war ihr Schlag- 
wort. Bis in die neueste Zeit hat die Anschauung geherrscht, daß der Staat nicht geeignet sei - von Ausnahmen abgesehen - wirtschaftliche Unternehmungen selbst zu betreiben. Neuerdings bereitet sich hierin wieder eine Umwandlung vor. Immer mehr werden staatliche Eingriffe in den Gang des Wirtschaftslebens verlangt. Der Staat soll nicht allein die Auswüchse des Wirtschaftslebens verhindern und bekämpfen, sondern er soll auch selbst in weitem Maße als Erzeuger, Händler und Organisator auftreten. Dies soll geschehen sowohl aus rein fiskalischen Gründen als auch zur Wahrung der Interessen der Allgemeinheit und zur besseren Ordnung wirtschaftlicher Vorgänge, das heißt zur Erzielung eines größeren wirtschaftlichen Effektes. Seit etwa einem Jahrzehnt haben die Sozialisten sich in der Hauptsache ebenfalls zu diesen Forderungen bekannt. Wie schon früher gesagt, ist für sie dabei hauptsächlich bestimmend, daß sie glauben, die Verstaatlichung der Industrien und auch des Handels führe schneller die Vergesellschaftung des Kapitals herbei, fördere also ihre parteipolitischen Ziele. So wünschen sie die Uebernahme großer Industriekartelle durch den Staat, Verstaatlichung der wichtigsten Industrien, Schaffung verschiedener Monopole (Getreide, Petroleum usw.). Um ihre gegen früher veränderte Stellungnahme zu erklären oder, wenn man will, zu rechtfertigen, sagen sie, daß sich in neuerer Zeit die Industrien zu Privatmonopolen einzelner herausgebildet hätten. Und wenn nun einmal doch ein Monopol vorhanden sei, so sei es besser, daß es unter öffentlicher Kontrolle stehe und im Allgemeininteresse ausgebeutet werde, was nur der Staat machen könne. Das Prinzip ist also aufgegeben. Opportunismus ist an seine Stelle getreten.

Wenn es auch nicht richtig ist, im wirtschaftlichen Leben sich an Grundsätze zu klammern, so ist doch bei Beurteilung der Verstaatlichungsbestrebungen zu bedenken, da $\beta$ beim Umsetzen einer wirtschaftlichen Anschauung in die Praxis naturgemäß stets über das Ziel hinausgeschossen wird. In der Freihandelsperiode ist vieles ver- 
schwunden, was besser erhalten geblieben wäre. In konservativen Zeitläuften sind Einrichtungen beibehalten worden, die sich überlebt hatten und den neuen Bedingungen und Verhältnissen nicht mehr entsprachen. Man braucht nur an die Zünfte zu denken. So sollte manden jetzt stark und allgemein a uftretenden Verstaatlichungsbestrebungengegenüberunserglänzend bewährtes Wirtschaftssystem, wodurch wir groß und stark geworden sind, nicht a ufgeben. Bei den starken sozialistischen Tendenzen, die im Reichstag zur Geltung kommen, und bei der noch mangelnden Erkenntnis der Wirkungen weitgehender Verstaatlichungen liegt die Gefahr inahe, daß Monopole usw. eingeführt werden, die unsere wirtschaftliche Entwicklung schädigen.

Man könnte hier entgegnen, daß die Anschauungen über die wirtschaftliche Betätigung des Staates sich von Zeit zu Zeit ändern und ändern müßten, weil auch der Staat als Subjekt und die Wirtschaft als Objekt sich ebenfalls ändern. Ersteres kann zwar nur mit starker Einschränkung in seltenen Fällen zutreffen - denn das Wesen des Staates bleibt trotz aller Veränderungen bestehen aber der Gedanke enthält eine kleine Wahrheit. Es gibt Wirtschaftszweige, die infolge der Entwicklung, die sie genommen haben, oder der Bedeutung, die sie für die Allgemeinheit besitzen, die Verstaatlichung rechtfertigen, z. B. Post, Telegraph, Bahn. Es wird deshalb schließlich stets eine Tatfrage sein, ob eine Industrie oder ein anderer Erwerbszweig sich überhaupt für den Staatsbetrieb eignet. Trotzdem wird es immer Gründe allgemeiner Natur geben, die gegen den Staat als praktischen Unternehmer sprechen. In den Fällen, wo man trotz dieser Bedenken den Staatsbetrieb für richtig hält, erklärt es sich daraus, daß die Vorteile des einheitlichen staatlichen Betriebes die durch ihn herbeigeführten Nachteile überwiegen. Hierbei ist auch zu beachten, daß eine Eigentümlichkeit des Staates für den einen wirtschaftlichen Betrieb von Nutzen, für den añderen aber schädlich sein kann. Der Bureaukratis- 
mus ist beim Handel zweifellos ein Nachteil, für den Bahn-, Post- und Telegraphenverkehr ist er eher ein Vorteil, vielleicht gar nicht $\mathrm{zu}$ entbehren. Hieraus folgt indessennicht, daß nur der Staat einen Betrieb der letztgenannten Art führen könne, weil dieser bureaukratisch aufgebaut sei; denn die private Unternehmung kann, wo es erforderlich ist, auch bureaukratische Formen entwickeln. Bestenfalls wird man sagen können, der Staat sei in der Lage, diesen und jenen Betrieb ohne Schädigung der allgemeinen Wirtschaftsinteressen zu übernehmen. Die Verstaatlichungen werden wohl immer auf Ausnahmen beschränkt bleiben müssen.

Die Bedenken, die gegen den Staatsbetrieb sprechen, beruhen hauptsächlich darauf, $d a B$ der staatliche Organismus seinem Wesen nach nicht geeignet ist, wirtschaftliche Unternehmungen $\mathrm{z} u$ betreiben. Daraus ist auch erkennbar, da $\beta$ die dem Steatsbetrieb immanenten Nachteile schwer zu beseitigen sind, weil dies die innere Umwandlung des Staates voraussetzen würde. Organisationsänderungen mehr äußerlicher Natur könnten hier kaum helfen. Es würde langer Zeiträume bedürfen, um die Umgestaltung des Staates von innen heraus so durchzuführen, $d a ß$ er Erzeugung und Handel in weiterem Umfange übernehmen könnte. Hiervon kann noch lange keine Rede sein.

Das Wesen des Staates wird man am besten als intellektuellen Bureaukratismụs bezeichnen können. Das staatliche Leben vollzieht sich in festen starren Formen. Die Art zu handeln, ist schwerfällig und zeitraubend. Die vielen Vorschriften, der Instanzenweg, die budgetmäßige Erledigung finanzieller Vorgänge, der unbewegliche Apparat schränken die Bewegungsfreiheit ein. Das wirtschaftliche Leben aber verlangt rasche Entschlüsse, Initiative, Freiheit der Form und des Handelns, alles Dinge, die sich mit dem Bureaukratismus nicht vereinigen lassen und zu ihm im Gegensatz stehen. Dem Staat ist es aus diesen Gründen nicht möglich, sich den oft schnell wechselnden wirtschaftlichen Verhältnissen und Lagen anzu- 
passen und sie auszunutzen. Außerdem muß er in hohem $\mathrm{MaBe}$ auf die öffentliche Kritik, auf Parlament und Presse Rücksicht nehmen. Es dürfte nicht zu bestreiten sein, $\mathrm{da} \beta$ ein Organismus, der diesen vielen Beschränkungen unterliegt und wegen seines öffentlichen Charakters unterliegen muß, nicht soviel leisten kann als der dieser Fesseln und Rücksichten ledige Privatbetrieb.

Es kommt ferner hinzu, daß dem Staat beziehungsweise seinen Organen der Erwerbssinn fehlt. 'Dieser ist es, welcher der wirtschaftlichen Betätigung Leben verleiht. Ungemessene latente Energien bringt er zur Auslösung. In ihm verkörpert sich eine Kraft, die das ganze Wirtschaftsleben im Gange hält. Ohne schwere Schädigung kann dieser Trieb nicht ausgeschaltet werden. Fiskalische Bestrebungen können ihn nicht ersetzen. Auf ihn führen zurück der Wagemut, die Unternehmungslust, die Arbeitsfreudigkeit unserer wirtschaftlich tätigen Kräfte. Weil dem Staatsbetrieb der Geist und die äußeren und inneren Bedingungen des Privatbetriebes fehlen, so ist er auch nicht imstande, das Persönliche des privaten Unternehmers zu ersetzen. Die Bedeutung der Einzelpersönlichkeit für ein Unternehmen und oft für eine Industrie ist bekannt. Fast jedes Werk führt auf einen tatkräftigen Unternehmer zurück. Ihm verdankt es sein Entstehen und Aufblühen. In ihm verkörpert sich der Unternehmungsgeist, er geht bereitwillig die mit dem Betriebe des Unternehmers verbundenen Risiken ein. Die Gefahr, Verluste zu erleiden, wirkt erziehend und aneifernd und zwingt zu scharfer Prüfung und Erforschung aller wirtschaftlichen Vorgänge und Möglichkeiten. Sein Geist hat in der Regel dem ganzen Unternehmen seinen Stempel aufgedrückt, ihm sein Wesen gegeben. Die Person des Unternehmers ist aufs engste mit dem Betrieb, den Arbeitern und Angestellten verwachsen. In dem organisch entstandenen Werk werden potenzierte Leistungen erreicht. Diese Beobachtungen treffen mit geringen Einschränkungen auch auf die Leiter der Aktiengesellschaften usw. zu. - Was hat der Staat 
diesen Vorteilen gegenüberzustellen? Der Erwerbssinn kann beim staatlichen Beamten nicht durch die Aussicht auf $\mathrm{Be}$ förderung ersetzt werden. Alle kaufmännischen Handlungen werden für fremde Rechnung vorgenommen. Gewinne kommen den betr. Beamten nicht zugute. Verfehlte kaufmännische Dispositionen schädigen lediglich den Fiskus, entbehren daher des erzieherischen Einflusses auf ihre Urheber. Es fehlt durchaus der Zwang zur Wirtschaftlichkeit. Besonders ist dies der Fall bei Monopolen, wo der Staat konkurrenzlos die Preise diktieren kann. Die Tatkraft des einzelnen erleidet im starken Maße Einbuße. Mit dem Individualismus wird die Hauptkraft der Erzeugung ausgeschaltet. Der Staatsbetrieb ist außerdem ungeeignet, solche Industriekapitäne und hervorragende Handelsleute auszubilden und heranzuziehen, wie sie im Privatbetriebe vorhanden sind. Der objektive Geist des Beamtentums ist hierzu nicht geeignet. Hier herrschen andere Anschauungen und Auffassungen, die der Entwicklung in dieser Richtung nicht günstig sind. Der Beamte wird in der Regel nur in einer Verwaltung beschäftigt. Er hat keine Gelegenheit, wie der junge Kaufmann oder Ingenieur, in vielen Betrieben zu arbeiten, sich mit Erfahrungen auf verschiedenen Gebieten und Erwerbszweigen zu bereichern. Die Auslese der Tüchtigen ist im Privatleben viel eher, wenn nicht allein möglich. Für das Vorwärtskommen in der Beamtenlaufbahn sind in der Regel noch andere Momente außer der Tüchtigkeit maßgebend. Beziehungen aller Art spielen eine Rolle. Vielen ist von vornherein der Eintritt in die Beamtenlaufbahn von gewissen Verwaltungszweigen unmöglich, weil ihre Abstammung, ihr Vermögen usw. als nicht entsprechend angesehen werden. Alle diese Hindernisse fallen in Privatbetrieben fort. Jedem steht es frei, sich wirtschaftlich zu betätigen, wo es ihm beliebt und er seine Kräfte und Fähigkeiten aufs beste ausnutzen und verwerten kann.

$\mathrm{Da}$ die Nachteile des Staatsbetriebes in seinem Wesen liegen, so braucht keineswegs die Beamten irgendein Vor- 
wurf zu treffen. Der Staat wird auch meistens in der Lage sein, dem öffentlichen Urteil und der parlamentarischen Kontrolle gegenüber, von denen sich die Befürworter der staatlichen Betätigung auf wirtschaftlichem Gebiet so viel versprechen, nachzuweisen, daß die Beamtenschaft ihre Pflicht erfüllt habe; aber Pflichterfüllung ist im wirtschaftlichen Leben noch keine Leistung. Hierauf ist es hauptsächlich zurückzuführen, daß der wirtschaftliche Erfolg beim Staatsbetrieb nie im richtigen Verhältnis zum Aufwand steht, sondern stets zu klein bleibt.

Es wird nun oft der Vorschlag gemacht, daß der Staat im privaten Erwerbsleben vorgebildete Personen in seinen Dienst stellen solle. In dieser Beziehung hat der Krieg wertvolle Erfahrungen gezeitigt. In den Kriegsgesellschaften und den im wesentlichen kaufmännisch gestalteten Militärbetrieben sind zahlreiche Kaufleute tätig gewesen. Sie sahen sich plötzlich einem Wust von Vorschriften und Bestimmungen gegenüber, die ihnen jede Bewegungsfreiheit raubten. Sie wurden naturgemäß häufig selbst gehorsame Diener des Organismus, lebten sich in das System so ein, daß sie bald zu Bureaukraten wurden., Wo sie dem sie umgebenden Einfluß nicht unterlagen, war es ihnen nicht möglich, ihr Können zur Geltung zu bringen, ihre Kräfte zu entfalten. Sehr deutlich zeigte sich auch die Erscheinung, daß nun, wo nicht mehr für eigene Interessen gearbeitet wurde, der Eifer, die Energie, die Arbeitsfreudigkeit usw. nachließen, die im eigenen Betrieb die Rege! gewesen waren. Es ist kaum anzunehmen, daß der Staat, wenn er wirklich zum System der freien Privatverträge oder zur vermehrten Einstellung von Privatbeamten in den Staatsdienst schritte, andere Erfahrungen machen würde. Es kommt hinzu, daß er tüchtigen Kräften eine entsprechend hohe Bezahlung geben müßte, was auch nicht ohne weiteres möglich sein würde.

Folgen des Staatsbetriebes sind ferner eine starke Mechanisierung und Zentralisierung der Wirtschaft mit all ihren Nachteilen. Auf der Verschiedenartigkeit unserer Produktionsverhältnisse und unserer Erzeugnisse beruhte 
nicht zuletzt der Aufschwung unseres Wirtschaftslebens.. Auch die örtliche Verteilung der Erzeugung auf die einzelnen Gebiete des Reiches hatte bedeutende Vorteile, auf die beim Staatsbetrieb zum großen Teil verzichtet werden muß.

Aus dem Wesen und der Natur des Staatsbetriebes folgt weiter, daß man von ihm keine technischen Fortschritte wird erwarten dürfen. Auf dem Gebiet der Industrie und Handelsorganisation werden staatlicherseits. keine besonderen Leistungen, die eine bessere Gütererzeugung und -verteilung gewährleisten, hervorgebracht werden. Die Folge von Verstaatlichungen wird in der Regel technischer Stillstand sein. In der Einschätzung dieser Wirkung ist man ziemlich einig. Immer und überall ist es die Privatindustrie gewesen, die Erfindungen gemacht hat oder, besser gesagt, unter hohen Kosten und vielen Anstrengungen ausprobiert und entwickelt hat. Dagegen ist immer wieder festzustellen, daß dem Staat Neuerungen und technische Vervollkommnungen sozuságen stets aufgedrängt werden müssen. Diese Tatsache dürfte kaum bestritten werden. Sogar von sozialistischer Seite liegt ein verkapptes Eingeständnis vor, daß die technische Entwicklung nur von privater Seite möglich sei $^{1}$ ). Der Verfasser macht für die Verstaatlichung einer Industrie die Voraussetzung, da $\beta$ sie technisch und organisatorisch. dazu reif sei, das heißt doch, daß sie technisch voll entwickelt seir müsse, weil der Staat dazu nicht imstande sei. Dabei ist der technische Fortschritt bei einer Industrie von einem bestimmten Grade an doch nicht entbehrlich! Wenn an anderer Stelle ${ }^{2}$ ) gesagt wird, daß die Gefahr der technischen Stagnation beim Staatsmonopol wohl deshalb fortfalle, weil es unter öffentlicher Kritik und Kontrolle stehe, so liegt hierin eine unbewiesene Behauptung. Oeffentlichkeit und Parlament haben noch keine technischen Erfindungen gemacht. Von der Kritik bis zur positiven Leistung ist ein weiter Weg.

Die in vorstehenden Ausführungen besprochenen Nach-

1) Monopole und Arbeiterschaft S. 242.

$\left.{ }^{2}\right)$ a. a. O, S. 232. 
teile des Staatsbetriebes müssen eine allgemeine Wirkung auf das Wirtschaftsleben eines Landes ausüben, wenn die Verstaatlichungsmaßnahmen auf weite Gebiete unserer produktiven Arbeit, auf Industrie und Handel übergreifen. In diesem Falle würden sich noch andere Nachteile und Schädigungen für die Gesamtwirtschaft ergeben. An erster Stelle wäre als Folge der Verstaatlichung die Lahmlegung des Unternehmungsgeistes des Kapitals zu erwähnen. Der Kapitalist wird aus einem Unternehmer zum Rentner werden. Dieser Vorgang bešchränkt sich nicht nur auf den Umfang, wie die Aktien und Kuxe usw. in festverzinsliche Staatspapiere umgewandelt werden, sondern es wird allmählich dér R e n t nergeist großgezogen werden. Dieser Zustand ist in Frankreich bereits eingetreten. Daß die Unternehmungsfreudigkeit des Kapitals einen großen Anteil an dem Aufblühen unserer Wirtschaft gehabt hat und in Zukunft haben wird, kann wohl kaum bestritten werden. Der hierin liegende Impuls für die Weiterentwicklung unserer wirtschaftlichen Kräfte und für den Ausbau unserer Weltstellung ginge damit verloren. Die französischen Verhältnisse sind nicht wünschenswert. Sie führen den ökonomischen Stillstand und Rückschritt herbei. Wie mit dem Kapital wird es auch mit dem Kaufmannsstand gehen.

Man wird ferner darauf hinweisen müssen, daß dem Staatsbetrieb, wenn er die Form eines Monopols hat, das Bestreben innewohnt, den Handel in weitem Maße auszuschalten. Diese Beobachtung hat man besonders deutlich während des Krieges machen können. Schritt für Schritt wurde der Handel bei den Kriegsgesellschaften auf den ihm eigenen Gebieten zurückgedrängt und ausgeschaltet. Die Nachteile, die sich hieraus für die Kriegsorganisation selbst und für die Allgemeinheit ergaben, sind zu bekannt, als $\mathrm{da} B$ sie weiter erörtert $\mathrm{zu}$ werden brauchten. Der Handel ist für den geregelten Gang des Wirtschaftslebens nicht zu entbehren. In dem Maße, wie der Kaufmann, der Pionier deutschen Geistes und deutscher Arbeit, zum Beamten herabgedrückt werden würde, wird auch der 
Wagemut, der frische Unternehmungsgeist, die die gewaltigen Erfolge auf dem Weltmarkt erzielt haben, dahinschwinden. Die werktätige Generation wird von einer solchen abjgelöst werden, deren Ziel die Rente und Bequemlichkeit sein wird. Dadurch kann unser Volk nicht groß werden. Die Folge wird eine Erstarrung des Wirtschaftslebens sein. Die wirtschaftlich tätigen Kräfte würden außer Wirkung treten.

Die Verhältnisse des Statsbetriebes wirken bei den einzelnen Unternehmungen in der Richtung einer Verminderung ihrer Rentabilität. Im Falle, da B der Staatsbetrieb auf weite Gebiete des Wirtschaftslebens übergreift, mu $B$ allgemein in der nationalen Wirtschaft mit einer Verringerung der Schaffung wirtschaftlicher Werte gerech net werden. In der Schaffung von Werten aber liegt das erste und höchste Ziel der nationalen Wirtschaft. Der Krieg hat mit Deutlichkeit gezeigt, daß die richtige Verteilung, mag sie noch so streng und bis aufs äußerste durchgeführt sein, wertlos ist, wenn die Gütererzeugung nicht auf angenuessener Höhe gehalten wird. Man wird um so eher dem Staat die Fähigkeit, Werte in höherem Maße als die Privatindustrie zu schaffen, absprechen müssen, als er während des Krieges nicht einmal imstande war, distributäre Aufgaben richtig durchzuführen. Es kann keine Rede davon sein, daß staatlicherseits die Lebensmittel-, Kriegsbedarf- und Rohstoffversorgung richtig durchgeführt worden ist. Diese Feststellung bezieht sich natürlich nur auf die rein kaufmännische Lösung der Aufgabe. Nur dadurch, daß bei der Verausgabung der Milliarden kein richtiger kaufmännischer Sinn gewaltet hat, ist es den Industrien und dem Handel möglich gewesen, die gewaltigen Kriegsgewinne zu machen. Die Ungewandtheit des Staates, kaufmännische Geschäfte abzuwickeln, die mangelnde Erfahrung und das Nichtvorhandensein eines auf diesem Gebiet durchaus bewanderten Beamtentums haben Fälle wie Philippi und andere 
herbeigeführt. Wie es unter diesen Umständen Kreise geben kann, die in der Wirtschaftsführung des Staates während der Kriegszeit die glückliche Lösung von Aufgaben sehen können, auf Grund deren man für eine weitere Betätigung des Staates auf diesem Gebiet eintreten könne, ist schlechthin unverständlich. Wenn überhaupt ein unwiderlegter und schlüssiger Beweis geführt werden könnte, daß der Staat sich für eine derartige Tätigkeit nicht eignet, so ist dieser durch die Kriegserfahrungen geliefert worden ${ }^{1}$ ). Wie ein Unkraut haben nach und nach die Kriegsgesellschaften und andere Organisationen das freie Wirtschaftsleben überwuchert ${ }^{2}$ ). Es ist dabei typisch die stetig wachsende Vermehrung dieser Stellen. In der Regel hat eine Gesellschaft oder Dienststelle eine ganze Reihe anderer geboren. Diese ungesunde Vermehrung und Neueinrichtung von Stellen zu allen möglichen Zwecken ist auch besonders dem Militärbetrieb eigen. Es ist anzuerkennen, daß das Kriegsministerium durch verschiedene Erlasse diesem Streben Einhalt zu gebieten versuchte. $\mathrm{Ob}$ mit Erfolg, ist nicht bekannt. Es dürfte vielleicht interessant sein, einige der Ursachen zu berühren, die die Mißerfolge auf diesem Gebiet herbeigeführt haben.

1) Nach Mitteilung des Abgeordneten Rießer im Reichstag am 28. 2. 1918 gab es 59 Kriegsgesellschaften mit Unter- und Geschäftsabteilungen, Verteilungs-, Ausgleichs-, Freigabestellen und Kriegsausschüssen. Allein für Leder gibt es neben der Kriegsleder-AktienGesellschaft die Riemenfreigabestelle unter einem Bergassessor a. D., die Kontrollstelle für freigegebenes Leder unter einem Rechtsanwalt, die Gutachterkommission für Lederhöchstpreise und die für Schuhwarenpreise, die Ersatzsohlengesellschaft, die Reichslederhandelsgesellschart und die Sattelledergesellschaft. Außerdem der Ueberwachungsausschuß der Schuhindustrie mit elf Schuhwarenherstellungs- und Vertriebsgesellschaften an verschiedenen Orten, der Hauptverteilungsausschris des Schuhhandels mit 18 Schuhhandelsgesellschaften an verschiedenen Orten und aus der Verwandtschaft noch die Deutsche Rohbautaktiengesellschaft und die Kriegsfellaktiengesellschaft.

2) Nach Mitteilung eines preußischen Abgeordneten im Landtag vom 2. 3. 1918 erfolgte beispielsweise bei der Kohlenverteilung die Festlegung der Entfernungen durch einen geraden Strich. Dieses geschah so bureaukratisch, daß Werke, die in ihrer Nähe eigene Kohlenbetriebe besaßen, aus diesen nicht beziehen durften, sondern aus entfernt liegenden Gruben zugeteilt erhielten. 
Bei den nach der Art ihrer Tätigkeit kaufmännisch gestalteten Einkaufsabteilungen des Kriegsministeriums war das System rein militärisch. Für die Tätigkeit und die Geschäftszuweisung an die die Aufträge vergebenden Personen waren nicht der Beruf und die praktisch-kaufmännischen Erfahrungen maßgebend, sondern der militärische Rang. Höhere Offiziere leiteten große Abteilungen, die fast ausschließlich kaufmännisch betrieben wurden. Andere aktive Offiziere wichtige Einkaufsreferate. Diese Persönlichkeiten, deren militärische Fähigkeiten nicht angezweifelt werden sollen und deren Pflichteifer anerkannt werden muß, sollten plötzlich große kaufmännische und wirtschaftliche Aufgaben ohne jede Erfahrung, ohne Kenntnis des Einkaufs und der sehr verwickelten Syndikatsverhältnisse lösen. Als Lieferanten traten ihnen gut geschulte geschäftskundige Kaufleute gegenüber. Es konnte von vornherein keinem Zweifel unterliegen, wer bei den Verhandlungen der Unterlegene war. Der Militärfiskus hat es außerdem nicht einmal dahin bringen können, daß der Einkauf eines Gegenstandes von ein und derselben Stelle erfolgte. Statt dessen gab es nicht nur mehrere, sondern oft eine Vielheit von militärischen Behörden, die sich beim Einkauf erbitterte Konkurrenz machten und dic Preise in die Höhe trieben.

Angesichts dieser Ergebnisse wird man vom Staat nicht erwarten können, daß die rein wer $\mathrm{ts}$ ch af $\mathrm{f}$ en de Tätigkeit, die unendlich viel schwieriger ist, durch ihn eine Erhöhung erfahren könnte. Es ist nicht einmal anzunehmen, daB sie auf gleicher Höhe wie bei der Privatindustrie gehalten werden könnte.

Betrachtet man unter den vorgetragenen Gesichtspunkten die Betätigung des Staates auf den einzelnen wirtschaftlichen Hauptgebieten, welches ist das Ergebnis? In erster Linie wird darauf hingewiesen, daß der staatliche Eisenbahnbetrieb glänzend arbeite und sich gut rentiere. Dabei sei er ein Riesenunternehmen und habe daneben gewaltige öffentliche Aufgaben zu erfüllen. Die Tatsache des Erfolges soll nicht bestritten werden, es kann sich 
nur um ihre Erklärung handeln. Das Eisenbahnwesen ist in seinem Aufbau bureaukratisch geordnet, entspricht also dem Wesen des Staates. Hierin liegt in erster Linie das Geheimnis des Erfolges. Die Verwaltung der Bahn ist Schema. Der Betrieb vollzieht sich in straffen festen Formen nach einer ins einzelne nach Zeit und Ort vorgenommenen Regelung. Der Bureaukratismus feiert hier Triumphe. Daneben gibt es für den wirtschaftlichen Erfolg noch Gründe, die ebenfalls Bedeutung haben. Schon der Erwerb der Bahnen vollzog sich unter sehr günstigen Bedingungen; denn der Staat besaß starke Machtmittel, um die Eigentümer zu zwingen, zu annehmbaren Preisen zu verkaufen. Man braucht nur an die Konkurrenz der ihm gehörigen Linien und die vielfache Abhängigkeit der Gesellschaften von der Staatsverwaltung zu denken. Des weiteren ist die Ausbeutung eines ungefährdeten Monopols, wie es die Eisenbahnen sind - der Wettbewerb der Wasserstraßen fällt nicht entscheidend ins Gewicht an sich keine besondere Leistung. Aber wàs das Wichtigste ist, das sind fortwährend gewachsene Erzeugung und größer werdender Verbrauch wirtschaftlicher Güter, wodurch ein von Jahr zu Jahr steigender Verkehr, der steigende Einnahmen sicherte, sich entwickelte. So hat das Aufblühen des deutschen Wirtschaftslebens außerordentlich viel zum Erfolge des staatlichen Eisenbahnbetriebes beigetragen. Wo der Staat im Bergbau eigene Betriebe besitzt, arbeitet er in scharfem Wettkampf mit der Privatindustrie. Dieser Umstand zwingt ihn, sich auch technisch auf der Höhe zu halten. In der Kaliindustrie ist es ihm wohl auch gelungen, in der Kohlenindustrie ist es schon zweifelhaft. Weite Kreise behaupten, daß die staatlichen Gruben hinter der Privatindustrie an produktiven Leistungen und auch im technischen Ausbau zurückstehen. Die finanzielle Rechnungslegung der staatlichen Gruben, insbesondere die Behandlung der Abschreibungen, Bewertung der Anlagen lassen kein unbedingtes richtiges Urteil über das finanzielle Ergebnis der staatlichen Gruben zu. Daher ist in dieser Hinsicht der Vergleich mit den privaten Bergwerken nicht 
ohne weiteres angängig. Immerhin spricht das von dem Abgeordneten Hirsch als Berichterstatter in der Landtagskommission, die zur Untersuchung über die Lage der preußisch-fiskalischen Bergwerke gebildet worden ist, vorgebrachte Material nicht für den staatlichen Bergbaubetrieb $^{1}$ ). Hué ${ }^{2}$ ) sucht dagegen nachzuweisen, daß der Staat ebenso günstig im Bergbau arbeite wie der private Unternehmer. Seine Ausführungen sind nicht überzeugend: Der Verfasser behauptet u. a. mit Recht, daß der Staat verschiedene Bergwerke zu unverhältnismäßig teueren Preisen erworben habe, woraus sich eine starke Verminderung der staatlichen Rente ergebe. Aus dieser Tatsache geht unzweifelhaft hervor, daß der Staat nicht das kaufmännische Urteil und die kaufmännische Gewandtheit besitzt, die zu solchen Transaktionen notwendig sind. Ein "Hineinlegen" ist nur dann möglich, wenn sich jemand findet, der sich „hineinlegen" läßt. Wenn dort weiter sinngemäß gesagt wird, die private Industrie habe ebenso große Unternehmungen hervorgebracht wie der Staat und damit sei auch die Schwerfälligkeit, die teuere Verwaltung und andere Nachteile des Staatsbetriebes auf sie übergegangen, so wird dabei übersehen, daß der Privatbetrieb von Grund auf anders organisiert ist. Der Vergleich nach Masse und Umfang ist nicht allein maßgebend, es kommt auch auf den Geist an. Gerade beim Bergbau hat der Staat die früheren Beschränkungen fallen lassen, weil man richtig erkannt hatte, daß der freie Wettbewerb eher imstande sei, wirtschaftliche Werte zu schaffen und zu heben. In der Begründung der preußischen Berggesetznovelle vom Jahre 1907 heißt es ausdrücklich, daß das preußische Berggesetz vom Jahre 1865 bei der Einführung der Bergbaufreiheit die bewußte Absicht verfolgt habe, ,die Bergwerksmineralien dem freien industriellen Verkehr zu überweisen und zur Grundlage eines auf den wirtschaftlichen

1) Landtagsdrucksachen Nr. 307 A. B. und C, 21, Legislaturperiode IV, Sektion 1914.

2) a. a. O. S. $126 \mathrm{ff}$. 
Kräften des Volkes fußenden großartigen Gewerbebetriebes $\mathrm{zu}$ erheben ". Hierin liegt zweifellos das Eingeständnis, daß der Staat nicht imstande war, die Bergwerksindustrie zu entwickeln. Aus diesem Grunde wurde sie der Privatindustrie überlassen. Heute dagegen wird wieder Ueberführung in Staatsbesitz verlangt, trotzdem der Staat zur Weiterentwicklung dieses Erwerbszweiges nicht besser wie früher befähigt ist und die technische und kaufmännische Leitung der Betriebe sicher nicht einfacher, sondern schwieriger geworden ist. Von Staatsbeamten sind die Mängel der staatlichen Bewirtschaftung ernstlich kaum bestritten worden. Hat doch der frühere Reichskanzler Michaelis in einer mehreren Zeitungsleuten gewährten Unterredung offen erklärt, ,er sei kein Freund von Monopolen, weil sie teuer arbeiten und die Qualität der Waren beeinträchtigen, aber man müsse sich darüber hinwegsetzen. Nur müsse man sich fragen, ob sie ohne zu große Schwierigkeiten durchgeführt werden könnten und sie ergiebig seien "1). Der Staatsbetrieb wird hier nicht als etwas Besseres bezeichnet, das man an Stelle des Privatbetriebes setzen könne, sondern seine Einführung wird mit der bitteren Notwendigkeit, Einnahmequellen zu erschließen, entschuldigt ${ }^{2}$ ).

\section{Die Gefahr des technischen Stillstandes.}

$\mathrm{Ob}$ sich eine Industrie für die Verstaatlichung eignet, wird, wie schon gesagt, bei jeder einzeln $\mathrm{zu}$ untersuchen sein. Es wird geprüft werden müssen, ob nicht Gründe

1) Berliner Tageblatt 8. 9. 1917, Ab. Bl.

${ }^{2}$ ) In seiner Schrift „Die neuel Wirtschaft" befürwortet W. Rathenau eine weitgehende wirtschaftliche Betätigung des Staates, allerdings in wesentlich anderer Weise wie bei der staatlichen Monopol-Wirtschaft. Sieine Ausführungen leiden unter zwei grundlegenden Irrtümern. Erstens ist nicht zutreffend und kein Beweis dafür geliefert, $\mathrm{da}$ eine um ein Mehrfaches erhöhte Erzeugung auch entsprechend höhere Abgaben und Steuern tragen kann. Zweitens werden rein theo. retische Konstruktionen auf historisch gewordene Dinge und Verhältnisse, die sich nur organisch weiter entwickeln lassen, übertragen. Abgesehen von anderen Irrtümern dürfte der Schrift aus diesen Gründen. eine wesentlich praktische Bedeutung nicht zukommen. 
vorhanden sind, aus ihrer Eigenart hervorgehend, welche an sich eine solche Maßnahme ausschließen oder unmöglich machen. Diese Gründe können sowohl besonderer Art sein, als auch in den schon angeführten Nachteilen und Gefahren des Staatsbetriebes bestehen. Wie verhält es sich in dieser Beziehung mit der Kaliindustrie?

In erster Linie kommt hier die Gefahr des technischen Stillstandes in Betracht. Diese ist bei der Verstaatlichung niemals ganz auszuschalten, sondern immer vorhanden. Es kann sich lediglich darum handeln, ob sie bei der Kaliindustrie in der Bedeutung nicht so sehr hervortritt, weil die technische Entwicklung bereits einen gewissen Abschluß erlangt haben könnte oder weil der technische Fortschritt für das Gedeihen dieses Wirtschaftszweiges nicht wesentlich ist. Man wird auch dieses verneinen müssen. Die Kaliindustrie beruht zwar teilweise auf der Förderung und dem unmittelbaren Absatz eines Rohproduktes. Sie ist aber andererseits auch in weitestem Umfange an der Weiterverarbeitung und der Gewinnung vieler neuer Produkte für industrielle $Z$ wecke beteiligt. Dies ergibt sich schon daraus, daß zu den meisten Werken größere chemische Fabriken gehören, deren Weiterentwicklung und Vergrößerung stetig fortschreiten. Die Verstaatlichung dieser chemischen Fabriken kann unter keinen Umständen befürwortet werden. Man wird in bezug hierauf den Ausführungen eines stark für die Verstaatlichung des Kalibergbaues eintretenden Schriftsteller's zustimmen müssen ${ }^{1}$. Er șagt darüber, ,daß die chemischen Fabriken der Kalizechen mehr bedeuten als die Aufbereitungsanstalten der Kohlenzechen und selbst mehr als die Kokereien, und da die Chemie überhaupt unter allen Wissenschaften am schnellsten voranschreite, so sei sie auf dem Gebiet der Kaliverwertung auch jetzt wieder in einer Umwandlung begriffen, die ihren Sporn, wie immer, durch den Wettbewerb empfange. Eine Verstaatlichung $\mathrm{m} \ddot{u} B t e$ vor ihr Einhalt tun und dürfte sich

1) Die Neuordnung der deutschen Finanzwirtschaft. München, Leipzig 1918. Eberhard Gothein, Seite 256 ff. 
nur auf die Rohsalze beziehen." Die chemischen Fabriken sind indessen mit den Zechen derart organisch zu einem Ganzen verbunden, daß nicht einzusehen ist, wie eine Verstaatlichung der Zechen mit Ausschluß der Fabriken erfolgen kann. Schon die Auseinanderrechnung der Betriebskosten und Gewinne würde unüberwindlichen Schwierigkeiten begegnen, ganz abgesehen von der Bewertung der Anlagen. Die chemischen Fabriken verarbeiten z. T. die Rohsalze zu Düngesalzen für die Landwirtschaft. Die Entwicklung ist auch hier nicht abgeschlossen. Insbesondere ergibt die begonnene $Z$ usammenarbeit mit der Düngerindustrie zur Herstellung neuer Düngeprodukte weite Aus blicke und Möglichkeiten. Die Fabriken stellen ferner eine große Reihe Produkte dar, die nur industriellen Zwecken dienen. Daneben werden noch Erzeugnisse fabriziert, die mehr als Nebenprodukte zu bezeichnen sind.

Der Verbrauch der Salze für industrielle Zwecke hat sich seit 1900 von ungefähr $700000 \mathrm{dz}$ auf mehr als eine Million Doppelzentner $\mathrm{K}_{2} \mathrm{O}$ im Jahre 1913 gesteigert. Das wichtigste in der Industrie verwandte Kalisalz ist Chlorkalium, in geringerer Menge wird Kaliumsulfat verbraucht, während schwefelsaure Kalimagnesia in ganz geringem Maße bezogen wird ${ }^{1}$ ). 1913 wurde hiervon in Deutschland in der Industrie $80 \%$ der Gesamtproduktion, das sind ca. $130000 \mathrm{dz}$, weiter verarbeitet. Der größte Teil ca. 72\% - entfiel auf die Fabrikation von Aetzkali und Pottasche, etwa $21,7 \%$ dienen zur Herstellung von Kalisalpeter, geringere Mengen zur Gewinnung von Kaliumchlorat und Kaliumbichromat und verschiedenen anderen Zwecken.

- Aetzkali wird hauptsächlich durch Elektrolyse hergestellt und zu Schmierseife, Teerfarben, Teerprodukten (Naphtol usw.) und Oxalsäure verarbeitet, bzw. bei deren Verarbeitung verwendet.

Pottasche wird durch Umsetzung von $\mathrm{KCl}$ mit $\mathrm{MgO}$ und $\mathrm{CO}_{2}$ gewonnen. Sie dient zur Herstellung von Glas,

1) Die Kalirohsalze, ihre Gewinnung und Verarbeitung von Dr. W. Michels und C. Przigylla, Leipzig, 1916. 
Schmierseife, Blutlaugensalz, Bromkalium, Jodkalium, Cyankalium, Kaliwasserglas usw. und wird ferner in der Färberei und Bleicherei benötigt.

Der Kalisalpeter, gewonnen durch Umsetzung von $\mathrm{KCl}$ mit Natronsalpeter, wird namentlich zur Fabrikation von Schieß- und Sprengpulver verwendet, ferner beim Pökeln von Fleisch, in der Metallbearbeitung, Gartendüngung usw. gebraucht.

Das durch Elektrolyse hergestellte Kaliumchlorat dient in steigendem Maße zur Herstellung von Sprengstoffen, und hat dadurch, besonders während des Krieges, erhöhte Bedeutung gewonnen. Auf Grund der in dieser Beziehung gemachten ausgezeichneten Erfahrungen ist nach dem Kriege ein bedeutender Aufschwung dieser Produktion zu erwarten. Bekannt ist ferner die Verwendung des $\mathrm{Ka}$ liumchlorats zur Herstellung von Zündhölzern und Feuerwerk etc. Auch für die Fabrikation des Kaliumpermanganats und einzelner Teerfarben wird Kaliumchlorat benötigt.

Das durch Umsetzung von $\mathrm{KCl}$ mit Natriumbichromat gewonnene Kaliumbichromat dient in der Färberei und im Zeugdruck als Beizmittel, ferner zur Reinigung von Oelen, Holzessig etc. Auch in der Photographie spielt es eine nicht unbedeutende Rolle.

Von den an die Industrie im Jahre 1913 abgesetzten $67000 \mathrm{dz}$. Kaliumsulfat wurden im Inlande nur $27000 \mathrm{dz}$ verbraucht. Auf das Ausland entfielen demnach 40000 Doppelzentner. $40 \%$ des Inlandsverbrauchs, $92 \%$ des Auslandsverbrauchs dienten zur Alaunherstellung, während der Rest für andere $Z$ wecke verbraucht wurde. Der Alaun wird in der Färberei, der Papierfabrikation und Gerberei verwendet, außerdem zur Herstellung von Farblacken.

Die Nebenproduktengewinnung und Verarbeitung bei der Kaliindustrie steht noch im Anfang der Entwicklung. An sie knüpfen sich noch bedeutende Möglichkeiten. Es dürfte interessieren, eine etwas eingehendere Darstellung dieser Fabrikation und der Verwendung der Produkte zu geben.

Der auf einigen Werken in größeren Mengen ge- 
wonnene Kieserit wird zum größten Teil auf Kaliumsulfat, Kalimagnesia weiter verarbeitet. Der andere Teil wird zu sogenanntem Blockkieserit umgesetzt, welcher zumeist in England und Nordamerika auf Biftersalz weiter verarbeitet wird.

Das Bittersalz dient zum Appretieren leichter Baumwollgewebe, zum Beschweren von Seide, für medizinische Zwecke, zur Herstellung von Bariumsulfat, und wird ferner in der Papierfabrikation benutzt.

Aus den Löserückständen von Karnallit und Hartsalz wird außerdem das Glaubersalz gewonnen, welches zur Glasfabrikation, Herstellung von Wasserglas, Ultramarin, essigsaurem Natrium, Schwefelnatrium, Natriumthiosulfat und anderen Natriumsalzen und in der Teerfarbenindustrie benötigt wird. Da dasselbe nur bei Temperatur von -5 bis $-10^{\circ}$ ausfällt, findet die Produktion nur in den Wintermonaten statt. Die Löserückstände werden in der warmen Jahreszeit auf die Halde gestürzt und im Winter durch Abspritzen mit heißem Wasser wiedergewonnen. Früher wurden, namentlich in Leopoldshall, die alten Rückstandshalden in dieser Weise aufgearbeitet. Der Betrieb an sich soll sehr rentabel sein, das Ergebnis der Produktion ist jedoch sehr schwankend, weil dieselbe, wie bereits gesagt, nur bei Frostwetter ausgeführt werden kann. Auch die durch die Fabrikation bedingte Verhärtung des Flußwassers kann gewisse Schwierigkeiten machen, wenn auch infolge der stärkeren Wasserführung der Flüsse in den Wintermonaten in dieser Beziehung ein gewisser Ausgleich gegeben ist.

Eine besondere Bedeutung der Nebenproduktengewinnung der Kaliindustrie liegt in der Bromfabrikation.

Das Brom reichert sich bei der Verarbeitung des Bromkarnallits in dor entstehenden Endlauge an, und zwar in der Form des Brommagnesiums, und wird entweder in Form von Brom oder in der Form von Bromeisen oder Bromsalzen (Bromkalium, Bromnatrium, Bromammonium) oder als sogenanntes Bromsalzgemisch hergestellt. Die Gewinnung des Broms aus Endlaugen erfolgt entweder auf chemischem Wege unter Zuhilfenahme von Chlor oder durch Elektrolyse. Das Brom und seine Verbindungen werden 


\section{$-80-$}

zur Herstellung von Teerfarbstoffen (Eosin), vielen organischen Präparaten, ferner für medizinische und photographische Zwecke und zur Goldextraktion benutzt. Hinsichtlich der Bromerzeugung ist, falls sich ein genügendes Absatzgebiet findet, eine starke Steigerung gegen früher nach dem Kriege möglich.

Besonderes Interesse verdient das Chlormagnesium, welches sich durch Eindampfen der Endlauge in fester Form gewinnen läßt. Es wird als geschmolzenes oder als kristallisiertes Produkt in den Handel gebracht. Bei den großen bei der Karnallitverarbeitung entfallenden Endlaugenmengen ist der Absatz des zurzeit gewonnenen Chlormagnesiums gering zu nennen. Schätzungsweise beträgt die Jahresproduktion $350000 \mathrm{dz}$. Das Chlormagnesium dient in der Baumwollspinnerei zum Feuchthalten der Fäden, ferner zur Herstellung von Steinholz, Magnesiazement, Chlorbarium, Magnesiumcarbonat etc., ferner zur Herstellung von Spülflüssigkeit bei Bohrungen im Salzgebirge und für Kältemaschinen.

In Leopoldshall wird schon seit über 25 Jahren die Darstellung von Magnesia und Salzsäure betrieben. Das durch Erhitzung in Gegenwart von Wasserdampf gewonnene Produkt wird in Calcinieröfen gebrannt und gemahlen, und kommt als Magnesia mit 94 bis $95 \% \mathrm{MgO}$ in den Handel. Durch neuere Vorschläge Hepkes ist eine wesentliche Verbilligung des Verfahrens zu erwarten. Von Bedeutung für dasselbe dürfte der günstige Ausfall der Düngungsversuche mit Chlorammonium sein, welche neue Absatzmöglichkeiten für die bei dem Prozeß entstehende Salzsäure schaffen. Leider hat sich während des Krieges die praktische Durchführung des von Hepke vorgeschlagenen Verfahrens noch nicht vornehmen lassen ${ }^{1}$ ).

Die Magnesia dient zur Herstellung von Magnesiazement, Steinholz, Kunststeinen, von basischen Steinen für metallurgische Zwecke, zur Wiedergewinnung des Chroms aus Chromalaunlösungen usw.

Im Zusammenhang hiermit sei die Bedeutung der als

1) Vergl. „Kali“ 1916, Heft 17, Seite 257 bis 262. 
Nebenprodukt der Kaliindustrie gewinnbaren Salzsäure kurz erörtert. Dieselbe besitzt den Vorzug völliger Arsenfreiheit und wird für die Herstellung von Anilin und vielen anderen Teerprodukten, von Salmiak und anderen Chloriden, von Knochenleim und beim Beizen und Löten von Metallen, in der Metallurgie usw. benutzt. Nach Barth wird die Salzsäure für manche Industrien als willkommener Ersatz für die bisher gebrauchte Schwefelsäure dienen können, wenn sie billig genug zu haben ist. Sie kann z. B. bei den Beizereien, Verzinkereien, Emaillieranstalten mit Vorteil die Schwefelsäure ersetzen. Dasselbe gilt für den Aufschluß von Phosphaten, 'wobei sogar die bisher wegen ihres Eisengehaltes unbenutzten bedeutenden Mengen von deutschen Phosphoriten verwertbar werden sollen.

Endlich sei noch auf die direkte Gewinnung von Chlor aus den Alkali-Chloriden durch Elektrolyse hingewiesen, welche eine der wichtigsten Chlorerzeugungsmethoden der Gegenwart geworden ist. Sie ermöglicht die Gewinnung unbegrenzter Chlormengen. Das vor dem Kriege elektrolytisch gewonnene Chlor wurde fast ganz auf Chlorkalk verarbeitet. Verschiedene Fabriken liefern auch flüssiges Chlor, welches in Stahlflaschen und Kesselwagen in den Handel kommt. Während des Krieges hat das Chlor eine erhöhte Bedeutung als Kampfmittel gewonnen.

Außer den vorerwähnten Fabrikaten werden noch andere $\mathrm{zu}$ industriellen Zwecken hergestellt und abgesetzt, beispielsweise Boracit zur Darstellung von Borsäure, hochprozentiger Karnallit für die Herstellung von Magnesiummetall, kristallisierte Kalimagnesia für die Alaunfabrikation, Rubidium-Alaun etc.

Die von der Kaliindustrie erzeugten Nebenprodukte könnten noch in größeren Mengen hergestellt werden. Es mangelt indessen am Absatz. Insbesondere trifft dies zu für Chlormagneșium und Brom, aber auch für Kieserit, EndlaugeSalzsäure, Magnesia und Glaubersalz.

Der Bedarf Deutschlands an Schwefeldioxyd zur Schwefelsäurefabrikation konnte nur zum kleinen Teile aus den deutschen Kiesen und Blenden und dem Schwerspat 
gedeckt werden, so da $\bar{B}$ eine starke Einfuhr von Pyriten aùs dem Auslande erforderlich war. Die Schwefelsäure dient zur Herstellung von Superphosphat und Amoniumsulfat für die Landwirtschaft, von Natriumsulfat und Salzsäure, von Salpetersäure zur Herstellung des künstlichen Indigos, vieler anderer Farbstoffe etc. Sie hat eine hohe Bedeutung für unsere Industrie, und es wäre deshalb wünschenswert, daß ihre Herstellung mehr aus einheimischen Produkten erfolgen würde.

Die Kaliindustrie ist nun in der Lage, in verschiedener Form abändernd auf die Schwefelsäuregewinnung einzuwirken. Sie kann Schwefelsäure aus einheimischen Rohmaterialien herstellen bzw. die Rohmaterialien liefern, welche die Gewinnung von Schwefelsäure ohne Benutzung von Kiesen und Blenden ermöglichen. Zunächst kann durch vermehrte Lieferung voń Salzsäure, die die Kaliindustrie aus Chlormagnesium herstellt, ein Teil der Schwefelsäure entbehrlich gemacht werden. Der vermehrte Verbrauch von Salzsäure wird dadurch erreicht, $\mathrm{da} B$ an Stelle von Ammoniumsulfat Chlorammonium für Düngezwecke verwandt wird. Im Zusammenhang hiermit ist auf die Bedeutung des Natriumsulfats (Glaubersalz) hinzuweisen, welches aus den Löserückständen der Kaliindustrie billig hergestellt werden kann, wodurch wiederum Schwefelsäure, also auch Pyrit gespart würde. Der durch Einschränkung der Natriumsulfatherstellung aus Schwefelsäure bedingte Ausfall an Salzsäure wäre unschwer durch vermehrte Zersetzung von Chlormagnesium auszugleichen.

Die Gewinnung von Schwefelsäure und Salzsäure aus Kieserit bzw. Chlormagnesiumlauge bedeutet die Mitgewinnung der Magnesia. Dadurch würde die Einfuhr von Magnesit zum großen Teil überflüssig werden.

Im Nachstehenden seien die vorstehenden Ausführungen kurz erläutert.

Die Herstellung von Schwefelsäure würde nach Precht nach zwei Verfahren möglich sein, von denen das eine von Ciips, das andere von Kieserit ausgeht.

Das von Gips ausgehende Verfahren beruht auf der 
Reduktion des Gipses zu Schwefelcalcium, Zersetzung des letzteren durch Chlormagnesiumlauge und Verbrennung des entwickelten Schwefelwasserstoffes zu Schwefeldioxyd, mit welch letzterem dann wie üblich Schwefelsäure hergestellt wird. Nach dem Verfahren von Claus kann man den Schwefelwasserstoff durch unvollkommene Verbrennung auch in Schwefel umwandeln. In technischer Hinsicht bestehen keine Schwierigkeiten; es muß sich zeigen, wie hoch nach dem Kriege die Selbstkosten sein werden. Sichere Schätzungen betreffend die Wirtschaftlichkeit sind zurzeit nicht möglich, weil man die Preise für Pyrit etc. nach dem Kriege nicht kennt.

Die Herstellung von Schwefeldioxyd aus Kieserit verspricht wirtschaftlich günstigere Aussichten, weil bei der Reduzierung von Kieserit unmittelbar Schwefeldioxyd entsteht, so daß weniger Kohlen erforderlich sein werden. Als günstiges Moment ist in Betracht zu ziehen, daß Magnesia als Nebenprodukt gewonnen wird, welche für die Magnesiaindustrien Verwendung finden kann.

Ferner kann als Ersatz für Schwefelsäure die aus Chlormagnesium zu gewinnende Salzsäure treten. Daß dies möglich ist, beweist die bereits 25 Jahre alte Fabrikation in Leopoldshall, deren Wirtschaftlichkeit erwiesen ist. Auch die von Hepke vorgeschlagene Neuerung des Verfahrens läßt eine nicht unwesentliche Verbilligung erwarten, zumal

- der günstige Ausfall der mit Chlorammonium angestellten Düngungsversuche das Absatzgebiet für die Salzsäure erweitert hat.

Den Pyrit bei der Schwefelsäurefabrikation gänzlich auszuschalten, ist wohl unmöglich, doch besteht begründete Aussicht, daß die Kaliindustrie durch Ausgestaltung ihrer Nebenproduktengewinnung einen erheblichen Teil der Pyriteinfuhr überflüssig machen wird, was ohne Zweifel einen bedeutenden Gewinn für unsere Volkswirtschaft darstellen würde.

Ein abschließendes Urteil über andere technische Möglichkeiten, die hier nicht besprochen worden sind, kann noch nicht gefällt werden. Es ist indessen festzustellen, 
daß die technische Entwicklung nicht abgeschlossen ist, im Gegenteil, es sind noch bedeutende chemisch-technische Fortschritte zu erwarten. Es hieße die ganzefortschreitende Entwicklung hemmen und unmöglich machen, wenn die Verstaatlichung durchgeführt würde. Damit würden bedeutende wirtschaftliche Werte ungehoben bleiben. Die nationale Wirtschaft würde dadurch eine schwere Schädigung erfahren.

\section{Die Schwierigkeiten des Erwerbs der Kaliindustrie.:}

Der Erwerb der Kaliindustrie durch den Staat dürfte bedeutenden Schwierigkeiten begegnten. Zunächst handelt es sich bei dem Objekt nicht allein um ausgebaute Werke, sondern auch um zahlreiche im Bau begriffene Schächte und ausgedehnte unverritzte Bergwerksfelder. Die Bewertung der unaufgeschlossenen Felder und der im Bau. begriffenen Anlagen dürfte außerordentlich schwierig sein. So gibt es Felder, auf denen noch kein Schachtbau begonnen ist, die aber nach Qualität der erbohrten Salze, der Lagerungsverhältnisse und der voraussichtlich günstigen Schachtbauverhältnisse größeren Wert als schon teilweise ausgeführte Anlagen haben. Andererseits gibt. es Anlagen, in die schon Millionen hineingesteckt sind, ohne da $\mathrm{B}$ ein Resultat erzielt worden wäre, bei denen aber trotzdem noch die Möglichkeit besteht, einen rentablen Bergbau zu betreiben. Die Entschädigung nach Maßgabe der aufgewandten Kapitalien würde daher zu großen Ungerechtigkeiten führen können, während andererseits diebloße Einschätzung nach den wirtschaftlichen Möglichkeiten oder den Zukunftserträgnissen ebenfalls falsche Ergebnisse zeitigen würde und unbillig wäre. In beiden Fällen handelt es sich aber um wohlerworbene Rechte, die nicht ohne entsprechende Gegenleistung erworben werden können. Die Besitzer der Felder und unausgebauten Anlagen lohne Entschädigung zu lassen, ist unmöglich; denn die Hingabe der Kapitalien ist im Vertrauen auf gesicherte: 
Rechtsverhältnisse, auf Grund des Rechtes jedes freien Staatsbürgers, sich wirtschaftlich frei zu betätigen, erfolgt. Hieran rütteln, hieße die Grundlage unseres ganzen Rechtsund Wirtschaftslebens, das Eigentum, untergraben.

Bietet schon die Art des Objekts für den Erwerb Schwierigkeiten, so stellt die gewaltige Größe der zu übernehmenden Vermögenswerte den Staat vor Aufgaben, deren Lösung bisher noch nicht versucht worden ist. Daß die Kaliindustrie für den Preis von rund 600 Millionen, wie G. Gothein ${ }^{1}$ ) annimmt, erworben werden könnte, ist ausgeschlossen. Nach einer Veröffentlichung des Kalisyndikats sind in der Kaliindustrie etwa 1800 Millionen angelegt. Auch der Küswert ist beträchtlich höher. Er dürfte gegenwärtig auf $11 / 2-2$ Milliarden zu veranschlagen sein ${ }^{2}$ ). Hinzu kommen die Anleihebeträge, die sich auf mehrere hundert Millionen belaufen, und die Entschädigungen für unverritzte Felder und dergl.

Der Kurs der Kalipapiere gibt nur eine höchst mangelhafte Bewertungsgrundlage. Für viele Papiere besteht kein eigentlicher Markt. Nur die Anteile von ganz wenigen großen Kaliunternehmungen werden offiziell an den Börsen gehandelt. Die Kuxe der Gewerkschaften haben nur einen inoffiziellen Markt an einigen Kuxenbörsen. Hierbei ist zu beachten, daß auch ein großer Teil der Kuxe, an denen die großen Gesellschaften beteiligt sind, sich im freien Verkehr befinden, denn in der Regel besitzen die größeren Werke nur die einfache Mehrheit, oft auch nur $1 / 4$ der

1) a. a, O, S, 64 .

2) Nach einer Berechnung des Bankiers Jacoby-Dortmund hatten am 1. Februar 1918 die Kuxe von 78 Gewerkschaften, die an der Börse notiert werden, einen Kurs von 788,12 Millionen Mark. Diesem, Kurs entsprach unter Zugrundelegung der Ausbeutezahlung von 1914 bis 1917 eine Verzinsung von $0,621 / 2 \%$. Tatsächlich dürfte die Verzinsung etwas höher sein, weil hierin auch Werke einbegriffen sind, die noch im Ausbau standen. Die Aktien der 20 an den Börsen notierten Aktiengesellschaften hatten am 1.2. 1918 einen Kurs von 352,99 Millionen Mark. Bei diesen Kursangaben ist zu berücksichtigen, $\mathrm{da}$ ß seit dem 1. 2. 18 eine weitere bedeutende Kurssteigerung eingetreten ist, und da $\beta$ ferner hierbei noch über 100 Gesellschaften, die keine Börsennotiz haben, nicht berücksichtigt sind. (Vergl. Frkft. Z. vom 12. 4. 1918, Abdbl.) 
Kuxe ihrer Tochtergewerkschaften. Solche Papiere haben meistens überhaupt keinen Markt. Die Kursgestaltung ist deshalb von zufälligen Umständen im hohen Maße abhängig. Der innere Wert des Unternehmens kommt für die Kursgestaltung niemals allein in Frage. Von großer Bedeutung sind eine ganze Reihe anderer Momente, die ihren Grund in der Spekulation haben. So entsprach beispielsweise der Kurswert der Deutschen Kaliwerke-Aktien im Februar 1918 nur der Summe der Kurswerte sämtlicher Beteiligungen und Forderungen der Aktiengesellschaft deutscher Kaliwerke. Der Eigenbesitz dieser Gesellschaft kam in der Kursbewertung gar nicht zum Ausdruck $^{1}$ ). Es kommt hinzu, daß sobald der Staat seine Absicht erkennen ließe, die Verstaatlichung vorzunehmen und zum Ankauf der Unternehmungen schritte, noch gewaltigere Kurssteigerungen eintreten würden, als sie schon erfolgt sind. Trübe Erfahrungen sind in dieser Beziehung beim Ankauf der Hibernia gemacht worden. Auch der Weg, zunächst die Mehrheit bei einzelnen Unternehmungen durch Vereinbarungen mit den maßgebenden Gruppen zu erwerben, ist unter den heutigen Verhältnissen kaum gangbar. Das Objekt ist zu groß und zu zersplittert. Der Hinweis auf Erwerbung der Staatseisenbahnlinien ist nicht zutreffend. Dort standen, wie schon erwähnt, dem Staat bedeutende Druckmittel zur Verfügung. Er war in der Lage, mit seinen eigenen Linien den einzelnen Eisenbahngesellschaften scharfen Wettbewerb zu machen. Auch waren diese von ihm in vieler Beziehung abhängig. Mit seinem Verwaltungsapparat konnte er ihnen jederzeit in ihrem Betriebe und in der Ausgestaltung des Bahnnetzes unüberwindliche Schwierigkeiten machen. Schon die Drohung mit derartigen Maßnahmen genügte, um annehmbare Bedingungen zu schaffen. Es ist deshalb leicht verständlich, da $\beta$ der Erwerb der Eisenbahnanteile zu angemessenen Preisen erfolgen konnte. Trotz der Nachteile,

1) Ausführungen des Generaldirektors Kain in der Generalversammlung der Aktiengesellschaft Deutscher Kaliwerke am 26. 2. 1918. 
die die Bewertung der Bergwerke nach ihrem derzeitigen Kurswert hat, wird der Staat den Kurs als Uebernahmepreis gelten lassen müssen. Ein anderer Weg ist kaum denkbar. Die Enteignung auf Grund der Abschätzung durch eine Sachverständigenkommission würde kein wesentlich anderes Ergebnis zeitigen können. Sie müßte auch alle die Momente und Zukunftsaussichten berücksichtigen und einschätzen, die eben die betreffende Kursbildung bewirkt haben. Selbst in Fällen, wo offensichtlich spekulative Preistreibereien vorliegen, würde eine Herabsetzung des Uebernahmepreises unter die Kurssumme nur Personen schädigen, die an ihnen nicht beteiligt sind. Die Spekulanten werden ihren Gewinn längst in Sicherheit gebracht haben. Die Enteignung zum Kurswert an einem bestimmten Stichtage würde zwar einige Nachteile ausschließen, aber an dem Ergebnis nichts ändern.

Was würde nun die Uebernahme der Bergwerke zum Kurswert für den Staat bedeuten? Der Kurs der Kalipapiere ist heute so hoch, daß er die finanziellen Ergebnisse für viele Jahre im voraus einschließt. Mithin würde der Staat in einem solchen Falle den Anteilsbesitzern den zu erwartenden Gewinn für lange Zeit im voraus kapitalisieren und auszahlen. Damit würde die Rentabilität des Staatsmonopols wahrscheinlich ausgeschlossen oder zum mindesten stark in Frage gestellt; denn die für den Erwerb aufzuwendende Summe dürfte so hoch sein, daß die Verzinsung nur eine geringe sein könnte ${ }^{1}$ ).

1) Sehr erhebliche Beträge für Ausfall an Steuern und Abgaben, die infolge der Verstaatlichung eintreten würden, müssen von dem finanziellen Ergebnis eines Staatsmonopols abgesetzt werden. Hierher sind zu rechnen Stempelkosten (Landesstempel) und Reichsstempel) bei Gründungen, Kapitalserhöhungen, Fusionen, Herausgabe von Obligationen, An- und Verkäufe an der Börse und Steuern auf Zinsscheinbogen, Zubußen, Umsätze im Kreise usw. Zur Schätzung dieser Summen fehlen die Unterlagen. Einen Anhalt gibt indessen die von der Aktiengesellschaft Deutscher Kaliwerke, deren Gründung im Jahre 1904 erfolgte, seither gezahlten Summen, die auf Anfrage mitgeteilt wurden. Ohne Berücksichtigung der Staats-, Gemeinde-, Grund-, Gebäude-, Gewerbe-Steuer hat die genannte Gesellschaft für sich selbst und die von ihr übernommenen Gewerkschaften bis Anfang 1918 eine Summe von rund 4 Millionen Mark gezahlt. Dabei sind noch einige 
Bei der Kaliindustrie liegen die Verhältnisse in einem weiteren Punkt sehr ungünstig. Bekanntlich sind die einzelnen Fisci in bedeutendem Maße an der Kaliindustrie beteiligt. Der prußische und anhaltische Fiskus hat eine Anzahl Kaliwerke im Eigenbesitz. Preußisch sind die Bergwerke Staßfurt, Bleicherode, Vienenburg. Anhalt besitzt einige Werke ganz und ist noch an einer Reihe von anderen Schächten in größerem oder geringerem Umfange beteiligt. Es sind dies die Werke Ilberstedt, Anhalt, Bernburger Kaliwerke, Erbprinz, Gröna, Coburg, Salzberg und Salzdetfurth. Eine Reihe anderer Staaten hat keine eigenen Werke im Besitz, hat sich dagegen Beteiligungen im weitesten Umfange gesichert. Gotha bei Volkenroda und Pöthen; Sachsen-Weimar bei Heiligenroda, Buttlar, Alexandershall, Sachsen-Weimar; Mecklenburg bei Conow; Elsaß-Lothringen bei Reichsland, Prinz Eugen, Theodor; Schwarzburg-Sondershausen beim Glückauf-Konzern. Braunschweig hat seine Beteiligungen an Asse kürzlich verkauft, besitzt aber noch Anteile an der Gewerkschaft Braunschweig-Lüneburg.

Die einzelnen Fisci haben sich mit diesen Werken aufs engste liiert. Sie haben weitgehende Verträge mit ihnen über die Kapitalbeschaffung, Ausbau, Gewinnbeteiligung, Schaffung von Verkehrsmöglichkeiten usw. geschlossen. Sie haben damit Rechte erworben und Pflichten übernommen. Für manche dieser Staaten, besonders Anhalt, ist die Abhängigkeit der Staatsfinanzen vom Kalibergbau augenșcheinlich und bekannt. Auch die anderen Staaten rechnen in ihrem Staatshaushalt mit den finanziellen Erträgnissen. Es kommt weiter in Betracht die große Bedeutung, die der Kalibergbau für das Emporblühen mancher Gegenden und Gemeinden dieser Kleinstaaten hat.

bedeutende Posten (Gründungskasten, Schlußnotenstempel), die sich noch auf über eine halbe Million Mark belaufen, nicht berücksichtigt. In dieser Summe sind beispielsweise enthalten für Obligationsstempel 1634000 Mark, für Zubußesteuern 1434000 Mark. Wenn man sämtliche von allen Werken gezahlten Steuern zusammenstellen könnte, so würde man sicher eine sehr beträchtliche Summe erhalten. 
Der Erwerb der Kaliindustrie durch das Reich würde in diese Verhältnisse mit harter Hand eingreifen. Es is t a usgeschlossen, da $B$ diese $S$ ta a ten freiwillig ihren Besitz veräußern, was im Interessedes Gedeihens eines Monopols unbedingt erforderlich wäre. Manche werden gar nicht auf diefinanziellen Erträgnisse verzichten können, selbst wenn sie wollten. Keine der Regierungen der genannten Staaten wird die Interessen ihres Landes so weit hintansetzen wollen, um in eine Stillegung bzw. Zusammenlegung der Betriebe, von der man so bedeutende Ergebnisse erhofft, $\mathrm{zu}$ willigen, weil dadurch für das betreffende Land größere Kapitalentwertungen und Verlust von Einkommen und Steuern verursacht würden. Ueberall werden Sonderrechte beansprucht und gewährt werden müssen, überall wird es Unzufriedene geben. Die Staats- und Reichsfreudigkeit wird sicherlich keine Förderung erfahren. Das Monopol wird ein Stückwerk werden, wie es das Kaligesetz auch geworden ist. Ebensowenig wie man glauben darf, daß die Einzelstaaten im Interesse der Reichsfinanzen in bezug auf den Kalibergbau Opfer zu bringen bereit wären, ist von der Reichsregierung ein scharfes Durchgreifen - wenn auch zum Schaden der kleinen Staaten - zu erwarten. Bei der Beratung des Kaligesetzes wurde durchgesetzt, daß Werke, an denen diese beteiligt waren, von der Quotenbeschränkung ausgenommen wurden ( $\$ 12$ Abs. 2 des Gesetzes), wodurch das Gesetz im wesentlichen seine Wirkung verfehlte. Die Erfahrungen im Kriege sind nicht besser. Im Interesse einer gleichmäßigen Verteilung der Kriegsaufträge auf die einzelnen Bundesstaaten hatte das Kriegsministerium eine ,Ausgleichstelle der Bundesstaaten" errichtet, die berufen war, die gerechte Verteilung der Kriegsaufträge auf die Bundesstaaten zu überwachen. Diese Einrichtung hat sich schließlich dahin entwickelt, $\mathrm{da} B$ die freie Konkurrenz bei der Vergebung der Kriegsaufträge, wenn nicht durchaus, so doch wesentlich ausgeschaltet wurde. Welche Mehrkosten dem Reich hierdurch 
erwachsen sind, läßt sich nicht annähernd feststellen. In dieser Beziehung ist ferner interessant, daß schon jetzt von elsaß-lothringischen Kreisen lebhaft - allerdings. durchaus unberechtigterweise - darüber Klage geführt wird, der elsaß-lothringische Kalibergbau werde bei der Deckung des Gesamtbedarfs nicht in genügender Weiseherangezogen. Hierher gehört ferner noch, daß es Staaten, wie z. B. Baden, gibt, die noch keinen Kalibergbau besitzen, wo aber Kalilager erbohrt sind. Man will dort selbstverständlich unter keinen Umständen auf den Kalibergbau verzichten. So erscheint es nicht einmal möglich, das Entstehen neuer Werke zu verhindern, was doch Grundvoraussetzung für die Rentabilität des Monopols ist. Es ist ferner ganz sicher, daß auch diejenigen Staaten, wo noch keine Kalilager erbohrt worden sind, eine Entschädigung für die Möglichkeit und evtl. Aussicht, daß solche gefunden werden, beanspruchen. Sie werden höchstwahrscheinlich auch verlangen, bei Auffindung von Kali eine gewisse Anzahl Werke bauen zu dürfen. Hierin würde wieder eine starke Beeinträchtigung und Belastung des Reichsmonopols liegen.

Die geschilderten Schwierigkeiten sind vielleicht nicht unüberwindlich, aber sie erschweren die Durchführung der A ufgabe in gewaltigem $\mathrm{MaBe} u n d$ gefährden den ganzen $Z$ weck der Verstaatlichung insofern, als sie das finanzielle Ergebnis schwer beeinträchtigen oder in Frage stellen. Diese Bedenken kommen auch bei G. Gothein ${ }^{1}$ ) zum Ausdruck. Er ist der Ansicht, daß ohne rücksichtslose starke Verminderung der Förderpunkte (d. h. der Bergwerke) ein finanzielles Erträgnis durch das Monopol überhaupt nicht herausgewirtschaftet werden kann. Ebensowenig sei dies möglich ohne Beseitigung des Wettbewerbs, der in neu erstehenden Betrieben zu erblicken wäre. Es wird von ihm weiter anerkannt, daß die Einzelstaaten ein großes Hindernis für die Schaffung

1) a, a. O. Seite $64 / 65$. 
dieser Voraussetzungen bilden. Man wird ihm hierin durchaus zustimmen können.

Die Kaliindustrie ist auch, unter den vorgetragenen Gesichtspunkten betrachtet, - es mangelt an Bewertungsgrundlagen und die Eigentumsverhältnisse sind $\mathrm{zu}$ vielgestaltig - kein geeignetes Objekt für die Verstaatlichung.

\section{Die Erschwerung des Absatzes.}

Die Weiterentwicklung und das Emporblühen der Kaliindustrie ist hauptsächlich abhängig von der A b s a t zgestaltung und damit von den Erfolgen des Kalihandels und Kalivertriebes. Der Vertrieb des Kalis ist grundsätzlich anders zu beurteilen wie beispielsweise der Vertrieb von Tabak, Zigaretten, Alkohol und dergl. Gegenständen. Bei diesen Erzeugnissen kommt es nicht darauf an, daß der Absatz in größtmöglichstem Maße gesteigert wird, wenn dies auch im fiskalischen Interesse läge. Eine solche Steigerung kann im Gegenteil vom nationalwirtschaftlichen Gesichtspunkte aus nicht einmal erwünscht sein. Die Absatzsteigerung aber ist unbedingt notwendig beim Kali. Wenn daher die Staaten z. B. Monopole auf Genußmittel usw. eingeführt haben und diese absetzen, so folgt daraus noch nicht, daß Kali und dergl. ebenso gut von staatlichen Organen dem Verbrauch zugeführt werden kann.

Der Kalihandel stützt sich auf eine weit ausgedehnte höchst intensive Propaganda. Diese setzt eine weit verzweigte ausgedehnte Organisation voraus. So mußten im weiten Umfange Versuchsgüter angelegt, eine große Anzahl Wanderredner angestellt und andere Maßnahmen ins Werk gesetzt werden. Daneben wurde seitens der Kaliindustrie eine nachhaltige kaufmännische Reklame betrieben. Auf diesem Gebiet wird, wie schon früher ausgeführt wurde, noch Bedeutendes geleistet werden müssen, um alle wirtschaftlichen Möglichkeiten zu erschöpfen. Insbesondere müßten in weiterem Umfange Versuchsgüter angelegt werden. Es wird niemand geben, der dem Staat die Lösung dieser Aufgabe zutrauen möchte. Selbst 
die begeisterten Anhänger einer Ausbreitung der staatlichen Tätigkeit auf wirtschaftlichem Gebiet möchten nicht den Ausfuhrhandel dem Staat überantworten. So äußert sich beispielsweise Jansson ${ }^{1}$ ) dahin, daß „gegen enge Monopolfesseln des Ausfuhrhandels schwere Bedenken bestehen. Der Vertrieb industrieller Erzeugnisse auf dem Weltmarkt sei ein so kompliziertes und in seinen Bedingungen so unübersichtliches Gewerbe, daß hier nur die persönliche Initiative und Verantwortung Aussichten auf Erfolg biete. Der staatlich organisierte Warenaustausch während des Krieges hebe diese Bedenken nicht auf. Dieser Austausch sei nur möglich gewesen, weil sowohl deutscherseits wie von seiten des neutralen Landes die Regierung als vertragschließender Teil aufgetreten sei." Diesen Ausführungen wird man ohne weiteres zustimmen können. Hierbei ist noch außer acht gelassen, daß gegen die Betätigung des Reiches als Handeltreibender in anderen Ländern auch bedeutende politische $\mathrm{H}$ indernisse bestehen, die in dem Austauschhandel während des Krieges wegfielen. Im Interesse der Steigerung des Absatzes ist es notwendig, nach den einzelnen Ländern zu verschiedenen Preisen zu verkaufen. Für die Preisgestaltung kommen in Frage die Żahlungsfähigkeit der Ảbnehmer, der Verwendungszweck der Kalisalze, der Stand des Absatzes nach dem betreffenden Gebiet usw. Die verschiedene Preisstellung ist dem Syndikat ohne weiteres möglich. Wie aber sollte das Reich als Monopolinhaber den einzelnen Ländern gegenüber die verschiedenen Preise rechtfertigen? Es ist unschwer vorauszusehen, daß alle die Einräumung des niedrigsten Preises fordern würden. Das Ergebnis würde sein, entweder Verzicht auf Mehrgewinne in Ländern, wo sich hohe Preise erzielen ließen, oder Beeinträchtigung des Absatzes. Man kann sich außerdem nicht vorstellen, daß das Deutsche Reich Niederlassungen, Lagerplätze und dergleichen für eigene Rechnung in einem fremden Lande errichten könnte. Dieselben Gründe, die gegen die Uebernahme des Ausfuhrhandels

1) Monopolfrage und Arbeiterklasse, S, $245 \mathrm{ff}$. 
durch den Staat sprechen, liegen natürlich auch beim Handel im Inlande vor. Es wird a u h hier nicht möglich sein, da $B$ der Staat rein technisch genommen die Leistungen des Handels zu vollbringen vermag. Grund hierfür ist die Eigenartigkeit des staatlichen Betriebes. Negativ hat sich dies auch daraus ergeben, da $\beta$ bei der Organisation der Kriegswirtschaft der Handel zunächst ganz oder zum großen Teil ausgeschaltet wurde, später aber, als man sah, daß man ihn nicht ersetzen konnte, seine Mitwirkung wieder gesucht wurde. Außerdem liegen beim Kali die Verhältnisse hinsichtlich der Preisgestaltung sehr ungünstig. Sie würden beim Staatsbetrieb wesentlich beeinflußt werden von dem politischen Einfluß der Abnehmer. Da der Hauptabnehmer von Kali die Landwirtschaft ist, so ist $\mathrm{zu}$ befürchten, daß diese durch die Parlamente, wo es immer nur möglich wäre, gegen Preiserhöhungen agitieren und stimmen ließe. Aus allen diesen Gründen wird die Frage, ob das Reich den Vertrieb des Kalis selbst übernehmen könne, aus der Erörterung ausscheiden müssen. Unter dieser Voraussetzung aber würde dás Monopol nur eine halbe Maßregel sein von zweifelhaftem wirtschaftlichen Wert.

Es wäre nunmehr denkbar, daß der Staat in Ansehung der dargelegten Bedenken und des hohen Risikos von dem Plan eines Monopols, das sich sowohl auf den Besitz der Kaliwerke und deren Betrieb als auch den Absatz der Kalierzeugnisse durch den Staat gründet, absähe und statt dessen zu einer Modifikation dieses Planes schreiten würde. Theoretisch wären unter der Voraussetzung, daß die Werke und Anlagen durch den Staat erworben würden, folgende Monopolgestaltungen möglich:

1. Das Reich erhält ein Besitz-, Betriebs- und Handelsmonopol. Es kauft danach sämtliche Kaliwerke und Kalivorkommen, betreibt die Werke und vertreibt die Erzeugnisse.

2. Das Reich erhält ein Besitzmonopol und verpachtet die Betriebsanlagen und den Absatz der Erzeugnisse. 
3. Das Reich erhält ein Besitz- und Betriebsmonopol und läßt die Erzeugnisse durch eine Vertriebsgesellschaft verkaufen.

Der erstgenannte Fall stellt das Staatsmonopol in seiner reinsten Form dar. Der Privatbetrieb ist ganz ausgeschaltet und durch den Staatsbetrieb ersetzt. Erzeugung und Vertrieb der industriellen Produkte geschehen durch den Staat.

In dem Falle zu 2 beschränkt sich die Ausübung der Monopolrechte seitens des Staats auf das Eigentum an den Werken, während der Betrieb der Werke und der Absatz der Erzeugnisse der privaten Industrie und dem privaten Handel überlassen bleibt.

In dem zu 3 erwähnten Fall hat der Staat nur den Vertrieb der Erzeugnisse einer privaten Gesellschaft übertragen, während er selbst die Werke betreibt und in vollem Umfange Erzeuger bleibt.

In allen genannten Fällen 'muß der Staat die Bergwerke, Felder und Fabriken erwerben. Das Risiko, das mit diesem Erwerb verbunden ist, ist in allen Fällen gleich groß und bleibt unverändert bestehen. Daher bestehen auch sämtliche zu diesem Punkt aufgeführten Bedenken gegen die unter 2 und 3 aufgeführten Abarten des Monopols in voller Kraft weiter. Es liegt auch hier die Gefahr vor, da $\beta$ eines Tages eine enorme Entwertung der Anlagen eintritt und damit eine gewaltige Schädigung der Staatsfinanzen erfolgt. Daher werden diese Monopolabarten von vornherein ebenso unmöglich wie ein in bezug auf Eigentum, Betrieb und Handel vollständig durchgeführtes Monopol. Die Verpachtung der Anlagen ist im übrigen ohne jede praktische Bedeutung. Es ist nicht daran zu denken, $\mathrm{da} B$ das Reich einen so ungeheueren Betrieb einer oder mehreren Privatgesellschaften verpachten könnte. Die hierzu nötigen Verträge würden sich zu kompliziert gestalten. Eine genaue Abgrenzung der Rechte und Pflichten der Vertragschließenden wäre kaum denkbar. Abgesehen hiervon aber würde auch mit Recht bezweifelt werden können, daß sich eine private Gesellschaft bereit fände, 
einen solchen Betrieb zu übernehmen, um so weniger, als der Staat den weitaus größten Teil des Gewinns beanspruchen müßte. Es könnte auch vom Standpunkt des Staatsinteresses und des Gemeinwohls nicht verantwortet werden, einer privaten Gesellschaft, die die Werke nicht im Eigenbesitz hat und als Eigentümerin für ihre Erhaltung sorgt, die Verwaltung so gewaltiger staatlicher Vermögenswerte zu übertragen.

Ein wesentliches praktisches Interesse beansprucht lediglich noch der Fall, wo der Staat den Vertrieb der Salze einer privaten Gesellschaft übertragen könnte. Denkbar wäre es, daß der Staat sich an dieser Vertriebsgesellschaft maßgebend beteiligen würde, so daß er zunächst eine Einnahme aus der Erzeugung der Salze und dem Verkauf derselben an die Vertriebsgesellschaft erzielen könnte und ferner an dem Gewinn der Vertriebsgesellschaft beteiligt wäre. Diese Konstruktion ist nicht unbekannt. Sie hat gewisse Aehnlichkeit mit den Gründungen amerikanischer Trusts. In dem vorliegenden Fall liegen die Verhältnisse jedoch wesentlich anders. Ein solcher Plan würde, wenn er praktisch in Frage käme, ohne weiteres das Eingeständnis enthalten, daß der Staat sich nicht imstande fühlt, die Absatzorganisation in die Hand zu nehmen. Wie würde sich nun in der Praxis der Vertrieb der Salze durch die Vertriebsgesellschaft und das Verhältnis des Staates zu ihr gestalten?

Die Vertriebsgesellschaft müßte sich auf der durch das Syndikat geschaffenen Grundlage aufbauen und auch möglichst dieselben Beamten beibehalten. Der Staat müßte bei Durchführung dieses Gedankens seine ganze Produktion an diese Gesellschaft absetzen und sich hierzu verpflichten. Seine Abhängigkeit von ihr, die alle Beziehungen zu den Abnehmern in der Hand hätte, würde wahrscheinlich bald größer sein wie umgekehrt der Gesellschaft vom Staat. Da sich eine solche Organisation nicht ohne große Kosten und Zeitverlust schaffen läßt, so wäre der Staat dauernd auf sie angewiesen. Ohne ausreichenden Gewinn würde die Vertriebsgesellschaft nicht arbeiten können, und es ist nicht 
anzunehmen, daß sie mit denselben Unkosten, wie sie beim Syndikat bestehen, den Vertrieb des Kalis vornehmen könnte. Aller Wahrscheinlichkeit nach würde das Ergebnis nur eine Erhöhung der Handelsunkosten sein ohne größere Leistungen. Es kommt außerdem noch ein nachteiliger Umstand in Frage: Das Interesse an der Steigerung des Absatzes kann bei einer Vertriebsgesellschaft nur ein relatives sein. Es ermangelt der Unmittelbar. keit wie beim Syndikat, das aus der Gesamtheit der Erzeuger besteht. Dies Interesse könnte nur bestehen in dem Handelsgewinn an der Menge eines $\mathrm{dz} \mathrm{K}_{2} \mathrm{O}$, die die Gesellschaft mehr abzusetzen in der Lage wäre. Dies gilt unter der Annahme, daß der Vertrieb der Salze, wie es auch anders gar nicht möglich wäre, auf der Grundlage erfolgt, $\mathrm{da} B$ ihr am Absatz eines dz $\mathrm{K}_{2} \mathrm{O}$ ein gewisser Handelsgewinn zugebilligt würde. Bei dieser Sachlage aber ist es kaum zweifelhaft, daß der Mehrgewinn, den die Gesellschaft am Mehrabsatz macht, nicht die erhöhten Propagandakosten decken würde. Der Gewinn an einem Mehrabsatz kommt bekanntlich fast ausschließlich nur den Kaliwerken, in unserm Falle dem Staat, zugute, und zwar in der Form einer erheblichen Verringerung der Selbstkosten. Höchstwahrscheinlich würde daher die Uebertragung des Absatzes an eine besondere Gesellschaft eine $\mathrm{S} t \mathrm{a} g \mathrm{n}$ a t i o $\mathrm{n}$ desselben bedeuten, während doch erstes und unbedingtes Erfordernis für das Gedeihen der Kaliindustrie ist, daß der Absatz steigt, und zwar möglichst schnell und bedeutend steigt. $\mathrm{Ob}$ eine Absatzprämie diese Gefahr ausschließen könnte, ist sehr fraglich.

In einer Vertriebsgesellschaft mit maßgebender staatlicher Beteiligung würde dieses Bedenken zum Teil in Fortfall kommen, weil der Staat als Besitzer der Werke ein unmittelbares Interesse an der Absatzsteigerung hat. Dagegen wird naturgemäß bei einer solchen Gesellschaft auch bald der staatliche Einfluß und der Beamtengeist seinen Einzug halten. Bei der Besetzung der einzelnen kaufmännischen Stellen wird staatlicher Einfluß ausschlaggebend werden. Eine solche Gesellschaft wird schon nach 
verhältnismäßig kurzer Zeit nicht mehr so gut arbeiten wie ein privates Unternehmen. Die Nachteile des Staatsbetriebs werden sich sehr bald auch hier einstellen.

Gegen eine Vertriebsgesellschaft, sei es mit oder ohne staatliche Beteiligung, bestehen außerdem dieselben Bedenken politischer Natur wie gegen den Vertrieb durch den Staat selbst. Es ist nicht einzusehen, daß die fremden Staaten einen wesentlichen Unterschied zwischen dieser Vertriebsgesellschaft, die im staatlichen Auftrage und vielleicht unter staatlicher Beteiligung arbeitet, und dem Deutschen Reich machen würden. Sie würde deshalb in ihrem Absatz auf dieselben Hindernisse und Schwierigkeiten im Auslande stoßen, die dem Staat selbst begegnen würden, wenn es ihm einfallen sollte, den Vertrieb der Salze zu übernehmen. Ueber eine derartige Auffassung der Sachlage durch das Ausland braucht man sich um so weniger zu wundern, als dieselbe auch bei uns herrscht. Es darf hier nur an das Beispiel der Anglo-Persian Oil Company erinnert zu werden, an der die englische Admiralität hervorragend interessiert ist. Weder die deutsche Presse noch die öffentliche Meinung haben jemals diese Gesellschaft als etwas anderes angesehen als eine zur Versorgung der englischen Marine mit Heizöl umgestaltete und hauptsächlich für diesen $Z$ weck und damit im staatlichen Interesse arbeitende Gesellschaft. Man wird zugeben müssen, daß es schwer ist, zwischen ihr und dem englischen Staat einen Unterschied zu machen. Es kann hier u. a. auch darauf hingewiesen werden, daß, als die schwedische Regierung. verschiedene Verträge mit schwedischen Erzgesellschaften bzgl. des Absatzes der Erze nach dem Auslande schloß, deutscherseits eine scharfe Prüfung und Durchsicht derselben erfolgte zum Zwecke der Feststellung, ob sie nicht in Widerspruch mit den bestehenden Handelsverträgen ständen.

Aus allen diesen Gründen wird man in der Uebertragung des Absatzes der Salze an eine Vertriebsgesellschaft keine wesentliche Verbesserung des ursprünglichen Monopolgedankens sehen können, weil die gegen das Mono- 
pol vorgetragenen Bedenken, namentlich das hohe Risiko, in unveränderter Weise fortbestehen und die von der Vertriebsgesellschaft sowohl in finanzieller wie in handelstechnischer Hinsicht erwarteten Vorteile sehr zweifelhafter Natur sind. Im wesentlichen bliebe die Vertriebsgesellschaft ein Versuch. Erst die Erfahrung müßte lehren, ob ein so enges Zusammenarbeiten des Staats mit einer privaten Gesellschaft beim Absatz eines Erzeugnisses Vorteile bietet und möglich ist. Jedenfalls wird man sagen können, daß die Gründung einer solchen Gesellschaft dem Reich und der Allgemeinheit nicht die Vorteile bringen und sichern kann, die man von der Einführung des Monopols erwarten müßte und die es rechtfertigen könnten.

In diesem Zusammenhang ist noch auf die Frage des Handelsmonopols einzugehen. Es sind hierbei folgende Fälle zu unterscheiden:

1. Das Reich übt das Handelsmonopol selbst aus, d. h. es erwirbt und vertreibt die Erzeugnisse.

2. Das Reich erwirbt die Kalisalze von den Zechen und läßt sie von einer besonderen Vertriebsgesellschaft, an der es sich gegebenenfalls beteiligt, verkaufen.

Der Gewinn an der Erzeugung. wird zunächst in beiden Fällen zwischen Zechen und Reich geteilt. Was den Han. delsgewinn angeht, so wird im ersten Fall das Reich ihn ganz behalten, während er im zweiten Fall der Vertriebsgesellschaft zufällt. Wenn sich aber das Reich an dieser Gesellschaft beteiligt, würde es noch einen Teil des Handelsgewinnes erhalten. Die Einnahme des Reichs würde sich dann zusammensetzen aus dem Preisunterschied zwischen Einkaufs- und Verkaufspreis der Salze an die Vertriebsgesellschaft und dem Gewinn aus der Beteiligung an der letzteren. Die erste Einnahme stellt lediglich eine Besteuerung der Kaliindustrie dar. Da der Besteuerung keine schwerwiegenden Bedenken entgegenstehen, so könnten dem Reich diese Einkünfte auch ohne Monopol zufließen. Der Anteil am Handelsgewinn der Vertriebsgesellschaft wird gegenüber dieser Einnahme gering sein. Wäre er hoch, so müßten die privaten Kreise, die an der 
Vertriebsgesellschaft' interessiert sind, auch entsprechend viel verdienen. Letzten Endes wird dies allerdings von der Regelung des Verhältnisses dieser Gesellschaft zum Staate, insbesondere von den Abmachungen über die Gewinnverteilung, abhängen.

Bei einem Handelsmonopol kann von vornherein keine Rede davon sein, da $B$ durch Betriebszusammenlegung und andere Maßnahmen eine starke Verminderung der Selbstkosten zu erreichen sei, wodurch das Reich angeblich schon ohne weiteres große Gewinne machen würde. Alle Vorteile, die sich aus der Vereinheitlichung der Unternehmungen in der Kaliindustrie ergeben könnten, fallen ohne weiteres fort. Nach Paxmann ${ }^{1}$ ) soll in der Zusammenfassung der Betriebe in einer Hand sogar der Hauptnutzen des Monopols liegen, der es erst wirklich rechtfertigt. Wie schon früher gezeigt, ist die Annahme, daß Betriebe in großem Maße zusammengelegt werden könnten, nichts anderes als eine Illusion. Es ist indessen interessant, festzustellen, daß bei dem Plan eines Handelsmonopols, der in neuerer Zeit anscheinend Anhänger gewinnt, von vornherein auf die Hauptvorteile, die sich die Monopolfreunde, bisher konstruiert hatten, verzichtet wird.

Der Hauptvorteil des Handelsmonopols wird indessen darin gesucht, daß es den Besitzstand der Kaliwerke unangetastet läßt. Diese erhalten nur die Verpflichtung auferlegt, ihre gesamte Erzeugung an Kalisalzen an das Reich abzusetzen. Damit will man das gewaltige Risiko, das mit dem Erwerb der Werke und Fabriken verbunden ist, vermeiden. Die Vermeidung des Risikos ist in dessen nur scheinbar. Wenn das Reich durch den Ankauf der Kalisalze von den Werken und den Weiterverkauf derselben an die Verbraucher oder an eine Vertriebsgesellschaft einen einigermaßen ins Gewicht fallenden Gewinn machen will, so wird es den Zechen nur so viel Fabrikationsgewinn bewilligen können, daß eine normale Verzinsung des Anlagekapitals erfolgt. Hierbei darf festgestellt werden, daß

1) a, a. O. Seite 76 . 
die Rentabilität der Kaliindustrie noch gewaltig steigen muß (die meisten Kalipapiere sind bis jetzt ertraglos geblieben), wenn dem Reich nach Verzinsung der privaten Anteilswerte überhaupt ein Gewinn verbleiben soll. Die Beschränkung der Gewinne bzw. der Rentabilität der einzelnen Werke auf ein bestimmtes $\mathrm{Maß}$ gibt den Kaliwerten den Charakter eines Papiers, dessen Verzinsung nach oben begrenzt ist, dagegen durchaus keine Garantie besitzt, daß es gewisse Mindestzinsen erhält. Es kann jederzeit dividendenlos bleiben. Daher kann auch ein Gewinnausgleich zwischen guten und schlechten Jahren nicht stattfinden. Dabei bleibt den Besitzern von Kalipapieren das gesamte Risiko des Kalibergbaues a uf g ebürdet. Die Kaliwerte haben daher nicht einmal die Vorzüge eines festverzinslichen Papiers. Diese Tatsache wird sich auch dann nicht ändern, wenn das Reich die Verzinsung über dem Satz der festverzinslichen Werte halten würde, womit auch nicht einmal gerechnet werden kann. Die Eigentümer von $\mathrm{K}$ aliwerten verlieren mit einer solchen Maßnahme wohIerworbene Rechte. Eswirdihnen mitder Einführung eines Handelsmonopolsdie Aussicht a uf $\mathrm{Gewinngenommen,} \mathrm{a} \mathrm{ufdensierechtmä} \mathrm{Big}$ Anspruch haben. Die Gewinnaussicht ist maßgebend gewesen beim Ankauf der Anteile und für die Einschätzung des Wertes derselben. Nur diese konnte allein die Anteilseigner dazu bringen, das mit dem Erwerb der Papiere verbundene Risiko des Bergbaues auf sich zu nehmen. Es ist deshalb ganz sicher zu erwarten, daß als Folge einer solchen Maßnahme die Kalipapiere sofort eine starke Entwertung erfahren würden, die große Kapitalverluste nach sich ziehen müßte. Hiervon würden weite Kreise, auch solche des Mittelstandes, betroffen werden, um so mehr als während des Krieges die Kalipapiere in hohem Maße. den Besitzer gewechselt haben. Ferner haben diejenigen, welche ihre Werte während des Krieges behalten haben, hohe Kriegsgewinnsteuern, Vermögenşabgaben usw. auf Grund der Kurssteigerung zahlen müssen. Diese Tat- 
sachen begründen unzweifelhaft eine. Entschädigungspflicht des Staates. Der wirtschaftliche Gedanke, der in einem Staatsmonopol liegt, beruht unbestritten darauf, daß der Staat die Produktionsmittel und sonstigen Vermögenswerte einer Industrie gegen volle Entschädigung bzw. zum Tageswerte übernimmt und durch eine einheitliche Bewirtschaftung und Ausnutzung des Alleinbesitzes Einnahmen erzielt, die der betr. Industrie oder Gewerbezweig in der alten Gestaltung und unter den zersplitterten Besitzverhältnissen nicht möglich wären. Dieser Gedanke kann auch nur bei einem Handelsmonopol maßgebend sein. Der Staat wird das Monopol nicht darauf gründen können, daß er auf gewaltsame unrechtmäßige Weise den Besitzern der Erzeugungsstätten den Gewinn wegnimmt und die Anlagen entwertet, und dagegen ihnen das Risiko in vollem Umfange überläßt. Dieses würde eine Ausnahme-Gesetzgebung allerschlimmster Art sein. Auf diese Weise könnte sich der Staat schließlich zum Besitzer sämtlicher wirtschaftlicher Unternehmungen in seinem Machtbereich machen. Es würde natürlich ebenso leicht möglich sein, der Kohlenindustrie durch Einführung eines Kohlenhandelsmonopols die Gewinne wegzunehmen und damit die Anlagen zu entwerten, um sie später selbst zu billigen Preisen ankaufen zu können. Auch bei jeder anderen Industrie oder Wirtschaftszweig könnte dasselbe sich ereignen.

Es könnte hier eingewandt werden, daß der Staat gemäß den Bestimmungen des Kaligesetzes schon jetzt die Preise der Kalisalze festsetzt und damit die Rentabilität der Kalipapiere bestimmt. Dieser Einwand übersieht indessen die Tatsache, daß die Kaliindustrie bis heute in der Lage war - abgesehen von der Verpflichtung, für das Ausland gewisse Mindestpreise einzuhalten -, die Auslandspreise nach Belieben hoch zu bemessen. Es wurde schon früher darauf hingewiesen, daß bei den Auslandsverkäufen der meiste Gewinn gemacht wird. $\mathrm{Da}$ in $\mathrm{Zu}$ kunft eine bedeutende Steigerung des Auslandsabsatzes zu erwarten steht, so fällt dieser Gewinn noch weit mehr 
als bisher für die Rentabilitätsgestaltung ins Gewicht. Bleibt deshalb Tatsache, daß ein Handelsmonopol die Rentabilitätsverhältnisse der Kaliindustrie außerordentlich zuungunsten der Werke verschieben würde.

Es ist nicht anzunehmen, daß der Plan, die Anteilseigner ohne Entschädigung $\mathrm{zu}$ lassen, besteht. Seine Verwirklichung müßte die Grundlage unseres ganzen Wirtschaftslebens erschüttern. Erkennt aber der Staat, wie es vorauszusehen ist, die Entschädigungspflicht'an, so bleibt auch bei einem Handelsmonopol das gesamte Risikobestehen, dasindem Erwerbder Werke liegt. Damit abertreten alle Bedenkengegen ein Monopol, das sich a uf den Besitzder Werke durch den Staat gründet, wieder in volle Wirkung und machen es unmöglich. Die Entschädigungspflicht muß sich naturgemäß auf Ersatz des Kursunterschiedes der Papiere, der sich zwischen dem jetzigen Stande und der Zeit nach Einführung des Handelsmonopols herausbildet, erstrecken. Bei allen Mängeln, die die Kursbildung auf weist, bleibt trotzdem der Kurs noch die beste Wertbemessung, weil bei seiner Bildung alle $\mathrm{Zu}$ kunftsmöglichkeiten und Ertragsaussichten am besten eingeschätzt worden sind. Auch eine Abschätzung des gegenwärtigen Wertes durch eine Kommission müßte die Momente berücksichtigen, die zu der jetzigen Kursgestaltung geführt haben.

Es ist notwendig, an dieser Stelle die Möglichkeit, bei der Einführung eines Handelsmonopols die Entschädigungspflicht $\mathrm{zu}$ umgehen, näher zu erörtern. An sich könnte der Staat die bisherige Rentabilität der Kaliwerke bestehen lassen, indem er die jetzigen Verkaufspreise der Kalisalze als Uebernahmepreise für das Reich gelten ließe, dann aber seinerseits die Preise für die Abnehmer derartig erhöhen würde, daß ihm ein ausreichender Gewinn für das Monopol verbliebe. Man kann zugeben, daß der Staat eine solche Presserhöhung vornehmen könnte. Dies trifft indessen nur theoretisch zu. Die Höhe der Preise bei Aus- 
landsverkäufen ist von rein natürlichen Bedingungen abhängig, die in der Hauptsache darin zu sehen sind, daß der Landwirt nur dann Kalidüngung anwenden wird, wenn ihm das dadurch erzielte Mehrerträgnis einen ausreichenden Nutzen im Verhältnis zu den aufgewandten Kosten sichert. Außerdem wird dabei berücksichtigt werden müssen, daß, wenn die Preise zu hoch angesetzt werden, die Gefahr besteht, da $B$ andere Gewinnungsarten rentabel werden und die fremden Staaten diese Verfahren durch Zollmaßnahmen schützen, um sich von Deutschland unabhängig zu machen. Hinzu kommt, daß voraussichtlich in den nächsten Jahren durch die ausländischen Funde außerdeutsche Kaliwerke entstehen werden, wodurch eine weitere Begrenzung der Preismöglichkeiten eintritt.

Sind der Preisstellung bei Auslandsverkäufen schon bestimmte Grenzen gezogen, so ist dies noch mehr bei Verkäufen im Inlande der Fall. Es bedarf keiner Ausführung; daß eine Erhöhung zu dem Zwecke, dem Staat bei der Einführung des Handelsmonopols einen erheblichen Gewinn zu verschaffen, die Urproduktion bedeutend verteuern würde und nichts weiteres darstellen würde, als eine Sonderbesteuerung der Landwirtschaft. Zwar ist die Auffassung, in dem Handelsmonopol eine steuerliche Maßnahme zu sehen, die den Zweck hat, Abgaben auf Gegenstände des täglichen Bedarfs, in der Hauptsache auf Genußmittel, die im Inlande abgesetzt werden, im vollen Umfange durchzuführen und zu steigern, nicht unbekannt. In der Regel wurde dabei der Auslandsabsatz dem freien Handel überlassen, und es wurde sogar gestattet, daß die im Inlande nicht unterzubringende Menge im Auslande zu billigen Preisen abgestoßen würde ${ }^{1}$ ). Der Auslandssatz spielt dabei kaum eine Rolle.

Die Kalisalze sind indessen ein ganz anders geartetes Objekt. Es kommt gerade hier darauf an, dem Auslande zu möglichst hohen Preisen und möglichst viel zu verkaufen, wie es bisher durch das Syndikat geschehen ist. Ferner ist S. $887 \mathrm{ff}$.

1) Vergl. Gesetz über das Branntweinmonopol $\S 133$ R.G. Bl. 
die steuerliche Erfassung im Inlande ohne Handelsmonopol restlos möglich. Es bedarf deshalb nicht zu deren Durchführung einer so tief in das Wirtschaftsleben eingreifenden Maßnahme. Man wird daher nach wie vor den Sinn und Zweck des Monopols - wenn ein solcher überhaupt auffindbar wäre - in einer größeren Wirtschaftlichkeit suchen müssen, welche Gewinne ermöglicht, die ohne Monopol sonst nicht möglich sind. Als bloße Steuermaßnahme ist es beim Kali durchaus verfehlt.

Die Einführung eines Handelsmonopols würde ferner zur Folge haben : daß es den Werken nach Einführung eines Handelsmonopols voraussichtlich unmöglich sein wird, das nötige Kapital für Erweiterungen und technische Verbesserungen $\mathrm{zu}$ erhalten. $\mathrm{Zu}$ Investitionen zur Verwirklichung des ökonomischen Prinzips und des technischen Fortschritts wird bei Privaten um so weniger Neigung bestehen, als nur der Staat Vorteile davon haben würde. Damit würde auch die Entwicklung der Nebenproduktengewinnung unmöglich werden. Bei einem Handelsmonopol wird die technische Weiterentwicklung noch viel eher zum Stillstand kommen, als bei einem Besitzmonopol, weil das Eigeninteresse, das der Staat an der Entwicklung seiner Werke hat, hier fortfällt.

Bei einem Handelsmonopol hätte außerdem der Staat gerade diejenige Aufgabe übernommen, für die er am wenigsten geeignet und die zu erfüllen am schwersten ist, nämlich den Vertrieb der Salze. Es erübrigt sich, die Bedenken nochmals aufzuzählen, die gegen den Handelsbetrieb durch Organe des Staats sprechen. Es darf als ausgeschlossen betrachtet werden, daß der Staat als solcher den Vertrieb übernimmt bzw. übernehmen kann. Es bliebe somit auch hier nichts anderes übrig, als einer Vertriebsgesellschaft den Absatz der Kaliprodukte zu übertragen. Der Staat könnte, wie schon gesagt, sich an ihr nach Belieben beteiligen oder sie ganz dem privaten Besitz überlassen. Da nicht damit $\mathrm{zu}$ rechnen ist, $\mathrm{da} B$ eine neue $\mathrm{Ab}$ satzorganisation neben dem Syndikat der Kalizechen geschaffen werden kann, so wird der Staat sich wegen des 
Vertriebs der Salze wieder an das Syndikat wenden müssen. Der Vertrieb könnte gegen eine Kommissionsgebühr geschehen oder der Staat könnte auch die Salze dem Syndikat mit einem Aufschlag verkaufen. Es ist auch hier nicht einzusehen, daß die vielen Umständlichkeiten und der große Aufwand, den ein Monopol erfordert, notwendig sind, um dem Staat eine Einnahme, die im Wesen nichts anderes als eine Steuer ist, zuzuführen. Außerdem bewirkt die damit verbundene Häufung von Organisationen eine wesentliche Erhöhung der Handelsunkosten und erzeugt unzweifelhaft eine größere Schwerfälligkeit und Umständlichkeit bei der Regelung des Absatzes. Man kann sich um so weniger mit diesem Gedanken befreunden, als dadurch ein sehr, wichtiger Industriezweig der privaten Initiative und Schaffenskraft entzogen und in staatliche Fesseln geschlagen wird. Das Handelsmonopol ist auch besonders deshalb bedenklich, weil dadurch in dem sicher bevorstehenden Konkurrenzkampf mit ausländischen Industrien die freie Beweglichkeit der Industrie und des Kalihandels lahmgelegt wird, und dies gerade in einem Zeitpunkt, wo diese Freiheit von hoher Bedeutung ist. D i e private Industrie würde sicherlich, wie früher schon angedeutet wurde, viel eherimstande sein - wenn eine solche Möglichkeit besteht mit dem a usländischen Wettbewerb durch Preisvereinbarungen, Einigung über Absatzgebiete, Preiskampf usw. fertig zu werden, als es dem Staat möglich sein wird. Die ausländische Konkurrenz wird es leicht haben, die Hilfe der eigenen Regierung oder derjenigen befreundeter Länder zu erhalten, wenn es sich um den Kampf gegen den Wettbewerb eines Erzeugnisses handelt, über welches das Deutsche Reich verfügt, woraus es Einnahmen zieht und dessen Vertrieb staatliche oder halbstaatliche Organe besorgen.

Den Gedanken eines Handelsmonopols wird man aus den erwähnten Gründen als ungeeignet ablehnen müssen. 


\section{Die handelspolitische Gefahr.}

Aus der Einführung eines Staatsmonopols erwächst eine weitere Gefahr, die den Erfolg des Auslandsabsatzes und damit der hauptsächlichsten Verdienstmöglichkeit an Kali überhaupt in Frage stellt. Diese Gefahr liegt in der Möglichkeit und Wahrscheinlichkeit, daB die Kalipreise Verhandlungsobjekt beim AbschluBvion Handelsverträgen mit anderen Staaten werden. Diese Möglichkeit rückt sofort in greifbare Nähe, wenn sich der Staat in irgendeiner Weise die Verfügung über die Produkte der Kaliindustrie verschafft, wobei es keinen Unterschied macht, in welcher Art dies geschieht. Es ist dabei gleich, ob die Verfügungsgewalt des Staates auf einem auf den Besitz der Werke und Fabriken sich gründenden Monopol oder auf einem reinen Handelsmonopol beruht. Es dürfte ferner bedeutungslos sein, wenn der Staat sich seiner Rechte wieder teilweise begibt, indem er den Absatz durch eine besondene Vertriebsgesellschaft besorgen läßt. Daß die erwähnte Gefahr sehr bald praktisch werden würde, steht zu erwarten. Es ist bekannt, daß Deutschland in der Hauptsache ein weiterverarbeitendes Land ist und auf die Einführung zahlreicher Rohstoffe usw. angewiesen ist, die zur Aufrechterhaltung unseres Wirtschaftslebens unbedingt nötig sind. Das Uebergewicht, das unsere wirtschaftlichen Vertragsgegner damit besitzen, werden sie sicherlich bald ausnutzen. Es könnte vielleicht dadurch ausgeglichen werden, daß auch wir über Rohstoffe verfügen, die das Ausland unbedingt braucht. Dieses trifft bei den Kalisalzen zu. Trotzdem würde der Glaube, da B mit den $\mathrm{Kal}$ isalzeneingewaltigerhandelspolitischer Druck auf die anderen Staten bei AbschluB von Handelsverträgen und bei Beschaffung der Rohstoffe ausgeübt werden könnte, wenig Berechtigung haben. In dieser Beziehung ist unsere Position aus doppelten Gründen sehr schwach. Wie schon gezeigt, gibt es außer zahlreichen anderen 
Kaliquellen reiche Lager in Spanien und wahrscheinlich auch in anderen Ländern. Nach einigen Jahren werden außer den deutschen zahlreiche fremde Bezugsquellen vorhanden sein. Ebenso wichtig ist aber, da $\beta$ die fremden Staaten die Verfügung über Erzeugnisse haben, die für uns nach Menge und Art von weit höherer Bedeutung sind als unser Kali für das Ausland. Man braucht hierbei. nur an Baumwolle, Wolle, Kupfer, Gummi, Phosphate usw. zu denken. Auch rein zahlenmäßig prägt sich dieses Verhältnis aus. Nach Nordamerika, welches unser bestes ausländisches Absatzgebiet für-Kali darstellt, wurden 1913 für etwa 68 Millionen Kalisalze ausgeführt. Von dort. wurden dagegen bezogen:

Baumwolle . . . im Werte von 561 Millionen Mark

\begin{tabular}{|c|c|c|c|c|c|}
\hline Kupfer & & , & , & 294 & " \\
\hline Weizen & & & ", & 164 & " \\
\hline Schweineschmalz & ," & ", & & 112 & " \\
\hline Felle. & , & , & ", & 66 & " \\
\hline rdöl & & , & , & 53 & " \\
\hline
\end{tabular}

Wenn auch infolge neuerer Erfindungen und der Erschließung neuer Zufuhrgebiete diese Zahlen Abänderungen erfahren werden, so ist doch damit $\mathrm{zu}$ rechnen, daß der natürliche Austausch, wie er zwischen den einzelnen Ländern bestand, allmählich wieder ungefähr dasselbe Verhältnis annehmen wird. Die Zahlen dürften zeigen, auf welcher Seite die Abhängigkeit größer wäre. Unter diesen Umständen kann mit Sicherheit angenommen werden, daB das Ausland bei dem Abschluß von Handelsverträgen an das das Monopol in habende Reich die Forderung. stellen würde, die Kalisalze zu mäßigen Preisen zu liefern. Wahrscheinlich würde das Ausland nicht mehr zahlen wollen als die deutsche Landwirtschaft. Die Forderung der fremden Staaten würde den nötigen Nachdruck verliehen erhalten durch Androhung von Ausfuhrzöllen und anderen Maßnahmen. Im Augenblick aber, wo diese Gefahr aufträte, würde ein Kalimonopol zu einer Waffe werden, die sich gegen die deutschen Interessen selbst kehren würde. 
In diesem Zusammenhang ist auch die Frage des A usfuhrzolles zu erledigen. Zwar steht die Zollfrage mit der Verstaatlichung nicht unmittelbar in Verbindung. Sie hat hier insofern einige Bedeutung, als eine Zollabgabe solche finanzielle Erträgnisse liefern könnte, da $B$ sich die Einführung eines Monopols vielleicht erübrigen würde. Der zu erhebende Zoll könnte seiner Natur nach nur Finanzzoll sein. Ihm unterliegen würden nur die Ausfuhrmengen, d. h. ungefähr die Hälfte der Erzeugung an Kalisalzen. Die Erträgnisse, die der Zoll liefern könnte, würden demnach von vornherein auf eine gewisse Höhe beschränkt bleiben. Ein Vergleich mit dem Monopol ist schon deshalb nicht angängig.

Wenn ferner eine ausländische Industrie entsteht, so würde der Auslandsabsatz sicherlich stark schwanken und erheblich zurückgehen; daher wäre eine auf die Zollabgabe basierte Reichseinnahme höchst unsicher und schwankend. Es ist weiter zu berücksichtigen, daß die ausländischen Abnehmer schon erheblich höhere Preise für die Kalisalze zahlen. Wenn der Zoll wirklich bedeutende Summen einbringen sollte, würden die ausländischen Kalipreise sich sehr schnell dem Punkt des Grenznutzens nähern. Abgesehen hiervon aberwürde der Zoll Repressiv-MaBregeln der fremden Staten hervorrufen. Es müßte unsererseits mit Ausfuhrzöllen auf Baumwolle, Phosphat, Erze usw. gerechnet werden ${ }^{1}$ ). Auf jeden Fall wird das Ausland versuchen, bei dem Abschluß von Handelsverträgen den Zoll zu beseitigen oder seine Niedrighaltung zu erreichen. Es bestehen mithin gegen einen Ausfuhrzoll im wesentlichen dieselben Bedenken handelspolitischer Natur, wie sie bei Besprechung des Monopols aufgeführt worden sind. Aus den aufgeführten Gründen muß der Gedanke eines Zolles auf die Ausfuhr fallen gelassen werden.

1) Vergl. Blankenstein a. a. O, S. 61 . 


\section{III.}

\section{Die finanzielle Nutzbarmachung der Kaliindustrie.}

Die Ergebnisse der Untersuchung lassen sich wie folgt zusammenfassen:

1. Für ein Staatsmonopol, sei es in der Form eines Besitz-, Betriebs-oder Handelsmonopols, fehlt die wichtigste Voraus setzung, nämlich, daß Deutschland ein aus schlieBliches Monopol an Kali besitzt. Die ausländischen Funde an Kalisalzen in Spanien, Eurithrea, RuBland und die Entstehung neuer Gewinnungsmethoden (Nebenprodukt der Zementfabrikation und des Hochofenprozesses, Eindämpfen von Laken, Zerlegung von kalihaltigen Gesteinen, Kelp usw.) haben das Monopol Deutschlands gebrochen bzw. a $\mathrm{B}$ erordentlich stark gefährdet. Diese Tat sache hat zur Folge, daB die Rentabilität eines Staatsmonopols nicht als gesichertangesehen werden kann. Diese wird a $B$ erdem erheblich beeinträchtigt durch die im Kalibergbau bestehende recht erhebliche Wassergefahr, die hohe Rückstellungen für Kapitalverluste und Bergschäden erfordert. In derselben Richtung wirkt die Feststellung, da $B$ eine weitgehende Betriebszusammenlegung nicht möglich ist, und somit a ch die von Befürwortern des Staatsmonopols 
hieraus errechneten Gewinne fortfallen. Der Monopolgedanke muB mithin aus rein privatwirtschaftlichen Gründen als ungeeignet abgelehnt werden.

2. Ein Staatsmonopol verbietet sich auch aus allgemein-wirtschaftlichen Gründen. Die Nachteile des Statsbetriebes wirken auf die Allgemeinwirtschaft höchst ungünstig zurück. Der Stat ist aus vielen Gründen nicht in der Lage, in dem gleichen Maße wirtschaftliche Werte $z$ u schaffen wie die Privatindustrie. Dieser Umstand ist entscheidend. Bei der Kaliindustrie kommen noch besonders ungünstige Momente hinzu. Die Besitzverhältnisse (staatliche Werke und Beteiligungen) erschweren den Erwerb a $u$ Berordentlich und verhinderndierestlose Durchführung der zur Ausnutzung des Monopols erforderlichen Maßnahmen. Ferner w ürde eine blühende Nebenproduktion mit Sicherheit $z$ um Erliegen und der technische Fortschritt zum Stillstand kommen. Von gleicher Bedeutung ist, da $B$ der Kaliabsatz, vondem die Blüteder Kaliindustrieabhängig ist, durch die Einführung des Staatsbetriebes nicht nur keine Förderung, sondern eine bedeutende Erschwerung erfahren würde. Hierbei spielt das politische Moment, das mit dem staatlichen oder im Auftrag des Staates erfolgenden Vertrieb des Kalis verbunden ist, eine entscheidende Rolle. Auch hier mu $B$ festgestellt werden, daß beim Handelsmonopol die erwähnten Nachteile in gleicher oder noch größerer Stärke fortbestehen. Diese Monopolart w ürde, wie gezeigt, jeden KapitalzufluB verhindern, die Schaffenskraft und das Interesse der Werksbesitzer an der Fortentwicklung ihres Besitzes 
lahmlegen. Damit w ürdedertechnische Fortschritt noch gründlicher ausgeschaltet wie bei einem Besitzmonopol. Der Hauptnachteil des Staatsmonopols liegt in der handels politischen Gefahr, die damit dem Deutschen Reich erwachsen würde. Aus diesem Grunde verbietet sich jedes Monopol, auch wenn die Voraussetzung einer gesicherten Rentabilität gegeben wäre. Um die vorgetragenen Bedenken richtig zu beurteilen, wird man ferner darauf hinweisen müssen, da $B$ die deutsche Kaliindustrie nach Beendigung des Krieges gerade der gröBten Freiheit der Entwicklung bedarf, damit sie mit dem neu a ufkommenden Wettbewerb fer. tig zu werden und ihran Absatz a uf eine Höhe zu bringen vermag, die ihr ihre zukünftige Stellung sichert. Dadurch, daB ihr staat liche Fesseln bei der Entwicklung ihres Besitzes, Ausbau ihrer Absatz-Organisation, Anknüpfung von Interessenverbindungen uș. angelegt werden, wird ihr die Erreichung dieses Zieles unmöglich gemacht.

Wenn auch der Plan eines Monopols als erledigt gelten muß, so wird es sich bei dem großen Finanzbedarf des Reiches schließlich nicht vermeiden lassen, die Kaliindustrie zu finanziellen Leistungen heranzuziehen. In welchem Maße dies geschehen kann, hängt zunächst von der finanziellen Lage der Industrie ab. Hierzu ist festzustellen, daß sich die Kaliindustrie infolge des Fortfalls des Auslandsabsatzes während des Krieges in sehr ungünstiger finanzieller Lage befindet. Die Preise für die ausgeführten Salze sind bekanntlich weit höher als die Inlandspreise und sichern in normalen Zeiten einen erheblichen Gewinn.. Der Verlust des Auslandsabsatzes wirkte daher besonders ungünstig auf die Rentabilitätsverhältnisse. Es kommt gleichzeitig hinzu, daß die Arbeiterlöhn€ eine erhebliche Verteuerung erfahren haben, und die 
für den Betrieb der Zechen und Fabriken notwendigen Materialien im Preise bedeutend gestiegen sind. Außerdem haben die Anlagen, Maschinen usw, unter den Einwirkungen des Krieges schwer gelitten. Ihre Instandsetzung wird erhebliche Aufwendungen erfordern. Daneben sind die Vorrichtungsarbeiten stark vernachlässigt worden. Auch hierfür sind bedeutende Summen nötig, bis wieder ein normaler Betrieb möglich ist. Die Erhöhung der Inlandspreise hat diese ungünstigen Verhältnisse nicht ausgleichen können. Die meisten Kaliwerke sind daher nicht imstande, irgendwelche Verzinsung des in ihnen angelegten Kapitals zu leisten. Es kann sogar ohne Uebertreibung gesagt werden, daß die finanziellen Ergebnisse der Kaliindustrie während des Krieges geradezu kläglich sind. Aus diesen Gründen ist gerade die Kaliindustrie nicht geeignet, große finanzielle Lasten auf sich zu nehmen. Man wird ihr zum mindesten die Möglichkeit geben müssen, sich zunächst von dem starken Rückschlag, den ihr der Krieg gebracht hat, wieder etwas zu erholen.

Die Erholung dürfte sich voraussichtlich in verhältnismäßig kurzer Zeit vollziehen, aber nur, wenn der Industrie die Freiheit der Entwicklung gewahrt bleibt. Wie in der Einleitung gezeigt, darf auf Grund der bisherigen Absatzentwicklung für das Jahr 1922 schon eine Absatzmenge von etwa $26000000 \mathrm{dz} \quad \mathrm{K}_{2} \mathrm{O}$ erwartet werden. Diese $\mathrm{Ab}$ satzsteigerung, die unter der Voraussetzung, daß keine staatliche Bewirtschaftung erfolgt, alle Wahrscheinlichkeit für sich hat, legt den Gedanken nahe, dem Staate durch eine $\mathrm{Kalisteuereine} \mathrm{beträchtliche} \mathrm{Einnahme-}$ quelle zu erschlieBen. Es bedürfte dazu lediglich des Ausbaues der bereits bestehenden Abgabe auf den dz $K_{2} O$. Selbst eine mäßige Steuer dürfte bei dem zu erwartenden Absatz eine hohe Einnahme bringen. Dabei würde sie alle Nachteile des Staatsmonopols und die mit diesem verbundenen Risiken vermeiden. AuBerdem hätte eine derartige Steuer den Vorteil, da B sie leicht 
erhebbarist, keinen besonderen technischen Aufwand erfordert und die restlose Erfassung des Objektes sicherstellt. Bringt aber die vorgeschlagene Steuer erhebliche Einnahmen, so fällt der finanzielle Grund für die Einführung eines Staatsmonopols fort, zumal dieses solche nicht einmal gewährleistet, dafür aber eine Menge Gefahren und Nachteile in sich schließt. Andere Gesichtspunkte, die ein staatliches Monopol rechtfertigen könnten, können nicht angeführt werden, weil das Kaligesetz im großen und ganzen andere Interessen, die durch die freie Wirtschaft etwa gefährdet wären, schützt, Seine Bestimmungen verhindern die Verschleuderung der Salze an das Ausland, schützen die inländischen Abnehmer, insbesondere die Landwirtschaft, und verhindern eine Ausbeutung der Arbeiter und Angestellten. Es wird Aufgabe der gesetzgebenden Faktoren sein, die Vorschriften über die Quotenübertragung zur Herstellung eines wirtschaftlicheren Betriebes und zur Verhinderung von Neugründungen in zweckmäßigerer Weise auszubauen. Wenn den vorstehenden Anregungen Folge gegeben wird und der ausländische Wettbewerb in Schach gehalten werden kann, so wird die deutsche Kaliindustrie ein blühender Zweig unserer nationalen Wirtschaft bleiben und in immer steigendem Maße werden. 

T a belle I.

Gesamtförderung an Kalisalzen 1861-1914.

\begin{tabular}{|c|c|c|c|c|c|}
\hline $\begin{array}{l}\text { Im } \\
\text { Jahre }\end{array}$ & $\begin{array}{c}\text { Karnallit } \\
\mathrm{dz}\end{array}$ & $\begin{array}{c}\text { Berg- } \\
\text { kieserit } \\
\mathrm{dz}\end{array}$ & $\begin{array}{c}\text { Kainit } \\
\mathrm{dz} \\
\end{array}$ & $\begin{array}{c}\text { Sylvinit } \\
\mathrm{dz} \\
\end{array}$ & $\begin{array}{c}\text { Zusammen } \\
\mathrm{dz} \\
\end{array}$ \\
\hline 1861 & 22930 & - & - & - & 22930 \\
\hline 1862 & 197269 & 203 & - & - & 197472 \\
\hline 1863 & 583035 & 683 & - & - & 583718 \\
\hline 1864 & 1154085 & 889 & - & - & 1154974 \\
\hline 1865 & 876709 & 748 & 13139 & - & 890596 \\
\hline 1866 & 1355537 & 4135 & 58084 & - & 1417756 \\
\hline 1867 & 1416042 & 11435 & 89765 & - & 1517242 \\
\hline 1868 & 1673367 & 14178 & 107717 & - & 1795262 \\
\hline 1869 & 2118838 & 2265 & 168572 & - & 2289675 \\
\hline 1870 & 2682256 & 707 & 203008 & - & 2885971 \\
\hline 1871 & 3359446 & 470 & 365817 & - & 3725733 \\
\hline 1872 & 4685375 & 225 & 180672 & - & 4866272 \\
\hline 1873 & 4410786 & 75 & 61013 & - & 4471874 \\
\hline 1874 & 4149613 & 160 & 97526 & - & 4247299 \\
\hline 1875 & 4987370 & 50 & 241238 & - & 5228658 \\
\hline 1876 & 5636691 & 1451 & 179376 & - & 5817518 \\
\hline 1877 & 7718193 & 1515 & 354768 & - & 8074476 \\
\hline 1878 & 7357502 & 5198 & 340038 & - & 7702738 \\
\hline 1879 & 6104270 & 7607 & 502065 & - & 6613942 \\
\hline 1880 & 5282120 & 8929 & 1394908 & - & 6685957 \\
\hline 1881 & 7447261 & 20819 & 1583299 & - & 9051379 \\
\hline 1882 & 10592998 & 46581 & 1484771 & - & 12124350 \\
\hline 1883 & 9502032 & 117905 & 2288171 & - & 11908108 \\
\hline 1884 & 7399590 & 123889 & 2171066 & - & 9694545 \\
\hline 1885 & 6447098 & 119696 & 2723695 & - & 9290489 \\
\hline 1886 & 6982293 & 139176 & 2473268 & - & 9594737 \\
\hline 1887 & 8402068 & 141859 & 2376288 & - & 10920215 \\
\hline 1888 & 8496025 & 107539 & 3755736 & 22203 & 12381503 \\
\hline 1889 & 7987214 & 93540 & 3626110 & 283288 & 11990152 \\
\hline 1890 & 8385256 & 69514 & 4018707 & 319168 & 12792645 \\
\hline 1891 & 8188624 & 58156 & 5124937 & 326612 & $\begin{array}{l}13698329 \\
8^{*}\end{array}$ \\
\hline
\end{tabular}




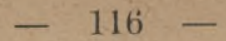

Fortsetzung der Tabelle I.

\begin{tabular}{|c|c|c|c|c|c|}
\hline $\begin{array}{l}\text { Im } \\
\text { Jahre }\end{array}$ & $\begin{array}{c}\text { Karnallit } \\
\mathrm{dz}\end{array}$ & $\begin{array}{c}\text { Berg- } \\
\text { kieserit } \\
\mathrm{dz} \\
\end{array}$ & $\begin{array}{c}\text { Kainit } \\
\mathrm{dz} \\
\end{array}$ & $\begin{array}{l}\text { Sylvinit } \\
\mathrm{dz} \\
\end{array}$ & $\begin{array}{c}\text { Zusammen } \\
\mathrm{dz} \\
\end{array}$ \\
\hline 1892 & 7367507 & 57825 & 5857748 & 326694 & 13609774 \\
\hline 1893 & 7946597 & 48072 & 6899943 & 491396 & 15386008 \\
\hline 1894 & 8513385 & 38646 & 7293009 & 634949 & 16479989 \\
\hline 1895 & 7829442 & 30121 & 6695319 & 760974 & 15315856 \\
\hline 1896 & 8562230 & 28409 & 8330251 & 903896 & 17824786 \\
\hline 1897 & 8512720 & 26190 & 10121856 & 831046 & 19501812 \\
\hline 1898 & 9909983 & 24443 & 11206157 & 942701 & 22083284 \\
\hline 1899 & 13179475 & 20664 & 10631952 & 1006532 & 24838623 \\
\hline 1900 & 16978032 & 20474 & 11893941 & 1477911 & 30370358 \\
\hline 1901 & 18601891 & 23352 & 14321360 & 1900342 & 34846945 \\
\hline 1902 & 17056646 & 18211 & 13545281 & 1888208 & 32508346 \\
\hline 1903 & 18440365 & 15534 & 15828674 & 1961403 & 36245976 \\
\hline 1904 & 19111660 & 10555 & 19068230 & 2344551 & 40534996 . \\
\hline 1905 & 22397099 & 27308 & 24055361 & 2306216 & 48785984 \\
\hline 1906 & 22631972 & 91904 & 26397322 & 2662593 & 51783791 \\
\hline 1907 & 25347888 & 103595 & 27889734 & 3041431 & 56382648 \\
\hline 1908 & 27687,939 & 184730 & 29215093 & 3052824 & 60104586 \\
\hline 1909 & 32807264 & 73878 & 32682903 & 3447494 & 69611539 \\
\hline 1910 & \multicolumn{2}{|c|}{35828853} & \multicolumn{2}{|c|}{45778932} & 81607785 \\
\hline 1911 & \multicolumn{2}{|c|}{44416640} & \multicolumn{2}{|c|}{52648433} & 97065073 \\
\hline 1912 & \multicolumn{2}{|c|}{52876427} & \multicolumn{2}{|c|}{57883716} & 110700143 \\
\hline 1913 & \multicolumn{2}{|c|}{53023505} & \multicolumn{2}{|c|}{63051600} & 116075105 \\
\hline 1914 & \multicolumn{2}{|c|}{36507506} & \multicolumn{2}{|c|}{45207610} & 81715116 \\
\hline
\end{tabular}




\section{- $117-$}

$\mathrm{T}$ a b e 11 e II.

\section{Erzeugung an konzentrierten Salzen (Fabrikate).}

\begin{tabular}{|c|c|c|c|c|c|c|c|}
\hline Jahr & $\begin{array}{c}\text { Chlor- } \\
\text { kalium } \\
80 \% \\
\mathrm{dz} \\
\end{array}$ & $\begin{array}{c}\text { Schwefel- } \\
\text { saures } \\
\text { Kali } \\
90 \% \\
\mathrm{dz}\end{array}$ & $\begin{array}{c}\text { Schwe- } \\
\text { felsaure } \\
\text { Kali- } \\
\text { magnes. } \\
\text { kalziniert } \\
48 \% \\
\mathrm{dz} \\
\end{array}$ & $\begin{array}{c}\text { Kali- } \\
\text { dünge- } \\
\text { salze }\end{array}$ & \begin{tabular}{|c|} 
Kristalli- \\
sierte \\
schwefel- \\
saure \\
Kali- \\
magnes. \\
$40 \%$ \\
$\mathrm{dz}$ \\
\end{tabular} & \begin{tabular}{|} 
Kieserit \\
in \\
Blöcken
\end{tabular} & $\begin{array}{c}\text { Kalzi- } \\
\text { nierter } \\
\text { gemah- } \\
\text { lener } \\
\text { Kieserit } \\
\text { dz } \\
\end{array}$ \\
\hline & 1063300 & 30000 & 80000 & 95000 & 4000 & 178000 & \\
\hline & & & & & & & \\
\hline & & & & & & & \\
\hline & & & & & & & \\
\hline & & & & & & & \\
\hline & & & & & & & \\
\hline & & & & & & & \\
\hline & & & & & & & \\
\hline & & & & & & & 108 \\
\hline 1893 & & & & & & & \\
\hline & & & & & & & 2160 \\
\hline & & & & & & & \\
\hline & & & & & & & 2110 \\
\hline & & & & & & & \\
\hline & & & & & & & 7282 \\
\hline & & & & & & & \\
\hline & & & & & & & 83 \\
\hline & & & & & & & \\
\hline & & & & & & & 7673 \\
\hline & & & & & 7776 & & 5481 \\
\hline & & & & & & & 4626 \\
\hline & & & & & 7178 & & \\
\hline & & & & & & & 6318 \\
\hline & 291 & & & & 7881 & & \\
\hline & & & & & & & 6684 \\
\hline & 3276321 & & & & 5067 & & \\
\hline & & & & & 1679 & & 7536 \\
\hline 1911 & & 1101226 & & & & & 7152 \\
\hline & & & & & 1725 & 454924 & 10703 \\
\hline 1913 & & 1107836 & & & & & \\
\hline & & & 548197 & 8995733 & 1550 & 179512 & 10598 \\
\hline
\end{tabular}




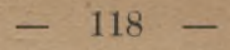

T a b e $11 \mathrm{e}$

Gesamt=Kali $-A$ b s a t $z$ an die Landwirtschaft

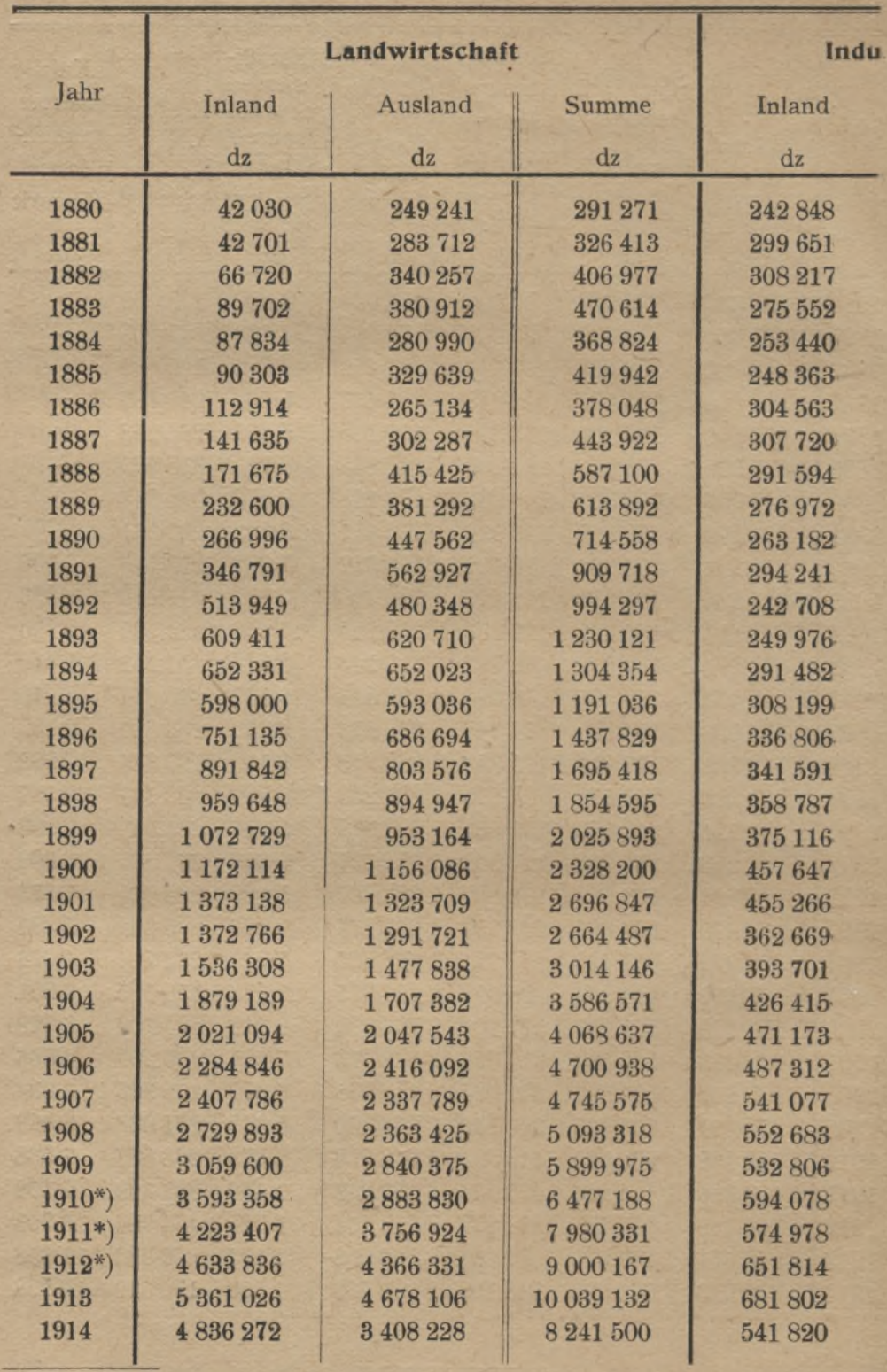

*) Ausschließlich der Außenseiter-Abladungen nach den Vereinigten 
III.

und Industrie in $\mathbf{~ d z}$ sowie Wert desselben in $\mathbf{M}$.

\begin{tabular}{|c|c|c|c|c|c|}
\hline $\begin{array}{l}\text { strie } \\
\text { Ausland } \\
\mathrm{dz} \\
\end{array}$ & $\begin{array}{c}\text { Summe } \\
\mathrm{dz} \\
\end{array}$ & $\begin{array}{c}\text { Gesamt- } \\
\text { Absatz } \\
\text { Gewicht } \\
\mathrm{dz} \\
\end{array}$ & $\begin{array}{c}\text { Durch- } \\
\text { schnitts- } \\
\text { wert von } \\
\text { I dz Kali } \\
\text { M. } \\
\end{array}$ & $\begin{array}{c}\text { Vom Ges } \\
\text { entfall } \\
\text { Landwirt- } \\
\text { schaft } \\
\%\end{array}$ & $\begin{array}{c}\text { amtabsatz } \\
\text { len auf } \\
\text { Industrie } \\
\% \\
\end{array}$ \\
\hline 151680 & 394528 & 685799 & $28,-$ & 42,5 & 57,5 \\
\hline 176960 & 476611 & 803024 & $27,-$ & 40,6 & 59,4 \\
\hline 278080 & 586297 & 993274 & $21,-$ & 41,0 & 59,0 \\
\hline 252800 & 528352 & 998966 & $23,-$ & 47,1 & 52,9 \\
\hline 180854 & 434294 & 803118 & $25,-$ & 45,9 & 54,1 \\
\hline 177901 & 426264 & 846206 & 24,50 & 49,6 & 50,4 \\
\hline 166255 & 470818 & 848866 & $24,-$ & 44,5 & 55,5 \\
\hline 231718 & 539438 & 983360 & 23,50 & 45,1 & 54,9 \\
\hline 232404 & 523998 & 1111098 & $23,-$ & 52,8 & 47,2 \\
\hline 232124 & 509096 & 1122988 & 22,26 & 54,7 & 45,3 \\
\hline 245279 & 508461 & 1223019 & 22,10 & 58,4 & 41,6 \\
\hline 228592 & 522833 & 1432551 & 21,42 & 63,5 & 36,5 \\
\hline 178121 & 420829 & 1415126 & 20,76 & 70,3 & 29,7 \\
\hline 159882 & 409858 & 1639979 & 20,01 & 75,0 & 25,0 \\
\hline 195677 & 487159 & 1791513 & 20,39 & 72,8 & 27,2 \\
\hline 197362 & 505561 & 1696597 & 20,48 & 70,2 & 29,8 \\
\hline 198225 & 535031 & 1972860 & 19,73 & 72,9 & 27,1 \\
\hline 180954 & 522545 & 2217963 & 19,23 & 76,4 & 23,6 \\
\hline 227401 & 586188 & 2440783 & 19,33 & 76,0 & 24,0 \\
\hline 217444 & 592560 & 2618453 & 19,65 & 77,4 & 22,6 \\
\hline 250252 & 707899 & 3036099 & 20,09 & 76,7 & 23,3 \\
\hline 279366 & 734632 & 3431479 & 19,39 & 78,6 & 21,4 \\
\hline 262209 & 624878 & 3289365 & 19,20 & 81,0 & 19,0 \\
\hline 256359 & 650060 & 3664206 & 19,19 & 82,3 & 17,7 \\
\hline 288420 & 714835 & 4301406 & 18,95 & 83,4 & 16,6 \\
\hline 292871 & 764044 & 4832681 & 18,50 & 84,2 & 15,8 \\
\hline 287038 & 774350 & 5475288 & 18,59 & 85,9 & 14,1 \\
\hline 292748 & 833825 & 5579400 & 18,98 & 85,1 & 14,9 \\
\hline 270219 & 822902 & 5916220 & 18,59 & 86,1 & 13,9 \\
\hline 320528 & 853334 & 6753309 & 18,74 & 87,4 & 12,6 \\
\hline 265924 & 860002 & 7337190 & 18,24 & 88,3 & 11,7 \\
\hline 260724 & 835702 & 8816033 & 18,16 & 90,5 & $\quad 9,5$ \\
\hline 401979 & 1053793 & 10053960 & 18,54 & 89,5 & 10,5 \\
\hline 382760 & 1064562 & 11103694 & 18,24 & 90,4 & 9,6 \\
\hline 256563 & 798383 & 9039883 & 18,19 & 91,2 & 8,8 \\
\hline
\end{tabular}

Staaten von Nord-Amerika. 
Uebersetzung aus der "Gaceta de Madrid" vom 28. Juli 1918, Nr. 209.

Alfons XIII., von Gottes Gnaden und durch idie Konstitution König von Spanien.

Alle, die das Vorstehende sehen und verstehen werden, mögen wissen, daß die Reichsstände das Folgende, welches durch Uns sanktioniert wurde, bestimmt haben:

\section{Artikel 1.}

Alle bereits bewilligten und noch späterhin zu bewilligenden Bergwerkskonzessionen für Kalisalze sowie auch für alle mineralischen Substanzen, die als Kalidünger Anwendung finden oder die als Rohmaterial für die Herstellung derartiger Produkte dienen können, werden bezüglich der Konzessionsverleihung, der Ausbeutung, der Regelung und des Verkaufes der Erzeugnisse der Staatsintervention in der, in diesem Gesetz vorgeschriebenen Form unterworfen.

Auch bleiben der Staatsintervention alle diejenigen Konzessionen unterworfen, die sich innerhalb der offiziell als Kaliläger bezeichneten Zone befinden, selbst für den Fall, daß dieselben für andere Mineralien bewilligt oder aufgeführt sind oder in der Folge bewilligt werden sollten. Voraussetzung bleibt dabei, daß das Ministerium der öffentlichen Arbeiten dies anordnet, und daß vorher die Bergämter und das geologische Institut besondere Studien 'darüber ausgeführt haben und dic oberste Bergbehörde darüber berichtet hat.

Auf Grund einer voraufgegangenen Berichterstattung des betreffenden Bergamtes sowie des geologischen Institutes sind von den Vorschriften dieses Gesetzes nur diejenigen Konzessionen ausgeschlossen, welche sich zwar in den Zonen befinden, in denen Kalisalzgewinnung möglich erscheint bzw. Mineralien vorkommen könnten, die zur Herstellung von Kalidüngern benutzt werden können, die sich aber ausschließlich mit der Gewinnung anderer Substanzen befassen, die von den oben erwähnten völlig verschieden sind und deren Ausbeute mit Kalisalzen oder Rohmaterialien zur Herstellung von Kalidüngern gänzlich unvereinbar erscheint. Die nach dem Vorstehenden ausgenommenen Minen sollen jedoch der direkten und ständigen Aufsicht des zuständigen Bergamtes unterstellt bleiben.

Artikel 2.

Die Konzessionsinhaber, welche den Vorschriften dieses 
Gesetzes unterworfen sind, müssen in den Konzessionen ununterbrochen arbeiten, und zwar sowohl zum Zwecke der Untersuchung als der Ausbeutung derselben.

Der Staat kann den Gang dieser Arbeiten dem öffentlichen Interesse anpassen und zugunsten des nationalen Verbrauches besondere Bedingungen auferlegen, und zwar unabhängig von den Maßnahmen fiskalischen Charakters, welche er hinsichtlich der Ausfuhr der Produkte trifft.

\section{Artikel 3.}

Diese Konzessionen sind der Zahlung der Bergwerksabgaken unterworfen und haben auch in Anerkennung der staatlichen Hoheitsrechte den Flächenkanon zu entrichten.

Dieser Kanon soll jedoch nach den niedrigsten zurzeit in Kraft befindlichen oder in der Folge noch aufzustellenden Sätzen zu entrichten sein. Der Kanon ist von dem Zeitpunkt ab zu erlegen, in welchem der Konzessionsinhaber den Besitztitel verliehen erhält. Diejenigen, welche vor dem Inkrafttreter. des vorliegenden Gesetzes den Kanon zu einem höheren Satze entrichtet haben sollten, ist der Ueberschuß zurückzuerstatten. Die in jedem Vierteljahr zuviel erlegten Beträge sind zu entsprechenden Verrechnungen und zur Bezahlung der nachfolgenden Vierteljahre zu benutzen.

\section{Artikel. 4.}

Vor. dem Zeitpunkt der Ausfertigung des Besitztitels ab werden den Inhabern der Konzessionen auf diese Art Bergwerke, zum Zwecke des Studiums der Lager und der Vorbereitung der Ausbeutung der zugesprochenen Konzessionen, zeitliche Fristen eingeräumt, welche zwischen zwei und fünf Jahren schwanken sollen. Diese Frist ist jeweils festzusetzen unter Berücksichtigung der besonderen Umstände der Konzessionen hinsichtlich der geologischen Verhältnisse des Lagers und der Lage der Konzession zu den allgemeinen Verkehrswegen. Dieser Zejtraum und die Bedingung, periodisch der Bergbehörde Bericht über den Fortgang der Arbeit zu erstatten, wird in die Besitztitelurkunde aufgenommen, und "sie stellen eine der Spezialbedingungen dar, welche den Konzessionsinhabern auferlegt werden müssen. Der Zeitraum wird von dem Minister der öffentlichen Arbeiten festgestellt, nachdem diesem vorher ein Bericht des geologischen Institutes und des Oberbergamtes über den Fall vorgelegt ist.

Auch die schon für Kalisalze bewilligten Konzessionen 
sollen den in dem vorstehenden Paragraphen festgesetzten Be dingungen unterworfen sein.

Die besonderen- Bedingungen, die für die Erforschung und später für die Ausbeutung als unumgänglich notwendig erachtet werden, sind auch denjenigen Bergwerkskonzessionen aufzuerlegen, welche vor dem Erlaß des gegenwärtigen Gesetzes verliehen worden sind. Es gehören hierher auch die übrigen Anordnungen und Bestimmungen gemäß $\S 2$, Artikel 1 des vorliegenden Gesetzes. In diesem Falle rechnen jedoch die gewährten Fristen von dem Erlasse des betreffenden Ministerialbeschlusses ab.

\section{Artikel 5.}

Der gemäß den vorhergehenden Artikeln festgelegte Zeitraum wird als unverlängerbar betrachtet. Er kann nur als nicht verstrichen betrachtet werden, wenn der Interessent ein entsprechendes Gesuch einreicht und eine der folgenden Tatsachen nachweist:

1. Die evtl. Zeit, während welcher die Studien und Arbeiten wegen unvorhergesehener $Z$ wischenfälle unterbrochen werden mußten.

2. Die Zeit, die auf den Instanzengang der Akten über die Enteignung der notwendig werdenden Grundstücke verwendet wurde, wenn diese rechtzeitig für das benötigte Gelände in die Wege geleitet worden war.

3. Die Zeit, in welcher jedes Jahr infolge klimatischer Ursachen und schlechter Gesundheitsverhältnisse in der Region, in der das bewilligte Gelände liegt, die Arbeiten gewöhnlich eingestellt werden.

4. Infolge der Schwierigkeiten, die die Beschaffenheit der zu untersuchenden Schichten den Arbeiten bietet, oder wenn das Fehlen des erforderlichen Materials eine Unterbrechung der Arbeiten nötig macht. Dieses Fehlen darf aber nicht auf einem Verschulden des Konzessionsinhabers beruhen.

Ueber die Gesuche zur Verlängerung der Frist, welche sich auf einen der $1-4$ angegebenen Fälle gründet, hat das Bergamt des Distriktes und der oberste Bergrat ein Gutachten auszuarbeiten und der Minister der öffentlichen $\mathrm{Ar}$ beiten darüber zu entscheiden.

Artikel 6.

Ist der Zeitraum, der gemäß den vorhergehenden Artikeln definitiv festgelegt worden ist, verstrichen, so muß der Kon- 
zessionsinhaber die Ausbeutungsarbeiten des Lagers in Angriff nehmen. Er hat davon dem Chefingenieur des Distriktes Mitteilung zu machen und gleichzeitig eine kurze Denkschrift einzureichen, in welcher er in allgemeinen Linien den Plan der Arbeiten, auf Grund dessen er den Abbau zu bewerkstelligen vorschlägt, vorzulegen.

\section{Artikel 7.}

Sind die Ausbeutungsarbeiten erst einmal begonnen worden, so müssen dieselben so lange fortgesetzt werden, bis die Regierung die Ermächtigung zur Einstellung derselben gibt, und sie auf Erhaltungsarbeiten der Anlagen und des Lagers und die Aufrechterhaltung etwa nötiger Wasserhaltung beschränkt.

Alle Arbeiten, sowohl die der Ausbeutung als auch der Unterhaltung, müssen unter der Aufsicht des Oberbergamtes des betreffenden Distriktes vorgenommen werden. Der Konzessionsinhaber trägt die Verantwortung, daß diese Arbeiten im Einklang mit den geltenden oder in Zukunft noch rechtskräftig zu erlassenden Bergpolizeivorschriften ausgeführt werden. Dabei sind sowohl die Vorschriften allgemeiner Natur als auch die für die Kalisalzlager speziell erlassenen $\mathrm{zu}$ befolgen

\section{Artikel 8.}

Die zeitweilige Unterbrechung der Arbeiten kann nur durch folgende Umstände gerechtfertigt werden:

1 Durch Einwirkung höherer Gewalt.

2. Durch nachgewiesenen und unwiederbringlichen Verlust bei der bergmännischen Ausbeutung, wenn der Nettowert der geförderten Produkte nicht genügt, um die Kosten der Ausbeutung zu decken.

3. Wenn ein Konzessionsinhaber verschiedene Konzessionen besitzt und von dem Staat ermächtigt wird, aus einer oder einigen von ihnen die gesamte $\mathrm{ihm}$ auferlegte Produktion zu fördern.

Dic von der Behörde genehmigte Einstellung der Förderung wird als gleichbedeutend mit dem völligen Aufgeben oder mit der Verzichtleistung auf die Konzessionen betrachtet.

Derartige Konzessionen sind durch das Ministerium der öfentlichen Arbeiten nach Anhörung des obersten Bergrates für verfallen zu erklären. 


\section{$-124-$}

\section{Artikel 9.}

Falls die Eigentümer oder Nutznießer der Kalibergwerke sich zu einer Gesellschaft oder zu einem Syndikat zusammenschließen wollen, soll dem Staate das Recht zustehen, bzw. er soll ermächtigt sein, sich an dem Syndikate oder der Gesellschaft zu beteiligen, sowie auch in die Verwaltung derselben einzugreifen. In diesem Falle bringt der Staat seine eigenen Läger oder die Ergebnisse der von ihm veranstalteten Studien oder dic von ihm für die Erforschung oder Ausbeutung der Kalikergwerke bereits geschaffenen Anlagen ein, oder aber, er beteiligt sich an den Forschungs- und Vorbereitungsarbeiten in den von den übrigen Gesellschaftern eingebrachten Lägern. Zuvor hat aber das geologische. Institut und der Oberbergrat einen Bericht darüber auszuarbeiten.

\section{Artikel 10.}

Behufs wirksamer Ausführung des vorliegenden Gesetzes soll der Staat die Herstellung der Kalidüngemittel beaufsichtigen und nötigenfalls eingreifen und die Erzeugung und den Verkauf derselben regeln.

Für den Fall, daß Verwicklungen internationaler Natur eintreten oder wenn die Ausbeutungsarbeiten gemäß Nr. 2 des Artikels 8 eingestellt werden, soll, falls dadurch die Versorgung der einheimischen Landwirtschaft beeinträchtigt wird, dem Staate außerdem das Recht zustehen, auf die Förderung derjenigen Betriebe zurückzugreifen; welche er von seinem eigenen Felderbesitz etwa abgegeben hatte.

Der Staat wird diese Betriebe für eigene Rechnung weiterführen, sowie auch von den übrigen diejenigen, deren Uebernahme sich bei weiterem Zunehmen des Konfliktes als notwendig erweiser: würde.

In beiden Fällen sind die Konzessionsinhaber oder Eigentümer der übernommenen Betriebe auf Grund sachverständiger Abschätzung zu entschädigen.

\section{Artikel 11.}

Wenn die Förderung von Kalisalzen in Spanien ein höheres Erträgnis als jährlich $50000 \mathrm{t}$ erreicht oder auch schon früher, wenn der Minister der öffentlichen Arbeiten dies anordnet, so ist eine Regulierungsbehörde einzusetzen, welcher die Regulierung der Erzeugung, der Fabrikation und des Verkaufs der Kalisalze obliegt. Diese Behörde hat auch die Gesamtförderung für jedes Jahr in Form einer Höchst- und Mindest- 
menge, welche je nach den Bedürfnissen der einheimischen Landwirtschaft zu berechnen sind, festzusetzen. Ferner bestimmt sie die Höchstpreise, zu denen die verschiedenen Erzeugnisse der Kaliindustrie auf den spanischen Märkten zu verkaufen sind, wie auch die höchstzulässige Ausfuhrmenge und den Mindestpreis, zu dem die Salze an das Ausland verkauft werden dürfen. Dieser Auslandspreis muß stets höher sein als der für Spanien geltende Verkaufspreis.

Dic genannte Regulierungsbehörde kann auch der Regierung alle diejenigen Maßnahmen in Vorschlag bringen, die sie zur Erhaltung und Bewirtschaftung des nationalen Reichtums, der ja Gegenstand des vorliegenden.Gesetzes ist, für vorteilhaft erachtet.

Der Herr Minister der öffentlichen Arbeiten führt den Vorsitz in dieser Behörde, entweder in eigener Person oder durch einen Stellvertreter. Stimmberechtigte Mitglieder dieser Behörde sind:

der Präsident des obersten Bergrates;

der Vorsitzende des beratenden Landwirtschaftsausschusses;; der Direktor des geologischen Institutes oder die Ingenieure, welche die Genannten als ihre Stellvertreter bestimmen; vier Vertreter der ältesten und wichtigsten landwirtschaftlichen Gesellschaften oder Korporationen, welche von diesen in der von dem Minister der öffentlichen Arbeiten anzuordnenden Weise zu wählen sind;

fünf Vertreter der kalisalzgewinnenden Bergwerkskörperschaften; dieselben müssen aber in Spanien Bürgerrecht besitzen und auch der einheimischen Gesetzgebung unterworfen sein; ein Provinzial-Abgeordneter, der von jeder Abordnung derjenigen Provinzen, in denen Bergbau auf Kalisalze betrieben wird, zu bestimmen ist.

Das Amt als Vertreter der Grubenkörperschaft darf durchaus nur Personen spanischer Staatsangehörigkeit übertragen werden.

\section{Artikel 12.}

Die Ausbeutungsquote, welche die verschiedenen Bergwerke zu fördern haben, wird von einem Ausschuß festgesetzt, der unter dem Vorsitz des Präsidenten des obersten Bergrates zusammentritt. Stimmberechtigte Mitglieder dieses Ausschusses sind:

der Direktor des geologischen Institutes; 
drei Inspektoren der Bergbehörde;

fünf Vertreter der kalibergbauenden Gesellschaften, welche der Regulierungsbehörde angehören.

Derselbe Ausschuß soll auch bei Meinungsverschiedenheiten, die etwa unter den Abbauenden bei der Erfüllung der Vorschriften der Regulierungsbehörde oder auch anläßlich des Abbaues und der Herstellung von Erzeugnissen der Kaliindustrie sich ergeben, entscheiden.

\section{Artikel 13.}

Gegen die von der Regierungsbehörde erlassenen Beschlüsse, wie auch gegen die von dem Oberausschuß (auf welchen sich der vorhergehende Artikel bezieht) getroffenen Entscheidungen, kann bei dem Herrn Minister der öffentlichen Arbeiten Berufung eingelegt werden. Dieser wird seine Entscheidung nach vorheriger Anhörung des Staatsrates fällen.

\section{Artikel 14.}

Die Ausbeutung der Kalisalzlager soll die Vergünstigungen. welche das Gesetz zum Schutz neuerer Industrien (vom 3. März 1917) bestimmt; genießen, wobei dieselben als bevorzugte Industrien im Sinne des Teiles I a Artikel 1 dieses Gesetzes gelten.

\section{Artikel 15.}

Innerhalb eines Zeitraumes von drei Monaten, von der Verkündigung dieses Gesetzes ab gerechnet, wird die Regierung ein spezielles Reglement für die Ausführung desselben erlassen.

\section{Artikel 16.}

Alle den Anordnungen des vorliegenden Gesetzes zuwiderlaufenden früher erlassenen Bestimmungen werden hierdurch aufgehoben.

\section{Zusatz-Artikel.}

Artikel 1.

Der Staat kann in seiner Eigenschaft als Entdecker, und wenn es sich um Minerale handelt, deren Erzeugung als im nationalen Interesse liegend erklärt wird, und welche insbesondere auch für die Landwirtschaft notwendig sind, sich diejenigen Länderstriche vorbehalten, in welchen derartige Lagerstätten vorkommen, sofern dieselben frei und eintragungsfähig sind. Vorher hat die Bergbehörde und das geologische Institut Studien hierüber anzustellen. 
Der Staat darf sich aber keine Gebiete vorbehalten, welche auf Grund der herrschenden Gesetzgebung denjenigen Eigentümern der anliegenden Bergwerke, welche zuerst darum nachsuchten, zugesprochen werden müssen.

Ebensowenig werden hiervon die Gebiete betroffen, die als Privatkonzessionen oder Privatregister eine Oberfläche von weniger als 40 ha umfassen. Diese Gebiete sollen durch die Bergämter den Anliegern zugesprochen werden.

\section{Artikel 2.}

Auf Grund des vorhergehenden Artikels kann jedes freie Gelände, sofern es für nötig erachtet wird, von dem öffentlichen Rechte der Eintragung in das Register ausgeschlossen werden, wenn der Minister der öffentlichen Arbeiten dies beabsichtigt und über die notwendigen Geldmittel verfügt, um Bohrungen oder andere Forschungsarbleiten anzustellen, die zur Entdeckung von neuen Minerallagern in offiziell für diesen $Z$ weck bezeichneten Gegenden bestimmt sind.

Das ausgeschlossene Gebiet ist, auch bei vorübergehender Inanspruchnahme, in allen Einzelheiten zugunsten des Staates abzugrenzen. Die Ausschließung soll eine vorläufige sein.

Artikel 3.

Die endgültige Ausschließung eines entdeckten Lagers, d. h. die definitive Reservierung zugunsten des Staates, ist unter Beotachtung der Vorschriften des vorhergehenden Artikels mittels königlichen Erlasses durchzuführen, und zwar durch den Minister der öffentlichen Arbeiten auf Grund eines Beschlusses des Ministerrates. Vorher haben das geologische Institut und der Bergrat ihr Gutachten abzugeben.

Jede Ausschließung dieser Art muß in der "Gaceta de Madrid" und dem „Boletin oficial“" (Amtlicher Anzeiger) der betreffenden Provinz zur Veröffentlichung gelangen, wobei die Grenzen des reservierten Gebietes peinlichst genau festgelegt werden müssen.

\section{Artikel 4.}

Der Staat kann die Minerallager, welche er entdeckt. für eigene Rechnung ausbeuten oder auch dieselben veräußern oder an diejenigen verpachten, welche die beste Gewähr dafür bieten, da $B$ die Ausbeutung zum Vorteil des nationalen Verbrauches vorgenommen wird. In den beiden letzten Fällen behält sich der Staat das Recht vor, entweder einen Teil des 
entdeckten Reichtums oder des aus der Ausbeutung erzielten Gewinnes für sich zu beanspruchen.

Um zu entscheiden, welche der angeführten Entschädigungsarten zu wählen ist, ist unbedingt die Ansicht des geologischen Institutes und des obersten Bergrates zu hören.

Im Fall der Staat die Ausbeutung von einer oder mehreren der entdeckten Gruben selbst ausführen will, sind die Bergbauarbeiten unter der Oberleitung des Ministers der öffentlichen Arbeiten zu beginnen und weiterzuführen. Die Leitung der Abbauarbeiten soll von Ingenieuren der staatlichen Bergbehörde unter Aufsicht einer technischen Kommission ausgeführt werden. In dieser technischen Kommission führt ein Generalinspektor der genannten Körperschaft den Vorsitz, die Beisitze: sind zwei Chefingenieure und ein Beamter des Finanzministeriums; als Schriftführer ist ein subalterner Ingenieur zu bestellen.

U ebergangsbestimmungen.

Die Untersuchungsarbeiten der Lager in dem dem Staate in den Provinzen Barcelona und Lérida vorbehaltenen Gelände sind unter der Leitung des geologischen Institutes nach den von dieser Körperschaft ausgearbeiteten Plänen auszuführen. Zur Ausführung dieser Untersuchungsarbeiten wird als erste Rate ein außerordentlicher Kredit von 800000 Pesetas eingeräumt, der in 'den Haushaltsplan beim Titel „Ministerium der öffentlichen Arbeiten" einzureihen ist. Wenn der Kredit im laufenden Jahr nicht erschöpft werden sollte, so soll er für das nächste Jahr verlängerbar sein.

Aus diesem Grunde ordnen Wir an:

$\mathrm{da} \mathcal{B}$ alle Gerichtshöfe, Rechtsbehörden, Vorstände, Gouverneure und sonstigen Behörden irgendwelcher Art und irgendwelchen Ranges, sowohl die Zivil- wie Militär- und geistlichen Behörden, das gegenwärtige Gesetz in allen seinen Teilen beobachten, erfüllen und zur Ausführung bringen lassen.

Gegeben in San Sebastian, am 24. Juli 1918.

Der Minister der öffentlichen Arbeiten:

Francisco Cambó.

Ich, der König.

\section{BIBLIOTEKA POLITEGHHIEZHA

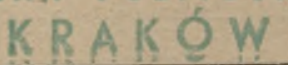

Druck von Trowitzsch \& Sohn, Berlin SW.

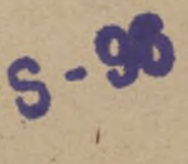





\section{:: Verlag von Juliu}

\section{*Chemisc Untersuch}

Unter

\section{POLITECHNIKA KRAKOWSKA BIBLIOTEKA GRÓWNA}

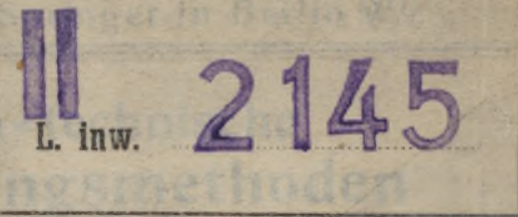

Kdn. 524, 13, IX, 54

B. Adam, P. Aulich, F. Barnstein, O. Bättcher , A. Bujard, C. Counclert, Z. Wieterich, K. Dïmmler, A. Ebertz, C. v. Eckenbrecher, A. Eibner, F. Fischer, F. Frank, H. FreuAenberg. E. Gildemeister, R. Gnehm, O. Guttmann †, E. Haselhoff, W. Herzberg, D. Holde, W. Klapproth, H. Köhler, Ph. Kreiling, K. B. Leheann, J, Lewkowitsch, C.J. Lintner, E. O. v, Lippmann, E. Marckwald, J. Meŝner, J. PaBiler, O. Pfeiffer, Q. Pufahl, O.Schluttig, K.Schoch, G.Schille, L. Tietiens, K. Windisch, L. W. Winkler herausgegeben von

\section{Dr. Georg Lunge, und Dr. Ernst Berl,}

emer. Professor der technischen Chemie am Eidgenössischen Polytechnikum in Zürich,

Privatdozent, Chefchemiker.

Sechste, vollständig umgearbeitete und vermehrte Auflage.

\section{In vier Bänden.}

\section{*I. Band. 1910.}

693 Seiten Text, 72 Seiten Tabellen-Anhang. Mit 163 Textfiguren.

Preis M. 18.-; geb. M. 20.50.

Allgemeiner Teil. - Technische Gasanalyse - Untersuchung der festen Brennstoffe. - Fabrikation der schwefligen Säure. - Salpetersäure und Schwefelșiure, - Sulfat- und Salzsäurefabrikation. - Fabrikation der Soda. - Die Industrie des Chlors. - Kalisalze. - Verflüssigte und komprimierte Gase.

*II. Band. 1910.

885 Seiten Text, 8 Seiten Tabellen-Anhang. Mit 133 Textfiguren.

Preis M. 20.-; geb. M. 22.50.

Cyanverbindungen. - Ton. - Tonwaren und Dachschiefer. - Tonerdepräparate. - Glas. - Die Mörtelindustrie (Zement). - Trink- und Brauchwasser. Wasser für technische Zwecke. - Abwässer. Boden. - Luft. - Eisen. Metalle außer Eisen. Metallsalze. - Calciumcarbid und Acetylen.

*III. Band. 1911.

1044 Seiten Text, 24 Seiten Tabellen-Anhang. Mit 150 Textfiguren.

Preis M. 22.-; geb. M. 24.50.

Künstliche Düngemittel. - Futterstoffe. - Explosivstoffe. - Zündwaren. Gasfabrikation, Ammoniak. - Industrie des Steinkohlenteers. - Petroleum; andere Mineralöle; konsistente Fette; Paraffin; Ceresin; Schmiermittel. - Oele, Fette, Wachse. Spezielle Methoden der Oel-Industrie. Seifenfabrikation, Kerzenfabrikation, Glycerin. - Harze, Drogen, Galenische Präparate. - Kautschuk, Ǵuttapercha. - Aetherische Oele. - Organische Präparate.

*IV. Band. 1911.

1063 Seiten Text, 58 Seiten Tabellen-Anhang. Mit 56 Textfiguren.

Preis M. 24.-; geb. M. 26.50 .

Zucker. - Stärke, Dextrin usw. - Spiritus, - Branntwein und Liköre; Essig. - Wein. - Bier, - Gerbstoffe, - Leder. - Papier. - Tinte. - Weinsäure, Weinstein und Zitronensäure. - Anorganische Farbstoffe, - Organische Farbstoffe und deren Ausgangsprodukte; Prüfung der Gespinstfasern, Appreturen.

Biblioteka Politechniki Krakowskiej 
$:$ Verlag von Julius Springer in Berlin W9. ::

* Kalibergwerke im Oberelsaß. Auszug aus dem Jahresbericht 1912 der Industriellen Gesellschaft von Mülhausen i. E. 1913.

Preis M. 6.-

* Über die Nutzbarmachung der Kali=Endlaugen.

Von Bergassessor Dr. Dietz. 1913.

Preis M. 3.-

*Gutachten des Reichs=Gesundheitsrats über den Einfluß der Ableitung von Abwässern aus der Chlorkalium= und Sulfatfabrik der Gewerkschaft Rastenberg in Rastenberg i. Th. auf die IIm, Lossa und Saale. Berichterstatter: Geheimer Medizinalrat Professor Dr. Fränken, Halle. Mitberichterstatter: Geheimer Oberbaurat Dr.-Ing. Keller, Berlin, und Regierungsrat Professor Dr. Spitta, Berlin. Mit 1 Tafel. 1913.

Preis M. 4.50

Bodenschätze als biologische und politische Faktoren. Von Prof. Dr. Walther Roth, Greifswald. 1917.

Preis M. 1.-

*Taschenbuch für die anorganisch-chemische Großindustrie. Von Prof. Dr. G. Lunge in Zürich und Chefchem. Dr. E. Berl. Fünfte, umgearbeitete Auflage. Mit 15 Textfiguren. 1914. Preis gebunden M. 8.-

* Der Betriebs - Chemiker. Ein Hilssbuch für die Praxis des chemischen Fabrikbetriebes von Dr. Richard Dierbach, Fabrikdirektor. Zw eite, verbesserte Auflage. Mit 117 Textfiguren. 1908.

Preis gebunden M. 8.-

- Hierzu Teuerungszuschlag. 

Biblioteka Politechniki Krakowskiej Minn II-2145 